\title{
Use of Bacteriolytic Enzymes in Determination of Wall Structure and Their Role in Cell Metabolism
}

\author{
JEAN-MARIE GHUYSEN \\ Service de Bacteriologie, Université de Liège, 32, Constitution, Liège, Belgium
}

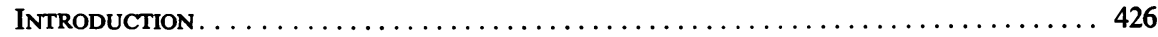

Lysozyme and Penicillin...................................... 426

Peptidoglycan in Gram-Positive Bacteria.............................. 426

Peptidoglycan in Gram-Negative Bacteria .......................... 427

Properties of Protoplasts and Spheroplasts................................ 427

Summation ........................................ 428

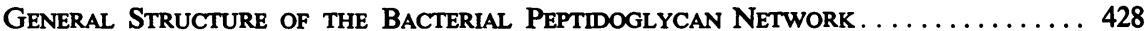

Glycan Strands .......................................... 428

Peptide Subunits............................................. 428

Cross-linking Bridges. .............................................. 429

Enzymes That Degrade Bacterial Peptidoglycans: Nature of the Hydrolyzed

LINKAGES . . . . . . . . . . . . . . . . . . . . . . . . . . . . . . . . . . . . 430

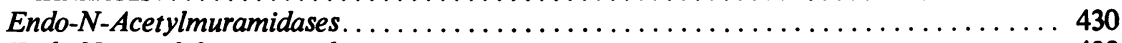

Endo- $N$-acetylglucosaminidases.......................................... 432

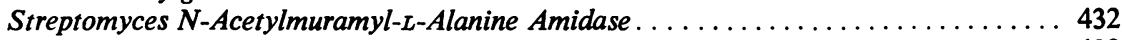

Streptomyces KM Endopeptidase. ................................ 432

Streptomyces $S A$ Endopeptidase ....................................... 433

Streptomyces $M L$ Endopeptidase . ............................... 433

Myxobacter AL 1 Protease .................................................. 433

Streptomyces MR Endopeptidase and Lysostaphin Endopeptidase............. 433

Peptidase Preparations with Mixed Activities.......................... 433

Summation ....................................... 434

Structure of Several Bacterial Peptidoglycans as Revealed by Enzymatic

Degradations: Glycan Moiety $\ldots \ldots \ldots \ldots \ldots \ldots \ldots \ldots \ldots \ldots \ldots \ldots, 434$

Staphylococcus aureus. . . . . . . . . . . . . . . . . . . . . . . . . . . . . . 434

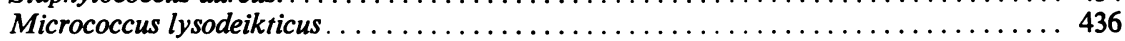

Other Bacterial Peptidoglycans.................................. 436

Molecular Size of the Glycan Moiety..................................... 437

Base-Catalyzed Lactyl Elimination from N-Acetylmuramic Acid............. 437

Structure of Several Bacterial Peptidoglycans as Revealed by Enzymatic

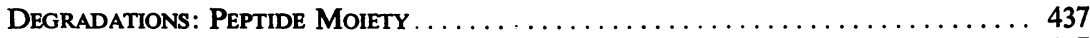

Peptidoglycans of Type I. .............................................. 437

Characterization of the $\mathrm{NH}_{2}-(1)$-meso-DAP in the link to glutamic acid . . . . . . 438

Characterization of the $\gamma$-carboxyl group of glutamic acid in the link to $\mathrm{NH}_{2}-(\mathrm{L})$-meso-

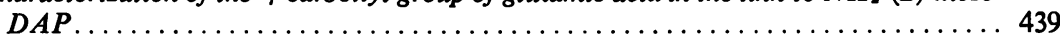

Characterization of the link meso-DAP-(L)-(D)-Ala................... 439

Characterization of the D-Ala-(D)-meso-DAP cross-linkages between peptide subunits ................................................ 439

Peptidoglycans of Type II with Peptide Bridges of Glycine or L-Amino Acid Residues,

or Both. . . . ....................................... 440

Peptidoglycans of Type II with a D-Isoasparaginyl Bridge . . . . . . . . . . . . . . 442

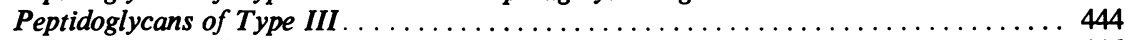

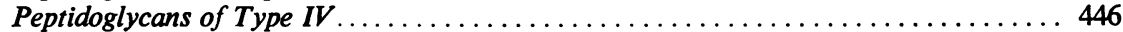

Molecular Size of the Peptide Moieties..................................... 446

Peptidoglycan as a Taxonomic Character $\ldots \ldots \ldots \ldots \ldots \ldots \ldots \ldots \ldots \ldots, 447$

Gram-Negative Bacteria ..................................... 447

Actinomycetes. . ......................................... 447

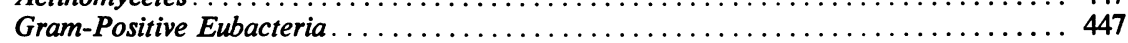

Unified View of the Bacterial Peptidoglycans .................... 448

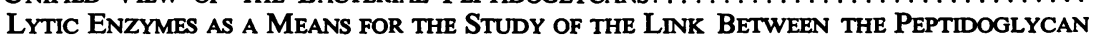

and OTHER COMponents IN Walls of Gram-PostTIVE Bacteria $\ldots \ldots \ldots \ldots \ldots \ldots 452$

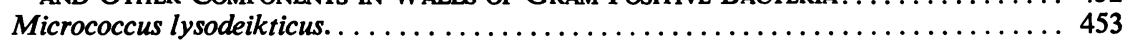

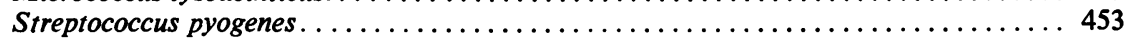


Autolytic Enzymes as Bacterial Wall Constituents $\ldots \ldots \ldots \ldots \ldots \ldots \ldots \ldots \ldots 45$

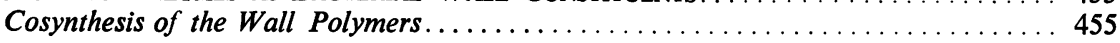

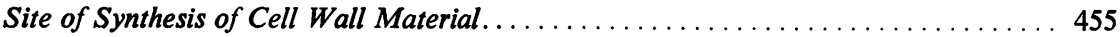

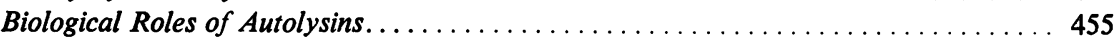

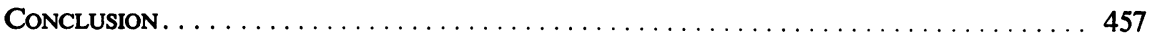

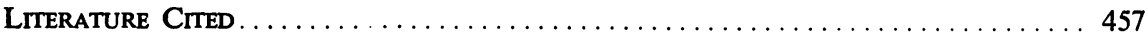

\section{INTRODUCTION}

Salton conducted an exhaustive survey of bacterial cell wall biochemistry (137). However, the field has developed so rapidly that since then at least 10 reviews have appeared, each of them emphasizing one aspect or another of the subject $(38,41,85,130,132,148,155,156,177,179)$. A few essential facts will be recalled briefly at the outset of this review.

\section{Lysozyme and Penicillin}

More than 40 years have elapsed since Fleming published his first observations of bacterial lysis by two different agents: lysozyme $(27,29)$, an enzyme present in many animal tissues; and penicillin (28), an antibiotic secreted by a mold (Penicillium). These studies prepared the way for major investigatons which led to the discovery of an impressive arsenal of antibacterial drugs. Chemotherapy underwent spectacular growth and culminated in the "antibiotic era," in which we are now living. Fleming's studies also catalyzed research into the structure and function of enzymatically active proteins and into the structure, function, and biosynthesis of the external bacterial layers, both currently proceeding at the molecular level. As has been pointed out, the fundamental similarity of the sites of action of penicillin and lysozyme is quite remarkable (156). Each brings about a loss of integrity of a rigid macromolecule which, underlying the outer bacterial cell envelope, confers to the bacteria their particular shape and allows them to live under hypotonic environmental conditions. Lysozyme and penicillin, however, act through entirely different mechanisms. Lysozyme hydrolyzes a specific structural linkage within this rigid layer, which consequently is solubilized. On the other hand, penicillin inhibits the biosynthesis of that same layer, leaving it incomplete and in soluble form. That different mechanisms are involved in the bacteriolytic activities of lysozyme and penicillin is evident from the conditions required for each to effect lysis. Early in the 1950's, Weibull presented a beautiful illustration of the lysozyme action (176). A resting cell suspension of the rod-shaped Bacillus megaterium was known to be entirely clarified by lysozyme. When the cell suspension, however, was made up in the presence of a solute unable to permeate the cells, such as sucrose, and at a concentration equivalent to the intracellular osmotic pressure (from 5 to $30 \mathrm{~atm}$, according to the physiological state of the cell), the bacteria were not lysed by lysozyme but were transformed into spherical bodies characterized by a high osmotic fragility. Contrary to lysozyme, penicillin has no lytic action on resting cell suspensions. To induce the loss of cellular integrity, it must act on actively growing bacteria (79). In the presence of penicillin, all processes involved in cell expansion and division continue to take place, except that the cells are no longer capable of synthesizing a normal external rigid layer. As a result, the external layers cannot withstand the high internal osmotic pressure, and the cells become osmotically sensitive bodies.

\section{Peptidoglycan in Gram-Positive Bacteria.}

The location of the rigid component among the cell surface structures has been clearly established in gram-positive bacteria. Electron microscopy of thin sections generally shows a thick ( 20 to $80 \mathrm{~nm}$ ), rather amorphous structure (the wall) covering an alternating electron-dense electron-transparent layering, about $7.5 \mathrm{~nm}$ thick (the plasma membrane). The wall and plasma membrane are separate, distinct structures. Both structures can be readily obtained free of mutual contamination and of other cellular components. Treatment of gram-positive bacteria with lysozyme, or with another suitable lytic enzyme, in the presence of an osmotic stabilizer, usually results in the selective and complete solubilization of the wall. The "protoplasts" that are formed have only one surface integument, the cytoplasmic membrane. Subsequent osmotic disruption of the isolated and purified protoplasts yields homogeneous preparations of plasma membranes. On the other hand, sonic or mechanical disruption of bacteria, followed by differential centrifugations, yields homogeneous preparations of bacterial walls. In the electron microscope, they appear as empty bags preserving the shape and the size of the original cells. Proteins, polysaccharides, or teichoic acid (polyol-phosphate polymers) (i.e., the specific determinants of the cells) usually represent about $50 \%$ of the dry weight of the walls. Relatively mild hydrolytic agents, such as 
trichloroacetic acid or hot formamide, can remove these components from the insoluble rigid matrix of the cell wall. Analysis of this matrix established its chemical nature. It is composed of a few amino acids and acetamido sugars, and it is called peptidoglycan. (The terms mucopeptide, glycopeptide, or murein, used by some authors, are all synonymous with peptidoglycan.) Essentially, this peptidoglycan is composed of six different compounds, present in equimolar amounts: two acetamido sugars, 2-acetamido-2deoxy-D-glucose ( $N$-acetylglucosamine) and 2acetamido-2-deoxy-3-O-(D-1 - carboxyethyl) -D glucose $(N$-acetylmuramic acid), and four amino acids, L-alanine (L-Ala), D-alanine (D-Ala), D-glutamic acid (D-Glu), and a diamino acid, L-lysine (L-Lys) or meso-diaminopimelic acid (meso-DAP). Glycine (Gly), L-serine (L-Ser), L-threonine (L-Thr), D-aspartic acid (D-Asp), additional $\mathrm{L}$-Ala residues, and amide ammonia are, in some species, also found as constituents of the bacterial wall peptidoglycan.

\section{Peptidoglycan in Gram-Negative Bacteria}

In this group of bacteria, the organization of the outer cell layers is exceedingly complex. By careful fixation and special staining techniques, Murray and his colleagues (102) recently succeeded in demonstrating that the rigid peptidoglycan layer of Escherichia coli ( 2 to $3 \mathrm{~nm}$ thick) is sandwiched between the underlying plasma membrane and an outer multiple-track layer. This latter layer is almost certainly composed of the lipoprotein and lipopolysaccharide complexes which are better known, in the case of $E$. coli and that of Salmonella sp., as the $O$-antigens or the bacterial endotoxins. Mechanical disruption of gramnegative bacteria always yields heterogeneous preparations consisting of the external multipletrack layer, the rigid layer, and at least some of the inner plasma membrane, all firmly associated. These have been designated as bacterial "envelopes" (138). The isolation of the rigid peptidoglycan, which represents as little as 5 to $10 \%$ of the total weight of the envelopes, is a difficult task. Of course, in this process, $N$-acetylmuramic acid and DAP, the diamino acid usually found in peptidoglycans of gram-negative bacteria, serve as useful markers. Various techniques involving treatments with phenol and detergents have been proposed to strip the other complexes from the peptidoglycan. Weidel and his colleagues were the first to succeed in isolating from $E$. coli a "rigid layer" consisting of a peptidoglycan sacculus with protein globules attached to it as a multitude of tuft-like appendages (177). Later on, it was shown that these globules could be removed by protease treatment. The "rigid layer" in Proteus mirabilis $(53,84)$ was also shown to have a similar structure. Unless modified by special procedures, such as the use of ethylenediaminetetraacetic acid, the outer multiple-track layer of the envelopes functions as a "barrier" and prevents most lytic enzymes from reaching the underlying peptidoglycan. The enzymatic breakdown of the peptidoglycan layer within the cell envelope does not result in the dissolution or disruption of the external multiple-track layer. The bacteria are transformed into spherical bodies, called spheroplasts (8), but the external lipoprotein and lipopolysaccharide "plastic" layers remain present and play some mechanical, protective role. Spheroplast formation can also be induced by inhibiting the biosynthesis of the peptidoglycan through the action of penicillin, for example. These spheroplasts retain a cell envelope, sometimes including a fragile, balloon-shaped peptidoglycan sacculus, as has been shown in the case of $P$. mirabilis (53). Consequently, spheroplasts are often less osmotically fragile than true protoplasts of gram-positive bacteria, but they are more osmotically sensitive than the intact parent cells.

\section{Properties of Protoplasts and Spheroplasts}

Protoplasts and spheroplasts possess many of the physiological capabilities of the parent bacterial cells, including the capability of growth (i.e., increase of cell mass). This cell growth, however, may proceed in an unbalanced manner, characterized by alterations in the dynamics and integration of the biosynthesis of macromolecules such as ribonucleic acid (RNA), deoxyribonucleic acid (DNA), proteins, and phospholipids (A. J. Isquith and G. D. Shockman, personal communication). When the agent which has induced the transformation into osmotically fragile bodies is removed, reversion to normal bacterial forms is sometimes observed, providing that the external integument of the cell still contains some peptidoglycan fragments, which probably act as primers. Usually, the osmotically fragile forms of the bacteria do not multiply as such. Lack of ability to multiply is a general property of protoplasts obtained by the enzymatic procedure. Exceptions may occur, however. According to two reports $(76,88)$, division of $B$. megaterium protoplasts was observed when special nutrient broths were used. More frequently, it has been shown that a number of gram-positive and gram-negative bacteria can be induced to grow and multiply, in the osmotically fragile form, by the influence of penicillin in a high-salt medium. These organisms are then designated as $\mathbf{L}$ forms. They 
lack an organized wall, or envelope, and are resistant to those antibiotics known to interfere with peptidoglycan synthesis. Some $L$ forms, however, continue to be able to make important peptidoglycan intermediates (14) when provided with appropriate substrates and, thus, they must still contain at least some of the enzymes involved in peptidoglycan synthesis. The study of the bacterial $L$ forms is a field of both academic and medical interest, but it is not within the scope of this paper. (For a thorough discussion of this problem, see 43.)

\section{Summation}

The bacterial peptidoglycan has excited much interest among bacteriologists, biochemists, chemists, and pharmacologists of this generation for several reasons. First, this peptidoglycan layer which is essential for the survival of the bacteria in normal environments must be an immense macromolecule (177), much larger than any within the cell, since that one molecule completely envelopes the cell. Yet, this macromolecule results from the assembly of a very small number of different compounds. Some of these, like the D-amino acids, DAP, and $N$-acetylmuramic acid, have the fascinating property of being unique to the microbial world and are not found anywhere else in nature. Second, evidence has been obtained that several antibiotics, notably the penicillins, cephalosporins, vancomycin, bacitracin, etc., exert their antibacterial activities through the inhibition of the biosynthetic pathways of this peptidoglycan macromolecule at specific steps. Thus this discovery offered a new basic, rational approach to the problem of selective toxicity in chemotherapy.

\section{General Structure of the Bacterial PePTIDOGLYCAN NeTWORK}

From an integration of the structural studies, a general agreement has emerged that the peptidoglycan polymer is a network composed of three constituents, glycan strands, peptide subunits, and peptide cross-linking bridges. A monolayer representation of such a network is given in Fig. 1. A multilayered structure could be easily built up by interconnecting several superimposed glycan sheets by means of peptides. As mentioned above, the peptidoglycan in walls of gram-negative bacteria has a thickness of about 2 to $3 \mathrm{~nm}$; thus, it probably occurs as a monolayer. In contrast to this, the peptidoglycan sheet in walls of grampositive bacteria is much thicker and is probably organized as a multilayered network. Rigidity and insolubility are properties solely of the intact network, so that a loss of integrity resulting from

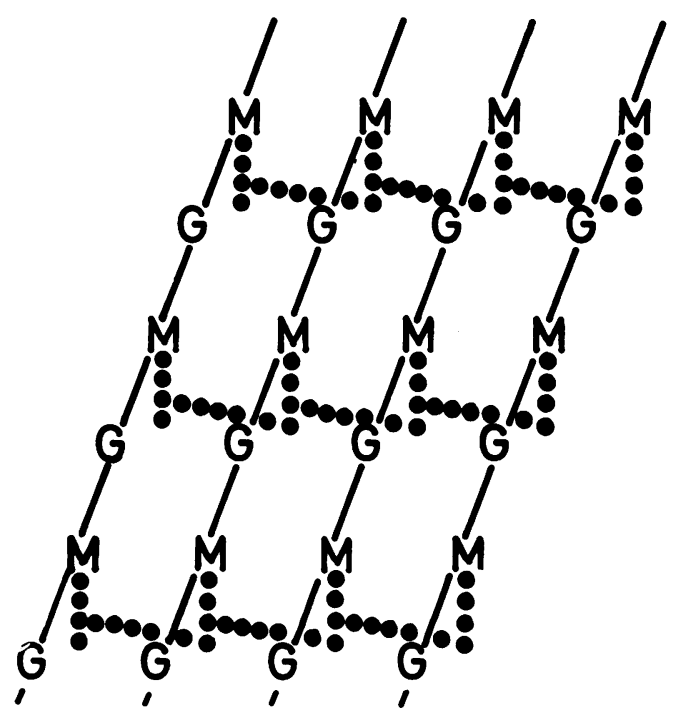

FIG. 1. Schematic representation of a peptidoglycan monolayer. Glycan chains are composed of $N$-acetylglucosamine (G) and $N$-acetylmuramic acid $(M)$. Vertical dots from $M$ represent the peptide subunits. The horizontal dots represent the cross-linking peptide bridges (38; figure reprinted by permission).

the breakdown of either the glycan or the peptide moieties brings about the solubilization of the whole complex. The general structural features of the three peptidoglycan constituents will be presented first.

\section{Glycan Strands}

In all bacteria so far examined, the glycan strands consist of alternating $\beta-1,4$-linked $N$ acetylglucosamine and $N$-acetylmuramic acid residues (Fig. 2). The only variation so far encountered among bacteria is the possible presence of $O$-acetyl substituents on C-6 of some of the $N$-acetylmuramic acid residues (vide infra).

\section{Peptide Subunits}

The peptide subunits substitute through their $\mathrm{N}$-termini the D-lactic acid moiety of some of the muramic acids in the glycan (Fig. 2). Figure 3 shows several peptide subunits for which the structures have been established. In these subunits, the $\gamma$-carboxyl group of the glutamic acid residue is linked to the next amino acid in the sequences. Depending upon the bacterial species, the $\alpha$-carboxyl group of glutamic acid is either free, or substituted by an amide or by an amino acid residue. In Micrococcus lysodeikticus (Fig. 3 , type C), the substituting amino acid is usually Gly (vide infra). This Gly can be replaced by 


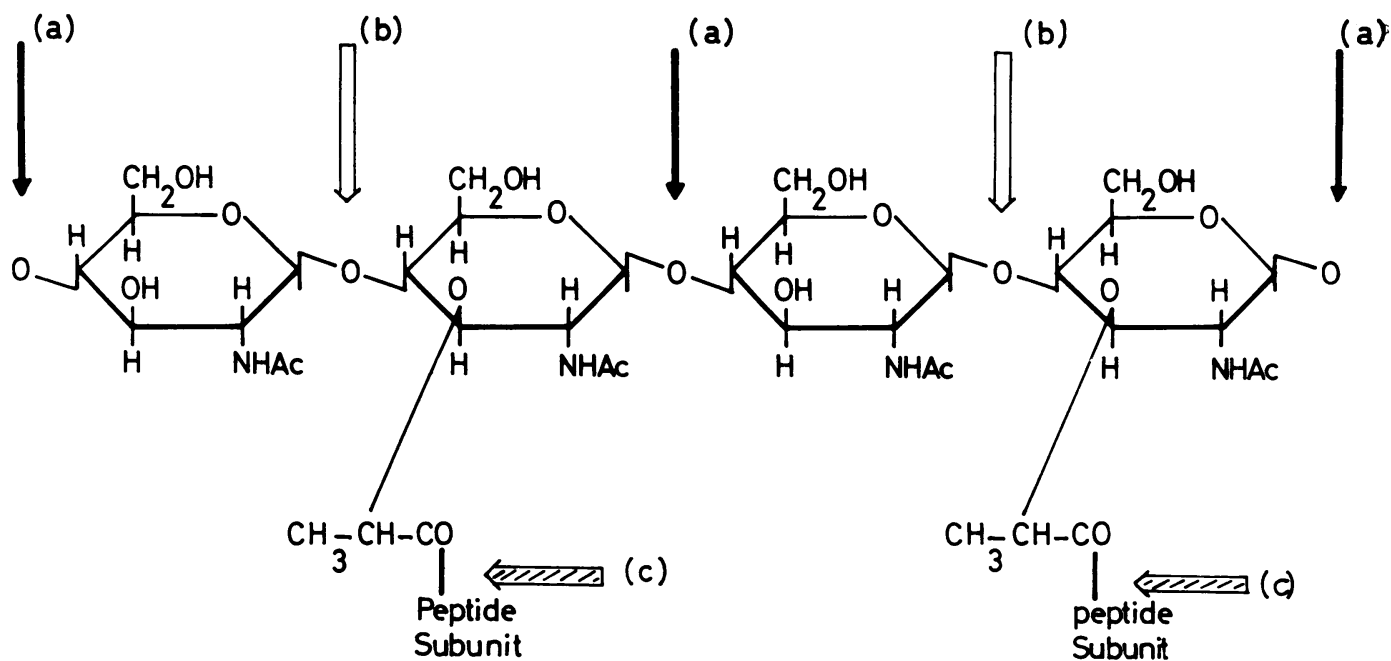

(a) : endo- $\mathrm{N}$-acetylmuramidase ; (b) : endo- $\mathrm{N}$-acetylglucosaminidase ;

\section{(c): $\mathrm{N}$-acetylmuramyl-L-alanine amidase.}

FIG. 2. A portion of a glycan strand. (a), Site of action of endo-N-acetylmuramidase; (b), site of action of endo$\mathrm{N}$-acetylglucosaminidase; (c), site of action of $\mathrm{N}$-acetylmuramyl-L-Ala amidase.

D-serine when $M$. lysodeikticus is grown in a defined medium in the presence of D-Ser (181). Similarly, the carboxyl group of meso-DAP not engaged in a peptide bond may be substituted by an amide group. Nomenclature involving mesoDAP-containing peptide subunits may be confusing. In order to specify which of the two asymmetric carbons of meso-DAP has the substituted amino groups, the notation (L) or (D) written immediately before meso-DAP has been suggested (9). It has also been proposed to write (L) or (D) immediately after meso-DAP in order to distinguish between the carboxyl-substituted groups. This terminology is used throughout this review.

The most common peptide subunits are the peptides A, B, and C (Fig. 3). The peptide subunits, D and E, (Fig. 3) contain neither L-Lys nor meso-DAP. Moreover, the $\mathrm{N}$-terminal amino acid (that is, the one which is joined to the glycan chains) is not an L-Ala residue. It is remarkable that the peptide subunit $D$ contains no diamino acid residue. Peptide subunits with sequences L-Ala- $\gamma$-D-Glu-diamino acid-D-Ala are known which differ from peptides A, B, or C (Fig. 3) by the fact that L-Lys or meso-DAP is replaced by another diamino acid. Examples of unusual diamino acids are the following: LL-DAP (in many actinomycetes, vide infra), DD-DAP in a minor part of the peptidoglycan of B. megaterium and probably in some Micromonospora and actinomycetes, vide infra; 2,4 diaminobutyric acid in Corynebacterium tritici (116); 2,6 diamino-3-hydroxypimelic acid in several Actinoplannaceae (112); L-ornithine (L-Orn) in $M$. radiodurans (182), Lactobacillus bifidus var Pennsylvanicus (175), L. cellobiosus (121-123), and in Treponema reiteri (164); and hydroxylysine, known to replace L-Lys in Streptococcus faecalis, but only under conditions of lysine deprivation (150). Hydroxylysine was also found as a minor constituent of the peptide of $S$. pyogenes (99).

Finally, variations in the peptide subunits can also occur in the nature of the dicarboxylic amino acid residue. The sequence Gly-threo-3hydroxy-Glu-L-Lys-D-Ala has been characterized in Microbacterium lacticum $(144,145)$.

\section{Cross-linking Bridges}

Several types of cross-linking bridges are presented in Fig. 4-9. The bridges which crosslink the peptide subunits have identical locations in bacterial peptidoglycans of types I, II, and III (Fig. 4-7). They extend from the $\epsilon$-amino group of L-Lys or from the amino group on the D-carbon of meso-DAP $\left(\mathrm{NH}_{2}\right.$-(D)-meso-DAP) of one peptide subunit to the C-terminal D-Ala carboxyl group of another peptide subunit. According to the bacterial species, however, the bridges present great variations in their chemical composition. In type I, the bridging results from direct peptide 


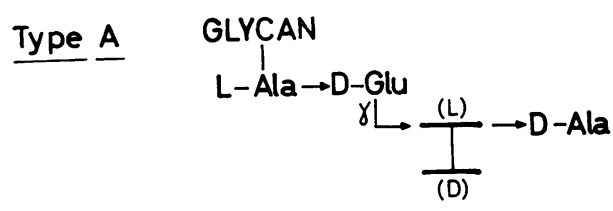

Type $\underline{B}$

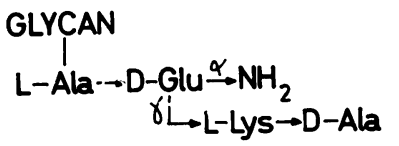

Type C

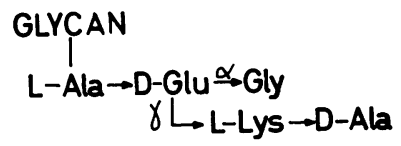

Type $\underline{D}$

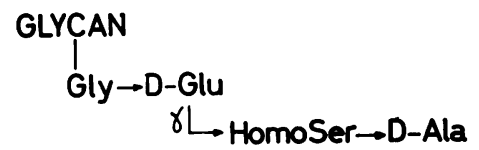

Type E

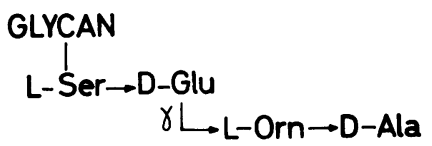

FIG. 3. Five types of peptide subunits. Glu-NH$=$ isoglutamine. A. Peptide subunits in E. coli, B. megaterium, and $B$. subtilis. In $B$. subtilis, the carboxyl groups on the $D$ carbon of meso-DAP of some peptide subunits are amidated. Vertical bar separating $(L)$ and $(D)$ represents diaminopimelic acid. B. Peptide subunits in Staphylococcus aureus, M. roseus, Streptococcus pyogenes, $A$. crystallopoietes, $S$. faecalis, $L$. acidophilus, and L. casei. C. Peptide subunits in Sarcina lutea, $M$. lysodeikticus, $M$. flavus, and $M$. citreus. $D$. Peptide subunits in C. poinsettiae, C. flaccumfaciens, and $C$. betae. E. Peptide subunits in Butyribacterium rettgeri.

Type I. E.coli; B. megaterium; B. subtilis

$$
\begin{aligned}
& \text {-.-G-M-G-- } \quad--G-M-G-\cdots
\end{aligned}
$$

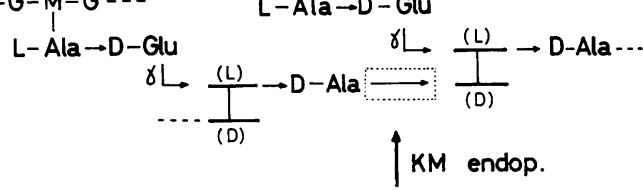

FIG. 4. Peptidoglycan type I. Direct cross-linkage between two peptide subunits $A$ (Fig. 3). Arrow: site of action of the KM endopeptidase.

bonds between peptide subunits (Fig. 4). This type of bonding seems to be frequent among meso-DAP-containing peptidoglycans. Thus, the bridges are D-Ala-(D)-meso-DAP. In type II, the bridges consist of several Gly or L-amino acid residues, or both (Fig. 5), or are composed of one D-amino acid, namely D-isoasparagine (Fig. 6). In type III, the bridges are formed by a "head to tail" assembly of several peptides, each having the same sequence of amino acids as the peptide subunit (Fig. 7). Two types of linkages, $N^{\epsilon}(\mathrm{D}$ alanyl)-L-Lys and D-alanyl-L-Ala, are involved in the binding between the peptide subunits. In type IV, in a few bacteria, the bridges which crosslink the peptide subunits extend from D-Glu of one peptide subunit to the C-terminal D-Ala carboxyl group of another peptide subunit. These peptide bridges are composed of one diamino acid residue, D-Orn in the case of $C$. poinsettiae and some other plant pathogenic Corynebacteria (115; Fig. 8), D-Lys and D-Orn in the case of Butyribacterium rettgeri (M. Guinand et al., Biochemistry, in press; Fig. 9). As shown in Fig. 8 and 9, the D-Lys or the D-Orn residues are linked through their $\epsilon$ - or $\delta$-amino groups, respectively, to the $\alpha$-carboxyl group of glutamic acid, and through their $\alpha$-amino groups to the carboxyl terminal D-Ala. A similar type of bridging probably occurs in Microbacterium lacticum (145), in which case a dipeptide $N^{\alpha_{-}}(\mathrm{Gly})$-Lys would extend from the threo-3-hydroxyglutamic acid residue of one peptide subunit to the D-Ala residue of another peptide subunit.

\section{Enzymes that Degrade Bacterial Peptido- GLYCANS: NATURE OF THE HYDROLYZED LINKAGES}

The establishment of the peptidoglycan structure has necessitated the development of accurate analytical and fractionation techniques and the discovery of a series of different hydrolytic agents of high specificity. Within the past 10 years, numerous bacteriolytic enzymes have been isolated, which have proven to be just such tools. A description of these techniques and a survey of the lytic enzymes so far discovered and characterized have been given recently (41). The following enzymes, selected for their specific action upon critical linkages, were particularly useful in dismantling the bacterial peptidoglycans into meaningful fragments (Table 1).

\section{Endo- $N$-Acetylmuramidases}

These enzymes, such as egg-white lysozyme (27), Streptomyces $32(34,36,37)$ or $F_{1}$ enzymes $(21,100)$, and Chalaropsis B enzyme $(46,47,172)$, hydrolyze the glycosidic linkages between $N$ acetylmuramic acid and $N$-acetylglucosamine (Fig. 2), releasing fragments with $N$-acetylmuramic acid residues at the reducing end. 
TABLE 1. Enzymes that degrade bacterial peptidoglycans ${ }^{a}$

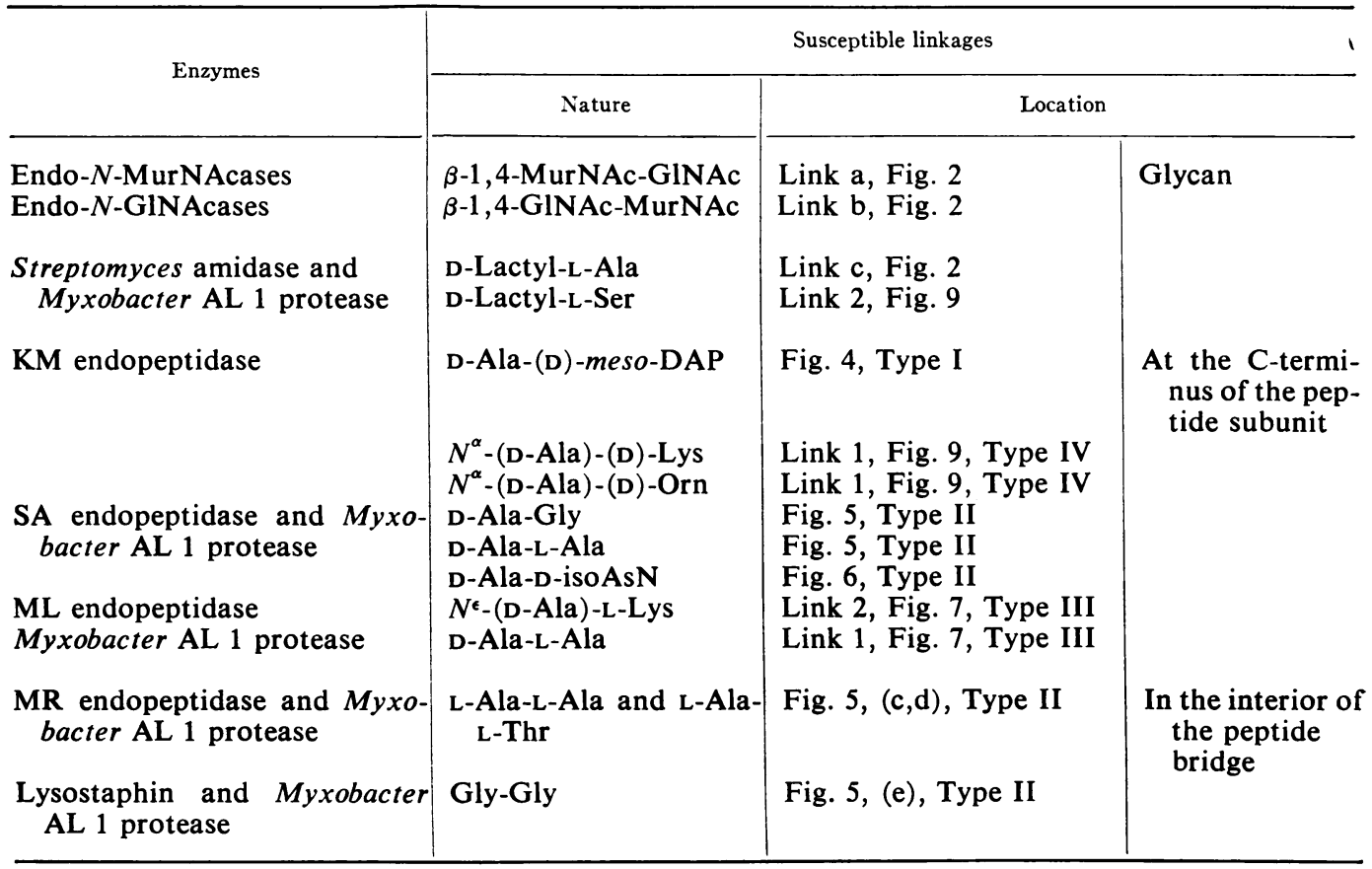

a Endo- $N$-MurNAcase $=$ endo- $N$-acetylmuramidase; Endo- $N$-GINAcase $=$ endo- $N$-acetylglucosaminidase; MurNAc $=N$-acetylmuramic acid; GINAc $=N$-acetylglucosamine.

Type II. (a): A. crystallopoietes ; (b) : $\underline{\text { S pyogenes; }}$

(c): $\underline{M}$ roseus $T h{ }^{(-)}$; (d): $\underline{M}$ roseus $R 27$; (e) $\underline{S}$ aureus Copenhagen.

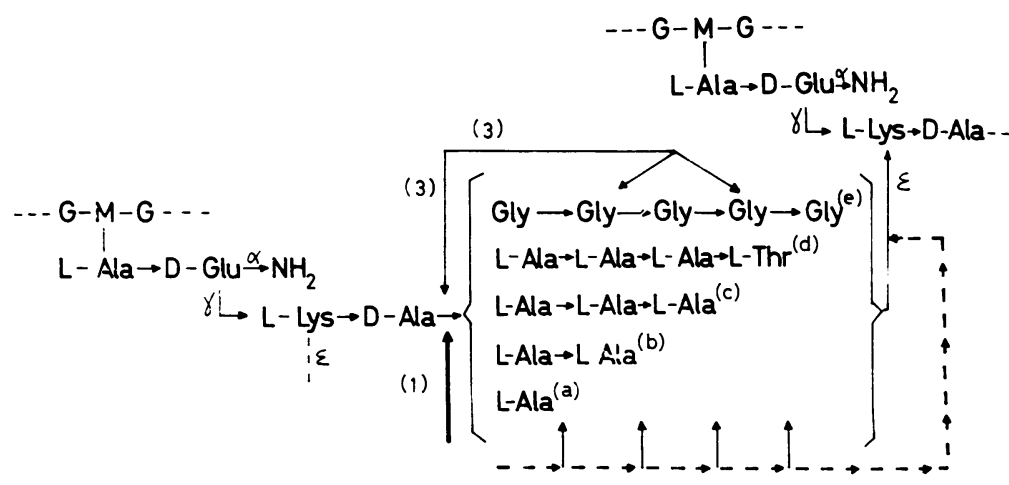

(2)
(1) : SA endop
(2) : Aminopeptidase
(3) : Myxobacter ALI

Fig. 5. Peptidoglycan type II. Peptide bridges composed of glycine or L-amino acid residues cross-linking two peptide subunits B (Fig. 3). (1), Site of action of the SA endopeptidase; (2), site of action of aminopeptidase; (3), site of action of Myxobacter AL 1 endopeptidase. Walls of Staphylococcus epidermidis belong to the same type II. The bridges are formed of Gly and L-Ser residues (D. J. Tipper, Federation Proc., p. 294, 1968). L-Ser is nonrandomly located. Four kinds of bridges in the following proportions have been shown to occur: Gly-Gly-Gly-GlyGly (20\%); Gly-Gly-L-Ser-Gly-Gly (55\%); Gly-L-Ser-Gly-Gly-Gly (10\%); and L-Ser-Gly-L-Ser-Gly-Gly (15\%). 


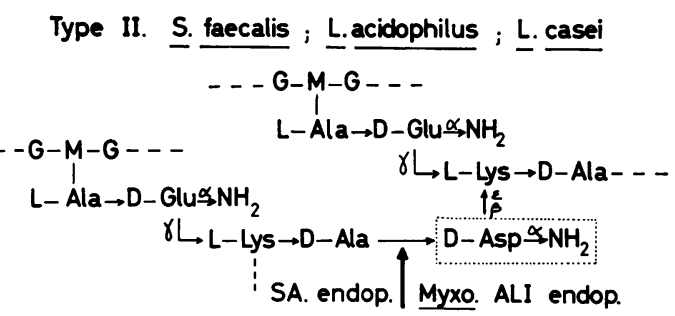

FIG. 6. Peptidoglycan type II. A D-isoasparaginyl bridge cross-linking two peptide subunits B (Fig. 3). Arrow: site of action of the $S A$ and Myxobacter $A L 1$ endopeptidases.

\section{Endo- $N$-Acetylglucosaminidases}

These enzymes, such as streptococcal muralysin (3) and the glycosidase in lysostaphin (170), hydrolyze the glycosidic bonds between $N$ acetylglucosamine and $N$-acetylmuramic acid (Fig. 2), releasing fragments with $N$-acetylglucosamine at the reducing end.

\section{Streptomyces $N$-Acetylmuramyl-L-Alanine Amidase}

This enzyme (J. M. Ghuysen et al., Biochemistry, in press; 34$)$ hydrolyzes the bonds between the D-lactic acid residues of the glycan strands and the $\mathrm{N}$-terminal residues of the peptide subunits (Fig. 2, 7, 9). The $\mathrm{N}$-terminal amino acid is usually L-Ala; thus, the enzyme is designated as $N$-acetylmuramyl-L-Ala amidase. However, this amidase is also able to cleave other linkages at identical locations in the peptidoglycan, such as the $N$-acetylmuramyl-L-Ser linkages in walls of B. rettgeri (Fig. 9). This enzyme has no significant activity on intact peptidoglycans. To be func-

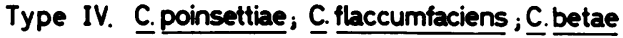

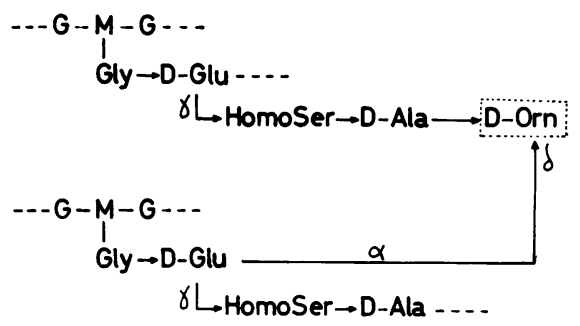

Fig. 8. Peptidoglycan type IV. A D-ornithine bridge cross-linking two peptide subunits D (Fig. 3). Note the absence of diamino acid in the peptide subunit.

tional, it requires that the glycan first be split. Thus, this amidase has no bacteriolytic action.

\section{Streptomyces KM Endopeptidase}

This enzyme (J. M. Ghuysen et al., Biochemistry in press) has been used to hydrolyze the crosspeptide linkages which serve as bridges between peptide subunits in the meso-DAP-containing peptidoglycans of E. coli and B. megaterium KM [J. Van Heijenoort et al., Biochemistry, in press; 9 (Peptidoglycan type 1, Fig. 4)]. The bonds specifically hydrolyzed are thus D-alanyl (D)meso-DAP linkages. This enzyme also hydrolyzes the $N^{\alpha}$-(D-alanyl)-D-Lys and $N^{\alpha}$-(D-alanyl)D-Orn linkages in walls of $B$. rettgeri (M. Guinand et al., Biochemistry, in press; Peptidoglycan type IV, Fig. 9). An endopeptidase whose specificity must be identical to that of the Streptomyces $\mathrm{KM}$ endopeptidase is present in the autolytic system of $E$. coli (177).

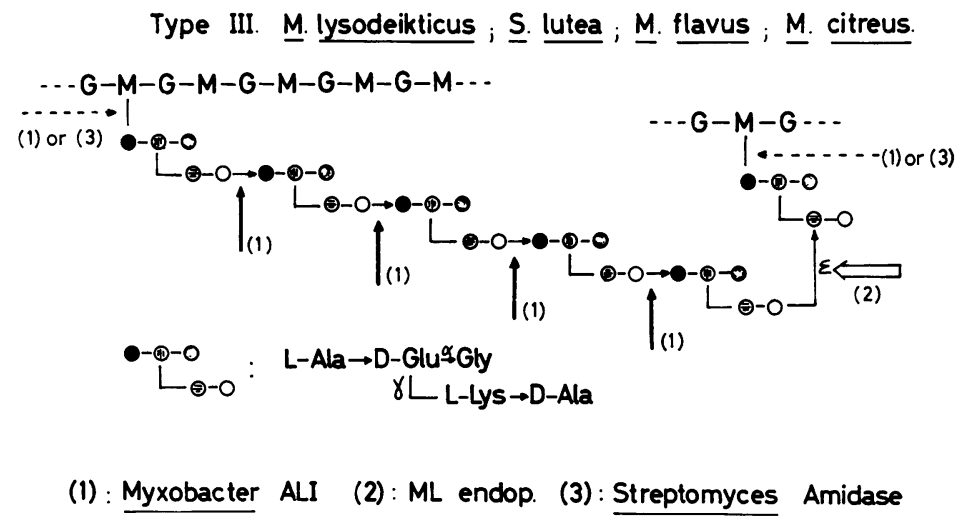

FIG. 7. Peptidoglycan type III. Assembling of peptide subunits C (Fig. 3) in some Micrococcaceae. (1), Site of action of Myxobacter AL 1 endopeptidase (hydrolysis of D-alanyl-L-Ala linkages and of $N$-acetylmuramyl-L-Ala linkages); (2), site of action of $M L$ endopeptidase (hydrolysis of $N_{-}^{\epsilon_{-}(D-a l a n y l)-L-L y s}$ linkages); (3), site of action of Streptomyces $\mathrm{N}$-acetylmuramyl-L-Ala amidase. 


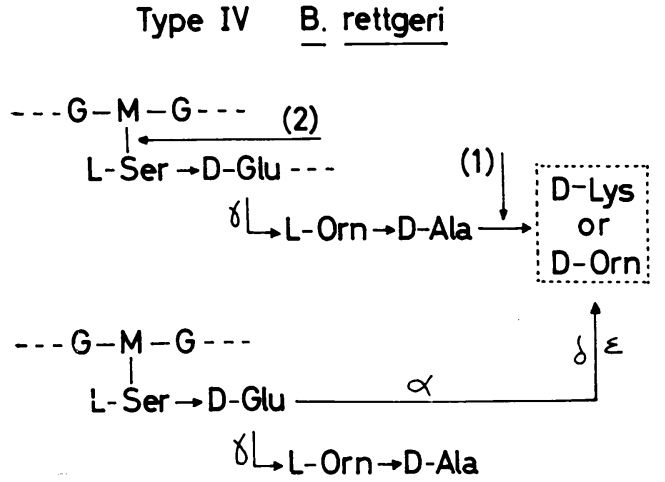

(1) KM endop. (2) Streptomyces Amidase

FIG. 9. Peptidoglycan type IV. Two peptide subunits $E$ (Fig. 3) cross-linked by a D-Lys or a D-Orn bridge. Note that the diamino acid L-Orn in the peptide subunit is not used for peptide cross-linking. Arrows: (1) site of action of the KM endopeptidase; (2) site of action of Streptomyces $N$-acetylmuramyl-L-Ala amidase. In Butyribacterium rettgeri peptidoglycan, D-lys and $D$-Orn bridges occur in the ratio $2: 1$.

\section{Streptomyces SA Endopeptidase}

This enzyme acts on type II peptidoglycans $(32,33,39,99,117$; Fig. 5, 6). It hydrolyzes the linkages at the $\mathbf{N}$ termini of the peptide bridges and at the C-terminus of the peptide subunits. Sensitive linkages are, for example, D-alanylGly, D-alanyl-L-Ala; D-alanyl-D-iso-asparogine. When opened at their $\mathbf{N}$ termini, the peptide bridges which contain glycine or L-amino acid residues, or both (Fig. 5), can be further degraded (117) by an amino peptidase such as that secreted by Streptomyces strains (J. M. Ghuysen et al., Biochemistry, in press). As a result, the amino acids are sequentially liberated until the $\epsilon$-amino groups of lysine in the peptide subunits, to which the peptide bridges are linked at their C termini, are exposed (Fig. 5).

\section{Streptomyces ML Endopeptidase}

This enzyme is active on type III peptidoglycans (Fig. 7; J. Campbell et al., Biochemistry, in press; $31,117)$. It specifically hydrolyzes $N^{\epsilon}$-(D-alanyl)L-Lysine linkages (link 2, Fig. 7), which serve as linking groups between peptide subunits.

\section{Myxobacter AL 1 Protease}

In contrast to Streptomyces KM, SA, and ML endopeptidases, all of which have restricted specificities and are, for example, unable to degrade casein, Myxobacter AL 1 enzyme (24) is a powerful protease, active on casein, and it possesses a broad bacteriolytic spectrum. It has several sites of action on the cell wall peptide. (i) Investigations of the mode of action of this enzyme upon Staphylococcus aureus $(59,17)$ have revealed that it catalyzes hydrolysis of two linkages within the peptide moiety (Fig. 5). Nterminal Gly and both $\mathrm{COOH}$-terminal D-Ala and $\mathrm{COOH}$-terminal Gly are liberated by this hydrolysis. The pentaglycine bridges are thus attacked at internal glycyl-Gly linkages as well as at their linkages to the D-alanyl termini of the peptide subunits (links 3, Fig. 5). (ii) Myxobacter AL 1 enzyme, acting upon walls of Arthrobacter crystallopoietes $(74,75), M$. lysodeikticus (31), and other Micrococcaceae (J. Campbell et al., Biochemistry, in press), hydrolyzes D-alanyl-LAla linkages in bridges of type II, as does the SA endopeptidase (Fig. 5), and the "head to tail" D-alanyl-L-Ala linkages in the type III bridges (link 1, Fig. 7). (iii) Moreover, Myxobacter AL 1 enzyme is capable of hydrolyzing D-alanyl-DisoAsN linkages (Fig. 6), as does the SA endopeptidase, and it has been used to study the peptidoglycan in L. casei (D. Hungerer, Federation Proc., p. 294, 1968). (iv) Finally, in all cases so far studied, Myxobacter AL 1 enzyme also hydrolyzes $N$-acetylmuramyl-L-Ala linkages (Fig. 2) at a slow but detectable rate $(31,71,75$, 171). In this respect, the Myxobacter $\mathrm{AL} 1$ enzyme has a very useful characteristic: it displays amidase activity on substrates with intact glycan chains. Thus, this enzyme provides a way of isolating the polysaccharide moiety free of its substituent peptide, but retaining its in vivo degree of polymerization.

\section{Streptomyces MR Endopeptidase and Lysostaphin Endopeptidase}

Lysostaphin endopeptidase $(11,170)$ is known to split glycyl-Gly linkages at several places within the pentaglycine bridges (type IIe, Fig. 5). Since this structure is limited to the Staphylococci, lysostaphin endopeptidase is specifically staphylolytic. Streptomyces MR endopeptidase disrupts types IIc and IId bridges (117; Fig. 5). It hydrolyzes the L-alanyl-L-Thr linkages in $M$. roseus $\mathrm{R} 27$ and, at a slower rate, the L-alanyl-LAla linkages in $M$. roseus $\left(\mathrm{Thr}^{-}\right)$.

\section{Peptidase Preparations with Mixed Activities}

The Streptomyces $\mathbf{L}_{3}$ enzyme preparation, when acting upon walls of $C$. diphtheriae (J. M. Ghuysen et al., Federation Proc., p. 410, 1966; $65,72,96,97)$, is mainly a bridge-splitting enzyme which catalyzes the hydrolysis of D-alanyl-mesoDAP. In this latter case, however, it is not known which amino group of meso-DAP of one peptide subunit is involved in the linkage to D-Ala of 
another peptide subunit. The $L_{3}$ enzyme preparation also contains (i) $\mathrm{N}$-acetylmuramyl-L-Ala amidase activity, (ii) an enzyme catalyzing the hydrolysis of an amide that substitutes one of the carboxyl groups of meso-DAP, and (iii) possibly, a D-Ala carboxypeptidase.

The Flavobacterium L-11 enzyme $(65,66)$ and the Staphylococcus epidermidis ALE enzyme (158) exert their lytic actions upon walls of $S$. aureus through the activities of glycyl-Gly endopeptidase, $\mathrm{N}$-acetylmuramyl-L-Ala amidase, and D-alanylGly endopeptidase (in the case of the L-11 enzyme).

As observed with Myxobacter AL 1 enzyme, the above L-3, L-11, and ALE enzyme preparations hydrolyze more than one type of linkage. From the data published to date, it seems likely that several enzymes are present in the L-3, L-11, and ALE preparations as they are obtained.

\section{Summation}

The foregoing enzymes permit the specific hydrolysis of many important linkages in the wall peptidoglycans (Table 1). Endo- $N$-acetylmuramidases and endo- $N$-acetylglucosaminidases act on the glycan chains. $N$-acetyl muramyl-L-Ala amidases hydrolyze linkages at the junction between the glycan and the peptide moieties, i.e., linkages that are located at the $\mathbf{N}$ termini of the peptide subunits. The endopeptidases may be grouped into three main types: (i) those which hydrolyze various linkages, all of which involve the C-terminal D-Ala of the peptide subunits; (with the exception of the following examples, all the known endopeptidases fall in this group); (ii) Myxobacter AL 1 which, in some bacterial walls, hydrolyzes linkages involving both $\mathrm{C}$ and $\mathrm{N}$ termini of the peptide subunits (Fig. 7); and (iii) lysostaphin and MR endopeptidase, which hydrolyze peptide internal bonds of the peptide bridges involving neither the $\mathrm{C}$ nor the $\mathrm{N}$ termini of the peptide subunits. With some bacterial walls (for example, those of $S$. aureus), Myxobacter AL 1 also has this latter type of activity (Fig. 5). Streptomyces $\mathrm{sp}$. appear to be a very interesting source of various peptidases active on bacterial peptidoglycans. Streptomyces aminopeptidase (link 2, Fig. 5) and the Streptomyces KM, SA, ML, and MR endopeptidases are basic proteins. They have been purified and separated from each other by chromatography on CM-cellulose, and their specific activities upon soluble, well-defined, bacterial wall degraded compounds have been studied (J. M. Ghuysen et al., Biochemistry, in press).

\section{Structure of Several Bacterial Peptido- GLYCANS AS REVEALED BY ENZYMATIC DEgRadATIONS: GLYCAN MOIETY}

The studies to be reported here deal with the wall peptidoglycan of some gram-positive bacteria. Intact cell walls were obtained by mechanical disruption of the cells followed by differential centrifugation. However, these wall preparations were usually treated with trypsin to remove cytoplasmic contaminants and, in some instances, protein constituents of the walls themselves. The walls were not subjected to any chemical agent such as trichloroacetic acid or hot formamide. Although these treatments are widely used and yield enriched peptidoglycan preparations by removing nonstructural wall components (other polysaccharides and teichoic acids), they also cause random cleavage of some covalent linkages within the peptidoglycan, as has been shown by end group analysis. In addition, various chemical modifications, such as formylation of free amino groups, can occur when hot formamide is used (114). Moreover, chemically stripped peptidoglycans are not capable of giving any information about the way in which the various constitutive polymers are held together within the bacterial walls, a question that ultimately must be resolved.

\section{Staphylococcus aureus}

Three types of glycan degradation procedure were carried out with (i) endo- $N$-acetylmuramidase (Chalaropsis B enzyme; Streptomyces 32 or $F_{1}$ enzymes), (ii) endo- $N$-acetylglucosaminidase (from lysostaphin), and (iii) Myxobacter AL 1 enzyme. In the first procedure, after solubilization of the wall by the $N$-acetylmuramidase (36, 37), teichoic acids were removed on Ecteola cellulose at $p \mathrm{H} 5$. The peptide substituents were detached from the glycan fragments by Streptomyces $N$-acetylmuramyl-L-Ala amidase (Fig. 2), and the liberated peptides were removed on CM cellulose at $p \mathrm{H}$ 6.4. The resulting free glycan fragments were separated into two components by preparative paper chromatography followed by gel filtration. They were characterized (167) as being Disaccharide $1(\beta-1,4-N$ acetylglucosaminyl- $N$-acetylmuramic acid) and Disaccharide II $[\beta-1,4-N$-acetylglucosaminyl$N$,6-O-diacetylmuramic acid; (Fig. 10)].

In the second procedure, a similar degradation sequence (170) yielded two disaccharides isomeric with Disaccharides I and II, Disaccharide III: $(\beta-1,4-N$-acetylmuramyl- $N$-acetylglucosamine) 


\section{Disaccharide I}

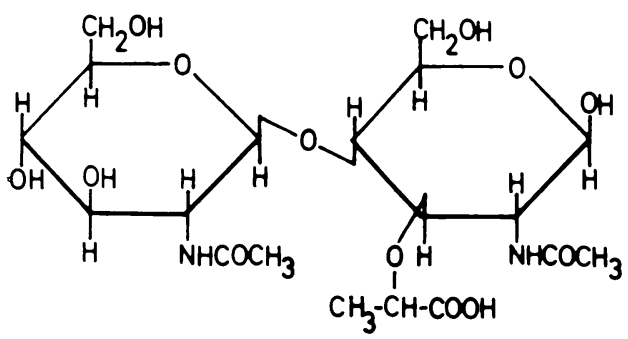

Disaccharide III

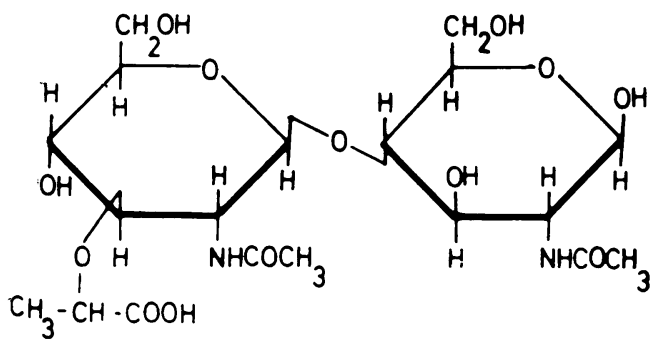

Disaccharide II

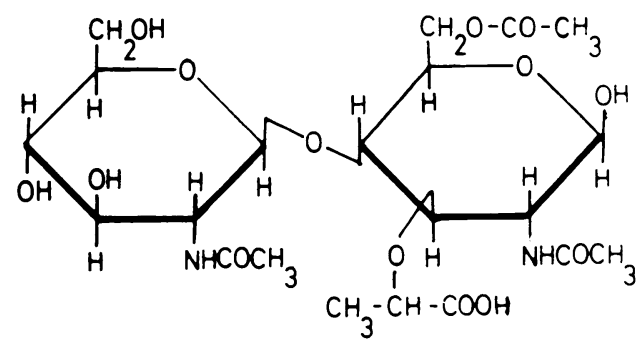

Disaccharide IV

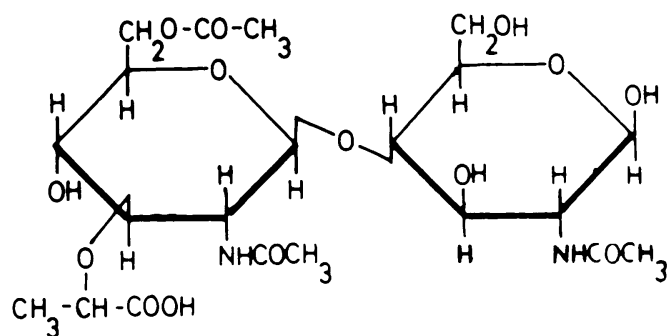

Fig.'10. Structure of disaccharides isolated from the peptidoglycan of Staphylococcus aureus Copenhagen. Disaccharide I and disaccharide III have also been obtained from M. lysodeikticus. Disaccharide I: $N$-acetylglucosaminyl- $\beta-1,4-N$-acetylmuramic acid. Disaccharide II: $N$-acetylglucosaminyl- $\beta-1,4-N$, 6-O-diacetylmuramic acid. Disaccharide III: $N$-acetylmuramyl- $\beta-1,4-N$-acetylglucosamine. Disaccharide IV: $N$, 6-O-diacetylmuramyl$\beta-1,4-N$-acetylglucosamine.

and Disaccharide IV $[\beta-1,4-N-, 6-O$-diacetylmuramyl- $N$-acetylglucosamine (Fig. 10)]. The observed yields of the disaccharides obtained by the various degradation procedures were consistent with a wall structure in which the glycan moiety is composed of linear strands of $\beta-1,4$ linked $\mathrm{N}$-acetylglucosamine pyranoside residues, (i.e., a chitin-like structure). Unlike chitin, however, every other sugar is substituted by a 3-O-D-lactyl group. In $S$. aureus, about $50 \%$ of the $N$-acetylmuramic acid residues have a 6-Oacetyl group, but whether the distribution of this substituent is regular, random, or localized is not yet known. Since glycan degradation yields free disaccharide units only if it is followed by $N$ acetylmuramyl-L-Ala amidase treatment, all $\mathrm{N}$-acetylmuramic acid residues must, therefore, be substituted by peptide subunits. For this reason, the $S$. aureus peptidoglycan is said to be a "tight" network.

In the third procedure, Myxobacter AL 1 enzyme was used to achieve, in a one-step operation, the opening of the pentaglycine bridges (Fig. 5) and the hydrolysis of the $N$-acetylmuramyl-L-Ala amidic linkages, thus yielding free unaltered glycan strands (171). Appropriate fractionation of the degraded products gave rise to various glycan fractions, some of which were bound to the teichoic acid polymer. Analyses of the fractions showed the glycan moiety to be polydisperse with an average chain length of about 12 disaccharide units, but containing chains with as few as $\mathbf{6}$ and as many as $\mathbf{5 0}$ disaccharide units. These figures were based on the estimation of the formaldehydogenic end groups that originate from the reducing $N$-acetylhexosamine termini of the glycan chains on reduction with $\mathrm{NaBH}_{4}$. An average chain length of 16 disaccharide units can also be deduced from an estimation of the free $N$-acetylglucosamine residues which are liberated from cell walls after complete hydrolysis of the linkages between $N$ - 
acetylmuramic acid and $N$-acetylglucosamine by means of an endo- $N$-acetylmuramidase (36). This liberation of free $N$-acetylglucosamine residues under these conditions (actual data, $32 \mathrm{nmoles} / \mathrm{mg}$ of walls or per $500 \mathrm{~nm}$ equivalents of disaccharide units) indicates that $N$-acetylglucosamine residues are located at the reducing ends of the intact glycan chains. These reducing $\mathrm{N}$-acetylglucosamine termini in the glycan result very probably from an endo- $N$-acetylglucosaminidase activity of the staphylococcal autolytic system (D. J. Tipper, Bacteriol Proc., p. 48, 1968).

\section{Micrococcus lysodeikticus}

Similar techniques of degradation, fractionation, and characterization showed the $M$. lysodeikticus glycan moiety to be identical with that of $S$. aureus, with the following exceptions, however. (i) $O$-acetyl substitution is absent in all but a few strains. (ii) Only $40 \%$ of the $N$-acetylmuramic acid residues are substituted by peptide subunits $(81,100)$. (iii) A small amount of the muramic acid residues are not $N$-acetylated (92). (iv) Splitting of the glycan with the help of either lysozyme or Streptomyces $\mathrm{F}_{1}$ endo- $\mathrm{N}$-acetylmuramidase is incomplete and free, unsubstituted glycan fragments, from di- to octasaccharides, are produced. Disaccharide I $(60,81,110,139,147)$, disaccharide III) (81; Fig. 10), and a tetrasaccharide (81; Fig. 11) were isolated in good yields, and their structures were thoroughly established. The lysozyme-catalyzed hydrolysis of isolated wall oligosaccharides has been studied in detail $(15,16)$ and interpreted on the basis of the three-dimensional model of lysozyme developed by Philips and co-workers $(5,6)$. The results obtained show that hydrolysis of the isolated tetrasaccharide to yield disaccharides proceeds chiefly via transglycosilation, leading to the formation of higher oligosaccharides. Hexa-, octa-, deca- and dodecasaccharides are readily degraded by lysozyme to yield the corresponding di- and tetrasaccharides. The tetrasaccharide is degraded at a much lower rate than the higher oligosaccharides because it is bound largely to lysozyme in a nonproductive manner, which does not lead to bond scission. Owing to the partial peptide substitution of its glycan moiety, the $M$. lysodeikticus peptidoglycan is referred to as a "loose" network to contrast it with that of $S$. aureus.

\section{Other Bacterial Peptidoglycans}

Disaccharides have also been isolated after endo- $N$-acetylmuramidase degradation of walls or envelopes of the following bacteria: $M$. roseus $(99,117)$, Sarcina lutea (J. Campbell et al., Biochemistry, in press), Staphylococcus epidermidis (D. J. Tipper, Federation Proc., p. 294, 1968), L. acidophilus (J. Coyette and J. M. Ghuysen, unpublished data), L. casei (D. Hungerer, Federation Proc., p. 294, 1968), Streptococcus pyogenes $(98,99), S$. faecalis $(149,151), B$. megaterium (9), B. licheniformis (93), Butyribacterium rettgeri (M. Guinand et al., Biochemistry, in press), and E. coli (J. van Heijenoort et al., Biochemistry, in press). None of these disaccharides was submitted to the same exhaustive structural investigations as were those of Staphylococcus aureus and M. lysodeikticus, but analyses were made which provided the following data. (i) $\mathrm{N}$-acetyglucosamine and $\mathrm{N}$-acetylmuramic acid were the only two monosaccharides present. (ii) Acid hydrolysis, followed by quantitation of glucosamine using the yeast D-glucosamine 6 phosphate $\mathrm{N}$-acetylase, revealed that half of the: hexosamine residues were glucosamine. (iii) Reduction of the disaccharide with $\mathrm{NaBH}_{4}$ destroyed all of the muramic acid, half of the total hexosamines, and none of the glucosamine, thus establishing that muramic acid is at the reducing end of the disaccharide. (iv) Susceptibility to pig epididymis exo- $\beta-N$-acetylglucosaminidase, which is specific for $\beta$ glycosidic linkages, established the $\beta$-anomery of the link. (v) Determination of the molar extinction coefficient of the disaccharide with the Morgan-Elson reaction (147) established the glycosidic linkage to be $1: 4$, not $1: 6$. Hence the linkage $\beta-1,4$ of the disaccharide (disaccharide I, Fig. 10) has been well characterized in several cases. Consequently,

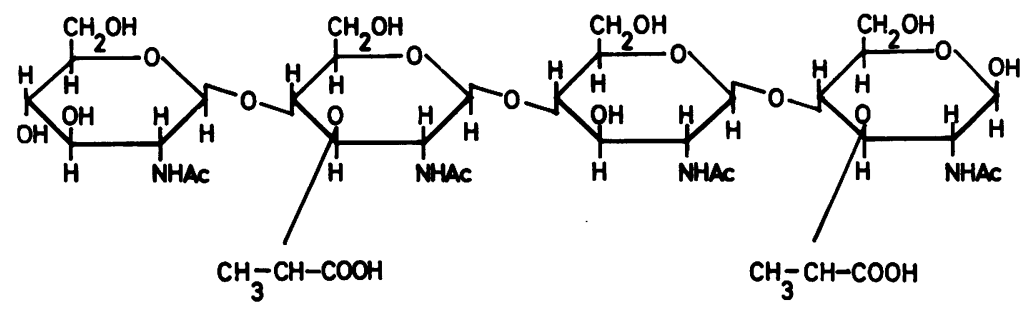

FIG. 11. Structure of a tetrasaccharide isolated from the peptidoglycan of $M$. lysodeikticus: $N$-acetylgluco-

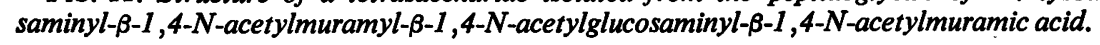


the glycosidic linkages, which in the glycan strands extend from $N$-acetylglucosamine to $N$-acetylmuramic acid, are known to be $\beta-1,4$. Final characterization of the linkages between $\mathrm{N}$-acetylmuramic acid and $\mathrm{N}$-acetylglucosamine requires the isolation and characterization of the isomeric disaccharide III (Fig. 10). This has been done only with the walls of $S$. aureus and $M$. lysodeikticus. In all the other cases, the hypothesis that these latter glycosidic links are also $\beta-1,4$ rests upon the assumption that the endo- $N$ acetylmuramidases which hydrolyze these linkages within the glycan have a strict $\beta-1,4$ specificity, which may not be true. With this one possible exception, there is good evidence for the prevailing hypothesis that the $\beta$-1,4-linked alternating $N$-acetylglucosamine and $N$-acetylmuramic acid structure is ubiquitous in the bacterial world.

\section{Molecular Size of the Glycan Moiety}

The estimation of average chain length of the glycan chains has been made for only a few bacterial walls. As pointed out previously, the $S$. aureus glycan consists of chains averaging 12 to 16 disaccharide units in length $(36,171)$. Walls of Arthrobacter crystallopoietes grown as spheres contain glycan strands composed of an average of 17 disaccharide units. Walls from the same organism grown as rods contain about 65 disaccharides per chain (74). This marked variation in polymer size between the glycans of rod and of spherical cells prompted Kolenbrander and Ensign to investigate the spiral-shaped Spirillum serpens (71). The ratio of total hexosamines to reducing end groups indicated an average length of about 50 disaccharide units. However, analyses of the wall glycan of $L$. casei (D. Hungerer, Federation Proc., p. 294, 1968) and the Porton strain of B. subtilis (A. D. Warth, personal communication) revealed an average of about 10 disaccharides per chain for each. From this small survey, there is no real evidence that a relationship exists between cell shape and the average length of the chains in the wall glycan.

\section{Base-Catalyzed Lactyl Elimination from $N$-Acetylmuramic acid}

Treatment of $N$-acetylmuramic acid with 10 equivalents of $\mathrm{NaOH}$ for $1 \mathrm{hr}$ at $37 \mathrm{C}$, using a $0.05 \mathrm{~N}$ solution, gives rise to a neutral, reducing compound, chromogenic in the Morgan-Elson reaction (without any further alkali treatment), and with an $R_{F}$ of 0.65 in a solution of 1-butanol, pyridine, and water $(6: 4: 3)$. It has been shown $(32,166)$ that under the above conditions, there is a specific elimination of lactate from $N$-acetyl- muramic acid. When the same treatment is applied to a $\beta-1,4 \quad N$-acetylglucosaminyl- $N$-acetylmuramyl-peptide subunit, a lactylpeptide and a neutral, reducing disaccharide are produced. The lactyl group, when liberated from the peptide by acid hydrolysis, was shown to be sensitive to D-lactic acid dehydrogenase and is thus the Disomer (166). The modified lactylless $N$-acetylmuramic acid residue can be liberated from the disaccharide by means of the pig epididymis exo$\beta-N$-acetylglucosaminidase. In its free form, it has all the properties of the chromogenic compound, which arises directly by alkali treatment of free $N$-acetylmuramic acid. The base-catalyzed elimination of the D-lactylpeptide from the $\mathrm{N}$-acetylmuramic acid residue of the disaccharidepeptide subunit was interpreted (Fig. 12) as the result of a $\beta$-elimination involving the acidic proton on $\mathrm{C}-2$, in the position $\alpha$ to the carbonyl, and the $O$-lactyl substituent on C-3. This results in the creation of a double bond between $\mathrm{C}-2$ and C-3, thus forming a $N$-acetylglucosaminyl-2,3dehydro- $N$-acetylglucosamine disaccharide. This 2,3-dehydro- $N$-acetylglucosamine, upon liberation by enzyme, would cyclize into a $\Delta^{3}$ dehydrofurane derivative, a chromogen in the MorganElson reaction. The demonstration of this $\beta$-elimination casts some light on the mechanism of the chromogen formation in the Morgan-Elson reaction. It also provides another way of removing the peptide moiety from the glycan. Further examples of the use of this type of degradation will be given later. Attention should also be called to the fact that $\beta$-elimination can occur at $37 \mathrm{C}$ under moderately alkaline conditions. Extreme care must be taken in the interpretation of the results of enzymatic degradations involving these conditions.

\section{Structure of Several Bacterial Peptidoglycans as Revealed by ENZYMatic DegradaTions: PePtide Molety}

The consistency of structure found in the glycan moiety is not reflected in the peptide substituents. It is necessary, therefore, to discuss individual species separately.

\section{Peptidoglycans of Type I}

The best known example of this type of peptidoglycan (Fig. 4) is found in E. coli, which is, in fact, the first peptidoglycan to have been analyzed enzymatically (177). It was shown to contain two main structural elements, the so-called fragment $\mathrm{C}_{6}$ or the disaccharide peptide subunit L-Ala-DGlu-meso-DAP-D-Ala and fragment $\mathrm{C}_{3}$, a dimer in which two $\mathrm{C}_{6}$ fragments are linked through a 


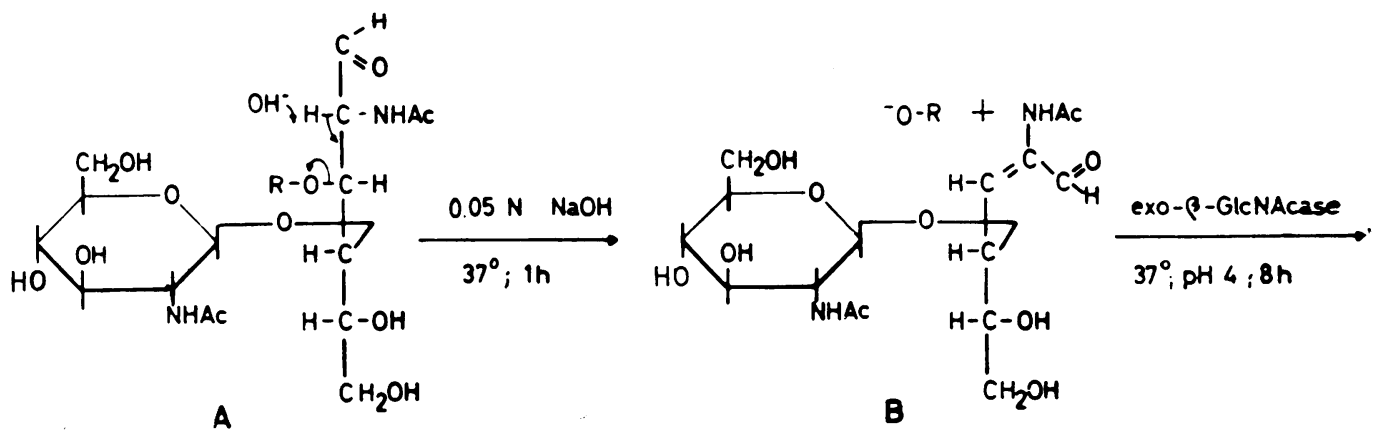

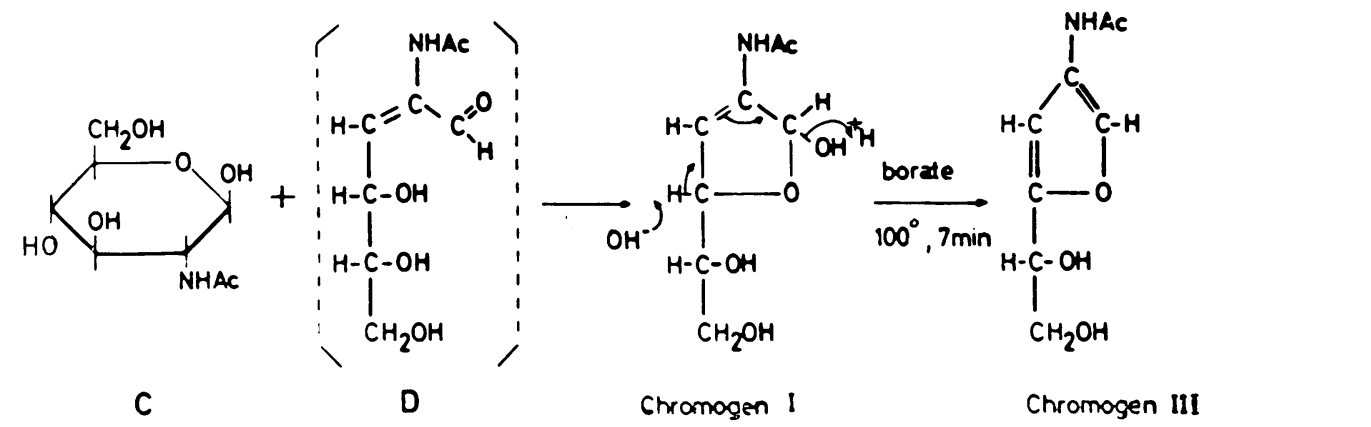

FIG. 12. $\beta$-Elimination of $D$-lactyl-peptide from disaccharide peptide. $R$, $D$-lactyl peptide residue; $A, N$-acetylglucosaminyl- $\beta-1,4-N$-acetylmuramyl-peptide subunit; $B$, Prochromogen glycoside: $N$-acetylglucosaminyl- $\beta-1,4-$ 2,3-dehydro- $N$-acetylglucosamine; Exo- $\beta$-GlcNAcase:exo- $\beta$ - $N$-acetylglucosaminidase; $C$ and $D$, free $N$-acetylglucosamine and free 2,3-dehydro- $N$-acetylglucosamine, respectively. During the course of its enzymatic liberation, 2,3-dehydro-N-acetylglucosamine would cyclize into a $\Delta^{3}$-dehydrofuran derivative or chromogen I. Transformation of chromogen I into a furan derivative such as chromogen III would result from further treatment with borate at $100 C$ (32; figure reprinted by permission).

peptide linkage in which one amino group of meso-DAP is engaged. This pioneering work of Weidel and his colleagues (177) contributed greatly to our present concept of the wall peptidoglycan as an enormous, net-like bag-shaped macromolecule. The E. coli autolytic system (109), which contains at least five enzymes (endopeptidase, $N$-acetylmuramyl-L-Ala amidase, endo- $N$ acetylmuramidase, D-Ala carboxypeptidase, and exo- $\beta-N$-acetylglucosaminidase) specifically degrading the wall peptidoglycan into small fragments, as well as the demonstration of the general structure assigned to the original peptidoglycan, have been described in several reviews $(38,41,85,156,177)$. In this peptidoglycan, virtually all of the disaccharide units in the glycan chains are substituted by peptide subunits. Some of the peptide subunits occur as tripeptides L-Ala-meso-DAP-D-Glu, the last D-Ala residue being lost as a result of the action of the autolytic D-Ala carboxypeptidase. The carboxyl groups of Glu and of meso-DAP, which are not engaged in peptide linkages, have no amide substituents.
About $50 \%$ of the peptide subunits are crosslinked to form peptide dimers, the disaccharide units from two adjacent glycan chains thus being paired (161). It is probable that there is a random distribution of the disaccharide peptide subunit and of its dimer throughout at least a major part of the network (Fig. 13). Only recently (J. van Heijenoort et al., Biochemistry, in press; 9, 22) has a complete structure been assigned to the peptidoglycan of $E$. coli, as well as to other mesoDAP peptidoglycans from gram-positive bacteria, such as that of $B$. megaterium $\mathrm{KM}$. The $B$. megaterium walls also present a low degree of peptide cross-linking. About $85 \%$ of the total DAP residues are meso. Most of these peptides occur as uncross-linked tetrapeptide (L-Ala-DGlu-meso-DAP-D-Ala) and tripeptide (L-Ala-DGlu-meso-DAP) subunits. About $15 \%$ of the total DAP residues in these walls are DD. None of these latter residues exhibits free amino groups (9).

Characterization of the $\mathrm{NH}_{2}$-(L)-meso-DAP in the link to glutamic acid. Making use of the 


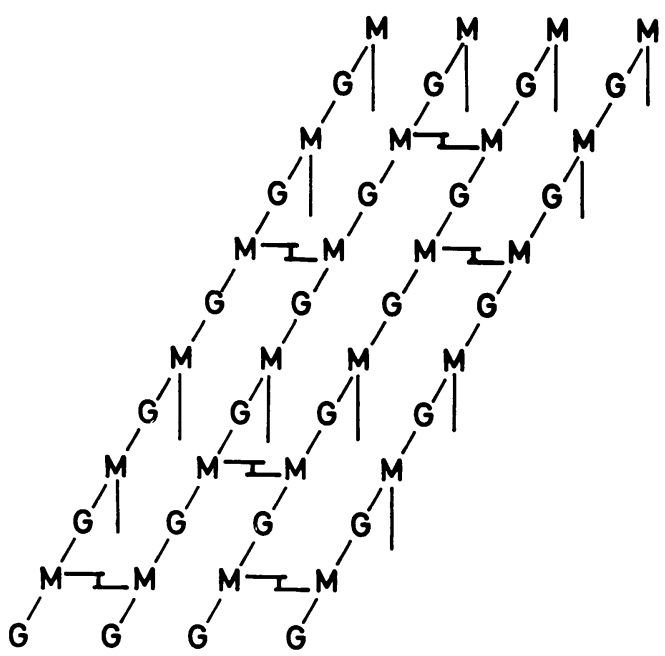

FIG. 13. Schematic representation of a peptidoglycan sheet of E. coli. In this loose network, all of the $N$-acetylmuramic acid residues are substituted either by peptide monomers (peptide subunits A; Fig. 3) or by peptide dimers (Fig. 4).

fact that dinitrophenylation of amino acids often enhances their optical rotation, Diringer and Jusic (22) determined the configuration of that asymmetric carbon of the meso-DAP residue which, in the $E$. coli peptide subunit, has a free amino group. The mono-dinitrophenyl (DNP)meso-DAP obtained after dinitrophenylation and acid hydrolysis of the peptide subunit presented a molar optical rotation, $[\mathbf{M}]_{\mathbf{D}}$, in glacial acetic acid equal to $+250 \mathrm{deg} \pm 10 \%$. Since synthetic di-DNP-LL-DAP and synthetic mono-DNP-LLDAP have $[M]_{D}$ equal to -444 and $-231 \mathrm{deg}$, respectively (61), the above value of $+250 \mathrm{deg}$ provided evidence that, in the $E$. coli peptide subunit, the free amino group of the meso-DAP residues was on the asymmetric carbon having the D configuration. The same conclusion was reached for the meso-DAP subunits in B. megaterium $\mathrm{KM}$ (9). A disaccharide peptide subunit fraction (with no amide substituent, as in the case of $E$. coli), representing a major part of the total meso-DAP peptide subunits, was isolated. After dinitrophenylation and acid hydrolysis, the isolated monodinitrophenyl derivative of the meso-DAP residues exhibited an $[\mathrm{M}]_{\mathrm{D}}$ equal to $+248 \mathrm{deg}$, i.e., a value identical, within the limits of experimental error, to that observed with the monoDNP-DAP isolated from $E$. coli and to that of the synthetic mono-DNP-(D)-meso-DAP (9). Moreover, both the synthetic mono-DNP-(D)meso-DAP and the natural mono-DNP-mesoDAP exhibited the same anomalous rotatory dispersions with a Cotton effect centered on 418 $\mathrm{nm}$ and, in the region 450 to $600 \mathrm{~nm}$, both followed the simplified Drude equation with identical $K$ coefficients. These determinations proved that in $E$. coli and in B. megaterium, the amino group engaged in peptide linkage to glutamic acid is located on the L-carbon of meso-DAP and, consequently, that the amino group used for cross-linking between peptide subunits must be located on the D-carbon of meso-DAP.

Characterization of the $\gamma$-carboxyl group of glutamic acid in the link to $\mathrm{NH}_{2}-(L)$-meso-DAP. The tripeptide monomers L-Ala-D-Glu-(L)-mesoDAP were isolated from walls of both $E$. coli and $B$. megaterium KM. They were chromatographically and electrophoretically indistinguishable and inseparable from synthetic tripeptide L-Ala- $\gamma$-D-Glu-(L)-meso-DAP under conditions which readily distinguish between the two synthetic peptide isomers containing either $\alpha$ - or $\gamma$-linked glutamic acid (J. van Heijenoort et al., Biochemistry, in press). Characterization of the $\gamma$-monohydrazide of glutamic acid and the absence of the $\alpha$ derivative among the compounds arising by hydrazinolysis of the peptide subunits of $E$. coli and $B$. megaterium $\mathrm{KM}$ also led to the conclusion that glutamic acid is linked to meso-DAP via the $\gamma$-carboxyl group. An identical conclusion was independently reached by Diringer (21a) by hydrazinolysis of the $E$. coli monomer.

Characterization of the link meso-DAP-(L)(D)-Ala. The tetrapeptide monomers with the sequence L-Ala- $\gamma$-D-Glu-(L)-meso-DAP-D-Ala were also isolated from $E$. coli and from $B$. megaterium KM (J. Van Heijenoort et al., Biochemistry, in press). The location of the terminal D-Ala on the L-carbon of meso-DAP was proved by an Edman degradation. After one cycle of the degradation, $N$-terminal alanine was replaced by $N$-terminal glutamic acid, thus demonstrating the sequence Ala-Glu. Concomitantly, most of the mono- $N$-terminal DAP groups disappeared, and no free alanine was liberated. Thus, the terminal D-Ala cannot be in $\alpha$ position relative to the free amino group, which, as shown above, is on the D-carbon of meso-DAP; consequently, the terminal D-Ala must be located on the L-carbon of meso-DAP. After the second cycle of the degradation, $N$-terminal glutamic acid disappeared and was not replaced by any other terminal amino group. The complete sequence of the peptide subunit in $E$. coli and $B$. megaterium is thus L-Ala- $\gamma$-D-Glu-(L)-mesoDAP-(L)-D-Ala as it is shown in Fig. 3A.

Characterization of the D-Ala-(D)-meso-DAP cross-linkages between peptide subunits. The bisdisaccharide peptide dimer from $E$. coli, i.e., 
fragment $\mathbf{C}_{\mathbf{3}}$ (177), was degraded into disaccharide peptide monomers with the help of the purified Streptomyces KM endopeptidase (J. van Heijenoort et al., Biochemistry, in press). C- and N-terminal group analyses, before and after degradation, together with the aforementioned demonstration that the amino group engaged in the link to glutamic acid is on the $L$ carbon of meso-DAP, established that D-Ala(D)-meso-DAP linkages are involved in peptide bridging (Fig. 4).

The demonstration of the existence of the same type of peptide bridging in walls of $B$. megaterium was attempted (J. van Heijenoort et al., Biochemistry, in press). Complications arose, however, due to the fact that about $15 \%$ of the total DAP residues are DD. DD-DAP residues were identified as follows. A disaccharidepeptide monomer fraction containing solely meso-DAP residues and a disaccharide-peptide oligomer fraction were isolated (9). After dinitrophenylation and acid hydrolysis of the latter fraction, the meso-DAP residues were removed as mono-DNP-derivatives. The remaining DAP residues were then bisdinitrophenylated and characterized as di-DNP-DD-DAP on the basis of the $[M]_{D}$ value equal to +426 deg. In J. van Heijenoort's more recent study, the walls of $B$. megaterium were solubilized with the help of a purified $\mathbf{K M}$ endopeptidase. $\mathrm{N}$ - and $\mathrm{C}$-terminal groups analyses strongly suggested that the few meso-DAP-containing peptide subunits which are cross-linked are actually engaged in D-Ala(D)-meso-DAP linkages, as in the case of $E$. coli. However, the DD-DAP residues appeared to be involved in another type of peptide cross-linkage, the significance of which is not clear at the moment. In summary, it has been now well established that the structure presented in Fig. 3 and 4 are valid for the $E$. coli and for the major part of the $B$. megaterium peptidoglycans. In the latter case, however, it is probable that D-Ala(D)-meso-DAP peptide cross-linkages are not the only important ones. The two tripeptides, L-Ala$\gamma$-D-Glu-(?)-meso-DAP and L-Ala-D-iso-glutaminyl-(?)-meso-DAP, have been characterized (93) in walls of B. licheniformis ATCC 9945 (previously designated B. subtilis ATCC 9945). Finally, it has been reported recently (A. D. Warth and D. L. Strominger, Bacteriol. Proc., p. 64,1968$)$ that the peptide subunits and the peptide cross-linkages in the vegetative cell wall and the spore cortex of $\boldsymbol{B}$. subtilis have structures identical to those found in $E$. coli with the exception, however, that in vegetative cells of $B$. subtilis, most of the peptide subunits have an amide substituent on the carboxyl group located on the D-carbon of meso-DAP. Finally, in the C. diphtheriae peptidoglycan, both the D-Glu and the meso-DAP residues are amide substituted (67).

\section{Peptidoglycans of Type II with Peptide Bridges of Glycine or L-Amino Acid Residues, or Both}

The following sequential degradation has permitted the characterization of the peptide bridges and the peptide subunits of this group of bacterial peptidoglycans $(99,117)$. (Degradation of the walls of $M$. roseus is given as an example in Fig. 14.) The first step involves solubilization of the walls by the SA endopeptidase. Equivalent amounts of C-terminal D-Ala, in all cases, and of N-terminal amino groups of either Gly or L-Ala, depending on the bacterium (Fig. 5), are released as a result of the opening of the peptide bridges at their $\mathbf{N}$ termini (hydrolysis of links 1, Fig. 5, 14). The second step involves aminopeptidase degradation of the opened peptide bridges until the $\epsilon$-amino group of lysine of the peptide subunits, to which the bridges are attached, are all exposed (hydrolysis of links 2, Fig. 5, 14). Quantitation of the number of free amino acids liberated, per lysine residue, at the end of the process, and kinetics of the degradation permitted the determination of the bridge sequences. In the case of $M$. roseus $\mathrm{R} 27$ cell walls, for example (Fig. 5, 14), first three L-Ala residues and next, one $\mathrm{L}-\mathrm{Thr}$ residue per lysine residue were sequentially liberated. It was also observed that the exposure of the $\epsilon$-amino group of lysine paralleled both the disappearance of $\mathbf{N}$-terminal threonine groups and the liberation of free L-Thr residues. At the end of this second step of the degradation, the peptide subunits are stripped of the peptide bridges but are still attached to intact glycan strands. The third step involves the degradation of the glycan into $N$-acetylglucosaminyl- $N$-acetylmuramic acid disaccharides through the action of an appropriate endo- $N$ acetylmuramidase (hydrolysis of links 3, Fig. 14). The disaccharide peptide subunits can then be readily isolated from the other degradation products by gel filtration on Sephadex. The fourth step involves cleavage of the isolated disaccharide-peptide subunit into free disaccharide and free peptide with the help of the $N$-acetylmuramyl-L-Ala amidase (hydrolysis of links 4, Fig. 14). Thus, through controlled degradations involving four successive enzymatic hydrolyses of specific linkages in the peptidoglycans, the peptide subunits can be readily obtained via the intermediate isolation of disaccharide-peptide subunits. Again, it should be emphasized that structural studies of a peptidoglycan, on the 


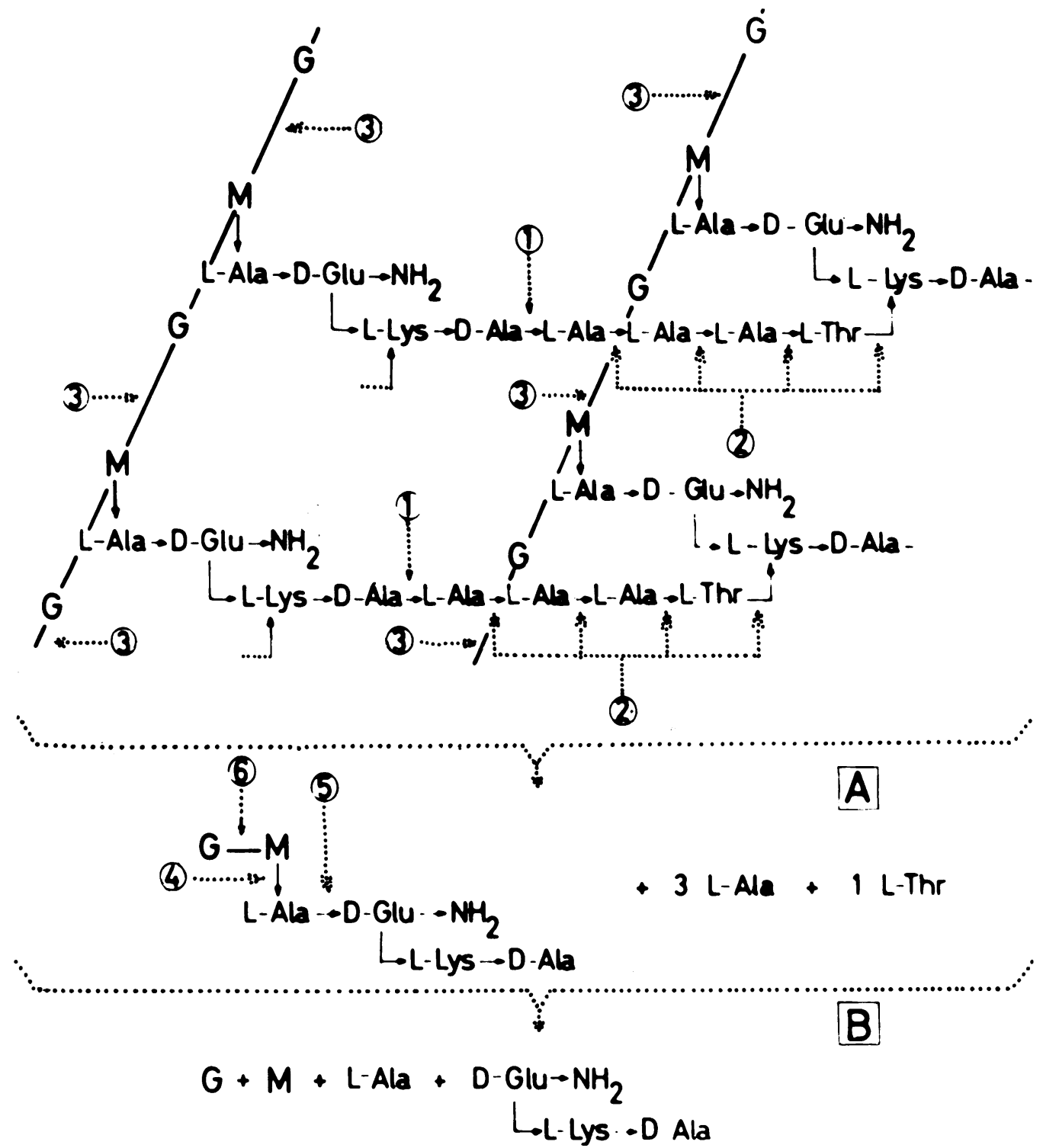

Fig. 14. Degradation sequence for the peptidoglycan of $M$. roseus $R$ 27. A. Disruption of the L-Ala-L-Ala-LAla-L-Thr bridges and liberation of the disaccharide-peptide subunits. (1), site of action of SA endopeptidase; (2), degradation of the opened bridges with aminopeptidase; (3), site of action of endo-N-acetylmuramidase. B. Further degradation of the disaccharide-peptide subunit. (4), Site of action of $N$-acetylmuramyl-L-alanine amidase; (5), site of action of aminopeptidase; (6), site of action of exo- $\beta-N$-acetylglucosaminidase.

basis of the fragments liberated by enzymatic degradations, can only be attempted after thorough study of the kinetics to ensure that each step is carried to completion (156). If the enzymatic hydrolysis at any step is stopped before all susceptible linkages are broken, an exceedingly complex mixture of fragments can be anticipated at the end of the sequential degradation. In particular, complete wall solubilization does not necessarily indicate that all sensitive linkages have been hydrolyzed. The peptide subunits obtained after the sequential degradation described above have been fully characterized (Fig. 3B, 14) as tetrapeptide amide $N^{\alpha}$-(L-alanyl-D-isoglutaminyl)-L-lysyl-D-Ala (99). The characterization of this structure was effected by the following 
chemical and enzymatic procedures. (i) A determination was made of total amino acid composition, ammonia amide, and $\mathrm{C}$ - and $\mathrm{N}$-terminal amino acids. (ii) The L-alanyl-D-isoglutaminyl sequence was demonstrated by degrading the tetrapeptide with aminopeptidase, which resulted in the liberation of one free L-Ala residue and the concomitant appearance of one $\mathrm{N}$-terminal D-isoglutaminyl residue per molecule of tetrapeptide (hydrolysis of links 5, Fig. 14). (For substrate requirements of the Streptomyces aminopeptidase, see 99). (iii) The residual tripeptide (Fig. 14) was isolated in the form of a di-DNP derivative which was chromatographically indistinguishable and inseparable from synthetic di - DNP - isoglutaminyl - lysyl - alanine. The chromatographic system employed for the comparison readily distinguishes between isomers containing $\alpha$ - or $\gamma$-linked glutamic acid, or glutaminyl residues $(10,80)$. (iv) The presence of an amide substituent was confirmed electrophoretically and the occurrence of the isoglutaminyl residue was demonstrated by chemical dehydration and reduction, followed by acid hydrolysis, according to the procedure of Ressler and Kashelikar (126). This produced $\gamma$-aminobutyric acid, as one would predict if, indeed, the glutamic acid is in the iso form in the endo position. No ornithine, which would be indicative of the presence of glutaminyl residues, was detected. (v) The involvement of the $\gamma$-carboxyl group of the glutamic acid in the peptide bond was shown by Edman degradation (168, 169). The first cycle removed the $\mathrm{N}$-terminal alanine, and the $\mathrm{N}$-terminal glutamic acid appeared. After the second cycle of the degradation, ammonia was liberated and $\mathrm{N}$-terminal amino acids were no longer detectable, again demonstrating that $\mathrm{NH}_{3}$ was a substituent of the $\alpha$-carboxyl group of glutamic acid. The Edman degradation was initially carried out on a carbohydrate free polypeptide fraction (169). It provided the first proof for the occurrence of an isoglutaminyl residue in the wall peptide moiety, which observation was in agreement with the previous demonstration (57) of the involvement of the $\gamma$-linkage of D-Glu to the next amino acid in the nucleotide precursor of the wall. Degradation by Myxobacter AL 1 enzyme of the walls of $S$. aureus (59) and of $A$. crystallopoietes (171) also led to the identification of the same peptide subunit and established the existence of a monoL-Ala cross-linking bridge in the rod-shaped $A$. crystallopoietes (75). Similarly, the same peptide subunits in Staphylococcus epidermidis strain Texas 26 were shown to be cross-linked by peptide bridges of Gly and L-Ser, with an average composition of $\mathrm{Gly}_{4}$ L-Ser 1 (J. D. Tipper, Federation Proc., p. 294, 1968). The location of the L-Ser residue was determined by Edman degradation (legend, Fig. 5).

\section{Peptidoglycans of Type II with D-Isoasparaginyl Bridge}

It has been known for some time that $\mathrm{D}$-aspartic acid is a constituent of cell walls of some species of Streptococcus and of numerous species of Lactobacillus, where it occurs in amounts nearly equivalent to that of L-Lys or D-Glu $(20,55,56$, $151,173)$. The hypothesis that the $D$-aspartic acid residues are located in the wall peptidoglycans as substituents of the $\epsilon$-amino groups of the L-Lys residues was first proposed by Swallow and Abraham (159). It was based on the isolation of a derivative of aminosuccinimide, $N^{\epsilon}$-(aminosuccinyl)-lysine, from walls of $L$. brevis which had been submitted to treatment with $11 \mathrm{~N} \mathrm{HCl}$ at $80 \mathrm{C}$ for $43 \mathrm{hr}$. On further treatment with dilute sodium hydroxide, the $N^{\epsilon}$-(aminosuccinyl)-lysine was converted into a mixture of predominantly $N^{\epsilon}$-( $\beta$-aspartyl)-lysine and a minor amount of $N^{\epsilon}$-( $\alpha$-aspartyl)-lysine. In later studies, the same cyclic peptide $N^{\epsilon}$-(aminosuccinyl)-lysine was found in hydrolysates of many other D-aspartic acid-containing bacterial walls $(55,56)$. However, the above ring formation, as a result of acid treatment and the subsequent interconversion of the aspartyllysine, made it impossible to determine whether the original sequence in the wall peptidoglycan consisted of an $\alpha$-or $\beta$-aspartyl peptide. Recent investigations (32) conclusively established that, in $S$. faecalis ATCC 9790 (reidentified as $S$. faecium var. durans by $O$. Kandler, personal communication), D-isoasparaginyl residues serve as bridges between peptide monomers type B (Fig. 3, 6). This conclusion arose from the results of a sequential degradation of the walls of $S$. faecalis essentially as described for $S$. aureus, $M$. roseus, and $S$. pyogenes with, however, the two following modifications. (i) Walls of $S$. faecalis, when prepared from cells harvested in logarithmic phase of growth (log walls), contain a powerful autolysin which has the specificity of an endo- $N$ acetyl-muramidase (151). It was observed that this enzyme can work in conjunction with the SA endopeptidase. Incubation of log walls with the SA endopeptidase thus resulted in the appearance of terminal amino groups of isoasparagine as well as cleavage of glycosidic linkages (Fig. 6). (ii) Because of its D-configuration, the D-isoasparaginyl residues at the termini of the bridges now opened could not be liberated as free amino acids by further treatment with the 
Streptomyces aminopeptidase, which is specific for the L-configuration. Consequently, the single incubation of $S$. faecalis $\log$ walls with the SA endopeptidase, followed by Sephadex filtration, resulted in the liberation and in the isolation of disaccharide-peptide monomer $N^{\alpha}-(\beta-1,4-N$ acetylglucosaminyl- $N$-acetylmuramyl-L-alanyl-Disoglutaminyl), $N^{\epsilon}$ - (D - isoasparaginyl) - L -lysylD-Ala (Fig. 6).

Amino acid and amide ammonia composition, results of $\mathbf{C}$ - and $\mathbf{N}$-terminal groups determination, of degradation with $N$-acetylmuramyl-L-Ala amidase which liberated the disaccharide and exposed an $\mathrm{N}$-terminal alanine of the peptide subunit, and of subsequent degradation of the liberated peptide with aminopeptidase (which removed the $\mathrm{N}$-terminal L-Ala residue and exposed an equivalent amount of $\mathrm{N}$-terminal glutamic acid) were all consistent with the proposed structure. The location of an isoasparaginyl residue as substituent of the $N^{\epsilon}$-Lys residue emerged from a series of comprehensive determinations: (i) presence of two amide ammonias per monomer unit; (ii) disappearance, through Edman degradation, of the terminal amino group of aspartic acid without consequent exposure of any other terminal amino group (which is compatible with a peptide bond involving the $\beta$-carbonyl group of aspartic acid), (iii) formation, by dehydration-reduction, according to Ressler and Kashelikar (126), of $\beta$-alanine (from the isoasparagine residue) and of $\gamma$-aminobutyric acid (from the isoglutamine residue); (ornithine or $\alpha, \gamma$-diaminobutyric acid, which would be indicative of a glutaminyl residue or of an asparaginyl residue, were not detected); (iv) absence of an aminosuccinimide ring, as shown by infrared spectroscopy (characteristic bonds at 1,705 and $1,785 \mathrm{~cm}^{-1}$ ); and (v) deamidation of the isoasparagine residue and interconversion of the peptide into a mixture of $N^{\epsilon}$ - $\alpha$ - and $\beta$-aspartyl)-lysyl peptides (Fig. 15). This transformation was easily performed by submitting the disaccharide pentapeptide subunit to the alkaline conditions used for the basecatalyzed lactyl elimination from $N$-acetylmuramic acid. The two peptides, $\mathbf{N}^{\alpha}$-(D-lactylL-alanyl-D-isoglutaminyl) and $N^{\epsilon}-(\alpha-$ and $\beta$-Daspartyl)-L-lysyl-D-Ala, were isolated by electrophoresis at $p \mathrm{H} \mathrm{2}$, and the location of the $\alpha$

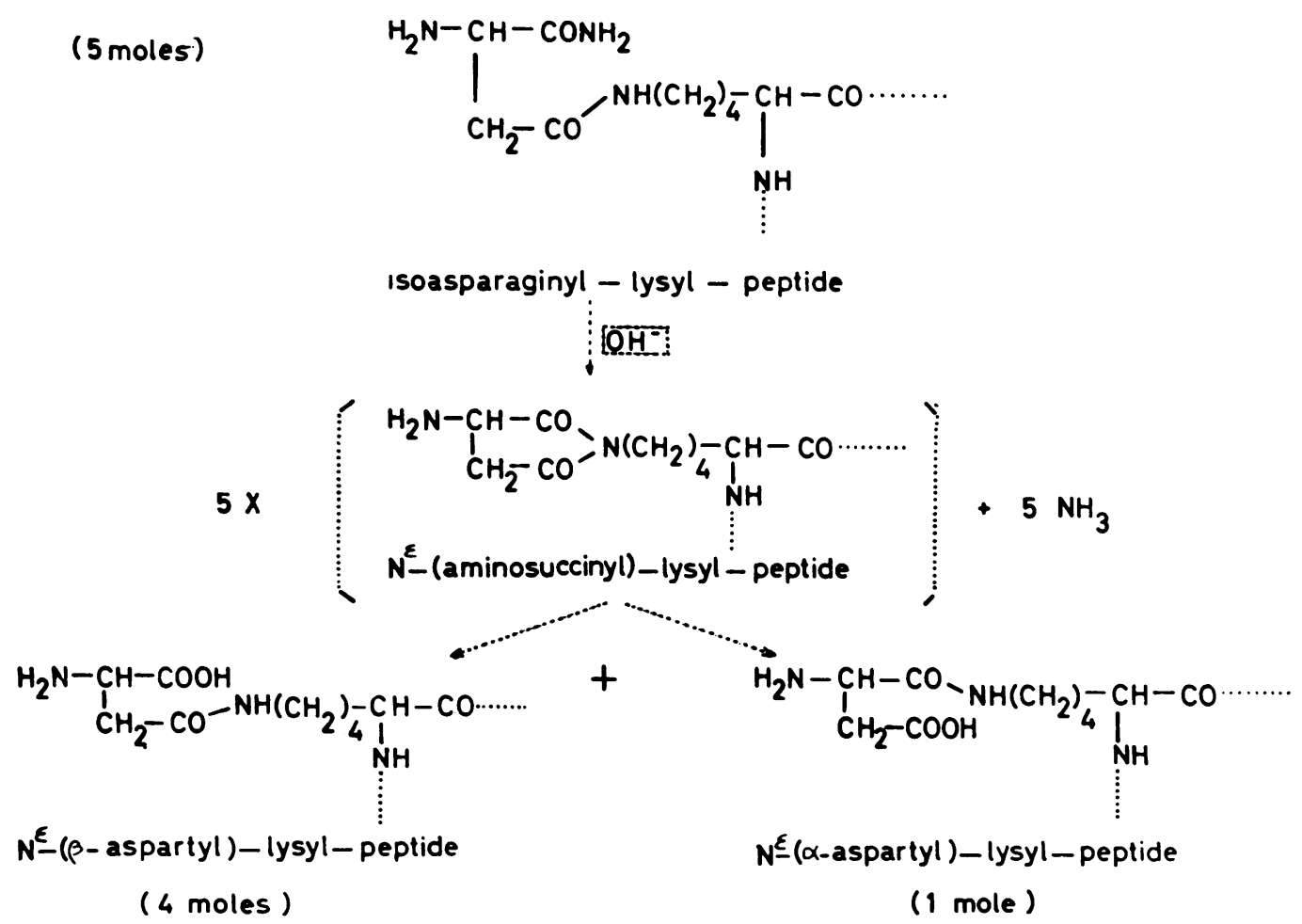

II Fig. 15. Deamidation and interconversion of $N_{-}^{\epsilon_{-}}$(isoasparaginyl)-lysyl peptide into $N^{\epsilon_{-}}(\beta$-aspartyl)-lysyl peptide and $N^{e}$-( $\alpha$-aspartyl)-lysyl-peptide via the aminosuccinimide derivative $N^{e}$-(aminosuccinyl)-lysyl-peptide. 
and $\beta$ links was conclusively confirmed by means of further Edman degradations. The succinimide derivative, $N^{\epsilon}$-(amino-succinyl)-lysine, was known to be rapidly converted by dilute alkali into a mixture of $\beta$ - and $\alpha$-aspartyllysines in which the $\beta$-isomer greatly predominates $(55,159)$. Consequently, it was proposed that the base-catalyzed transformation of the $N^{\epsilon}$-(isoasparaginyl)-lysyl portion of the disaccharide pentapeptide subunit into the $\beta$ - and $\alpha$-aspartyllysine derivatives, with the concomitant loss of 1 mole of ammonia, involved the transitory formation of a cyclic aminosuccinimide derivative (Fig. 15). This basecatalyzed imide formation from an $\alpha$-carboxamide $\beta$-peptide was unexpected. It is probably related to the well known imide formation from an amide ester (154) (cyclization of $N$-acylasparagine or $N$-acylisoasparagine esters) or from a peptide ester (4) [cyclization of esters of $N$-benzoyl- $(\alpha$ or $\beta)$-aspartyl peptides]. Imide formation does not occur, at least under the present experimental conditions, with the isoglutaminyl residue in the disaccharide pentapeptide subunit and might be restricted to $N^{\epsilon}$ (isoasparaginyl)-lysyl structures.

Other D-aspartic acid-containing peptidoglycans [i.e., those of $L$. acidophilus (J. M Ghuysen et al., Biochemistry, in press) and of L. casei (D. Hungerer, Federation Proc., p. 294, 1968)] were also studied. They were found to be built up from the same peptide subunits of type $B$ and from the same isoasparaginyl bridges. As discussed later, this type of cross-linking bridge appears to be valid as a taxonomic criterion for certain groups of bacteria. It should be emphasized that these peptidoglycans are the first natural peptides in which the occurrence of an isoasparagine residue has been demonstrated. $\beta$-Aspartyl peptides have been identified in human urine, mainly as the dipeptide $\beta$-aspartylglycine (23), and in enzymatic hydrolysates of proteins of various origins (44).

\section{Peptidoglycans of Type III}

The macromolecular structure of the wall peptidoglycan of $M$. lysodeikticus has been puzzling for a long time. The difficulties stemmed from the following, apparently conflicting, observations. (i) Chemical analyses of the wall revealed the presence of $N$-acetylglucosamine, $N$-acetylmuramic acid, D-Ala, L-Ala, D-Glu, L-Lys, and Gly, in equimolar amounts. That is, there was, theoretically, one peptide monomer for each $N$-acetylmuramic acid. (ii) It had been established by enzymatic investigations that at least $50 \%$ of the $N$-acetylmuramic acid residues in native walls were unsubstituted $(81,100)$.
Moreover, a direct distinction between the $\mathrm{N}$-acetylmuramic acid residues with unsubstituted carboxyl groups and those with peptide substituents had been achieved by esterification of the free carboxyl groups in intact walls, followed by reduction of the esters with $\mathrm{LiBH}_{4}$ (136). In this procedure, the carboxyl groups of the unsubstituted $N$-acetylmuramic acid residues are converted to carbinol groups. Consequently, some of the peptide subunits must be involved in a peptide-peptide link rather than an $\mathrm{N}$-acetylmuramic acid-peptide link in order to accommodate the presence of unsubstituted $N$-acetylmuramic acid residues. (iii) The further observation that virtually all of the glycine residues in native walls were $C$ terminal $(168,169)$ dismissed the possibility that Gly was the cross-linking bridge. A comprehensive structure for the $\boldsymbol{M}$. lysodeikticus peptidoglycan finally emerged and its establishment rested upon the following important contributions. (i) The peptide subunit has the sequence $N^{\alpha}$-[L-alanyl- $\gamma$ - $(\alpha$-Dglutamyl-Gly)]-L-lysyl-D-Ala, in which glycine substitutes the $\alpha$-carboxyl group of glutamic acid (Fig. 3C). Indeed, such subunits, linked at their $N$-L-Ala termini to $\beta-1,4-N$-acetylglucosaminyl- $N$-acetylmuramic acid disaccharides, were isolated (30), although in very low yield (about $2 \%$ of the weight of the peptidoglycan), from endo- $N$-acetylmuramidase digests of the walls, and their structure was fully established $(91,92)$. Moreover, a peptide fraction, representative of a substantial part of the peptide moiety, was isolated from walls degraded with the Myxobacter AL 1 enzyme. [During these investigations, this enzyme was erroneously thought to act on the walls only through its amidase activity (69); its endopeptidase activity, essential for the wall solubilization, was not recognized until later.] Sequential degradation of this peptide fraction with phenylisothiocyanate $(168,169)$ revealed L-Ala and D-Glu to be the first and the second amino acid, respectively, in the sequence, and it also showed a substituent, Gly on the $\alpha$-carboxyl group of the glutamic acid. (ii) Direct $N^{\epsilon}$-(D-alanyl)-L-Lys linkages were shown to be involved in peptide cross-linking. A bisdisaccharide-pentapeptide dimer was isolated (30), also in very low yield, from endo- $N$-acetylmuramidase digests of the walls. This dimer was shown to be composed of two pentapeptide subunits cross-linked through $N^{\epsilon}$-(D-alanyl)-L-Lys linkages $(91,92)$ (see Dimer, Fig. 16). Moreover, hydrolysis of those $N^{\epsilon}$-(D-alanyl)-L-Lys linkages by the Streptomyces ML endopeptidase was shown to cause solubilization of the walls (117). Finally, $N^{\epsilon_{-}}$(D-alanyl)-L-Lys dipeptide and $N^{\epsilon_{-}}$(D-alanyl)-L-lysyl-D-Ala tripeptide were isolated 
from partial acid hydrolysates of the walls and were characterized (142). (iii) According to end group determinations, 60 to $80 \%$ of the lysine residues in the walls had free $\epsilon$-amino groups; thus, only 40 to $20 \%$ of the total lysine residues were involved in the above $N^{\epsilon}$-(D-alanyl)-L-Lys cross-linkages. In order to accommodate the paucity of the $\mathrm{N}$ - and $\mathrm{C}$-terminal alanine groups in the walls, the existence of a second type of peptide bridges was postulated. It was proposed that peptide subunits were also cross-linked through D-alanyl-L-alanyl linkages, involving the $\mathbf{C}$ terminus of one subunit and the $\mathbf{N}$ terminus of another $(35,119)$. This thesis was strengthened by the isolation and the characterization of D-alanyl-L-Ala dipeptide from partial acid hydrolysates of the walls (142). (iv) The existence of the two types of cross-linkages was finally proved by a series of enzymatic degradations of the walls (31), in the course of which use was made of the different specificities of the two endopeptidases: the Streptomyces ML endopeptidase whose activity is restricted to $N^{\epsilon}$-(D-alanyl)L-Lys linkages (Fig. 7, 16), and the Myxobacter AL 1 endopeptidase, whose activity is restricted to D-alanyl-L-Ala linkages (Fig. 7, 16). Solubilization of the walls with ML endopeptidase, which hydrolyzes all the $\boldsymbol{N}^{\epsilon}$-(D-alanyl)-L-Lys linkages, followed by disruption of the glycan and removal of the glycan debris by $N$-acetylmuramyl-L-Ala amidase or by $\beta$-elimination, resulted in the isolation of a peptide monomer (Fig. 16) and of the peptide dimer (Ala $\rightarrow$ Ala; Fig. 17) or of their D-lactyl derivatives (after $\beta$-elimination). Solubilization of the walls with Myxobacter AL 1 enzyme, which hydrolyzes all of the D-alanyl-L-Ala linkages as well as the $N$-acetylmuramyl-L-Ala linkages, followed by fractionation, permitted the isolation again of the monomer (Fig. 16) and of the isomer peptide dimer (Ala $\rightarrow$ Lys; Fig. 17). As would be expected, the peptide dimer (Ala $\rightarrow$ Ala) was susceptible to Myxobacter AL 1 enzyme and the peptide dimer (Ala $\rightarrow$ Lys) was susceptible to ML endopeptidase, both being quantitatively converted to monomer in each case.

The observed yields of the peptide fragments obtained by the various degradation procedures conclusively established that the wall peptide moiety was a polydisperse system (Fig. 16) in which $15 \%$ of the pentapeptide subunits occur as monomers, $4 \%$ as dimers (Ala $\rightarrow$ Lys), $15 \%$ as trimers (in which a peptide monomer extends between two other peptide monomers through a D-alanyl-L-Ala linkage on one side and a $N^{\epsilon}$-(Dalanyl)-L-Lys linkage on the other side), and $60 \%$ as hexamers. This hexamer unit represents, of course, a statistical average of peptide oligomers having bridges of various sizes. Such a molar distribution explains the previous puzzling observations. Large glycan fragments unsubstituted by peptides can occur and still accommodate the $1: 1$ ratio between the peptide and the disaccharide subunits; $80 \%$ of the lysine residues have their $\epsilon$-amino groups free (actual data, 60 to $80 \%$ ). There are virtually no terminal amino groups of L-Ala, and there is one Cterminal D-Ala per 4 peptide subunits (actual data, the equivalent of $100 \mathrm{~nm}$ for 480 peptidoglycan units). About $15 \%$ of the peptide subunits are not accounted for by the above structural model, and the possibility exists that still other types of peptide cross-linking may also occur. A few Gly residues at the $\mathbf{C}$ terminus of some of the peptide subunits might be involved in peptide cross-linkages with $\epsilon$-amino group of lysine $(31,174)$.

The wall peptidoglycans of Sarcina lutea,

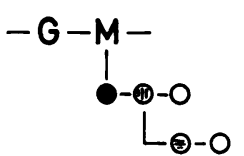

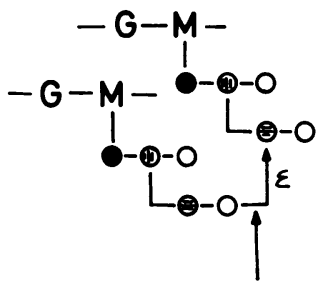

ML endop.

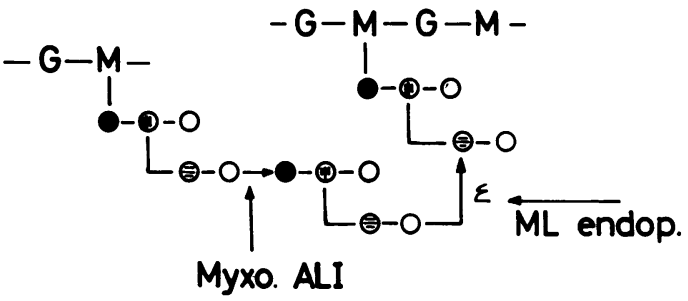

5 Trimers

5 Monomers + 2 Dimers

5 Trimers

\section{+ 10 Hexamers as Represented in Fig. 7.}

FIG. 16. Molar distribution of peptide monomers, dimers, trimers, and hexamers in the peptidoglycan of $M$. lysodeikticus. Arrows : peptide linkages specifically hydrolyzed either by ML endopeptidase or Myxobacter AL 1 protease. In the course of wall degradation, the $N$-acetylmuramyl-L-Ala linkages are also hydrolyzed (Fig. 7). 


$$
\begin{aligned}
& \text { Peptide Dimer (Ala } \rightarrow \text { Ala }) \\
& \qquad-A l a \rightarrow D-G l u \rightarrow \text { Gly } \\
& \gamma L \text { L-Lys } \rightarrow \text { D-Ala } \rightarrow \text { L-Ala } \rightarrow \text { D-Glu } \rightarrow \text { Gly } \\
& \gamma L \text { L-Lys } \rightarrow \text { D-Ala }
\end{aligned}
$$

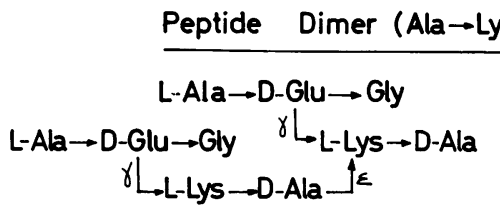

Fig. 17. Isomeric peptide dimers isolated from the peptidoglycan of $M$. lysodeikticus. Cross-linking involves a D-alanyl-L-Ala bond and a $N_{-}^{\epsilon}$-(D-alanyl)-LLys bond, respectively (31; figure reprinted by permission).

M. flavus, and $M$. citreus were also thoroughly studied with the same enzymatic means and shown to have a similar type of peptide subunits assembly (J. Campbell, Biochemistry, in press). A peculiarity of the peptidoglycans of these three micrococcal walls is that the number of peptide subunits is significantly higher than the number of disaccharide units. A mechanism for the loss of some glycan segments has been hypothesized by J. Campbell. According to recent developments (vide infra), the type III peptidoglycan also appears to be a criterion of taxonomic importance.

\section{Peptidoglycans of Type IV}

The structure of the peptidoglycan in $C$. poinsettiae (Fig. 8) has been established by the elegant work of Perkins $(113,115)$. His demonstration involved the isolation of the nucleotide precursor of the peptide subunit accumulated by the cells in the presence of vancomycin or penicillin. The precursor contained glutamic acid, glycine, homoserine, and alanine in the ratio $1: 1: 1: 2$, but no ornithine. The demonstration also involved the solubilization of the walls by lysozyme degradation. Both the nucleotide and the degraded walls were submitted to a $\beta$-elimination procedure. After partial acid hydrolysis of the D-lactyl peptides, the degraded peptides were isolated and their structure was established using, among other procedures, the photolability of the dinitrophenyl derivatives according to a technique proposed by Russell (134). Similarly, the nucleotide precursor accumulated by Butyribacterium rettgeri in the presence of D-cycloserine, was shown to have the sequence L-Ser-D-Glu-L-Orn (90). Partial acid hydrolysis of the walls yielded significant concentrations of peptides, the established structures of which were consistent with the existence in the native peptidoglycan of the sequence L-Orn-D-Ala, and with the substitution of the $\alpha$-carboxyl group of glutamic acid by the $\epsilon$-amino group of lysine (89). A more refined structure was subsequently worked out (M. Guinand, Biochemistry, in press) by enzymatic degradation of the walls, involving the sequential hydrolysis of (i) $N^{\alpha}(\mathrm{D}-\mathrm{Ala})-\mathrm{D}-\mathrm{Lys}$ and $\mathrm{N}^{\alpha}$-(D-Ala)-D-Orn linkages at the $\mathrm{C}$ termini of the peptide subunits using the KM endopeptidase, (ii) glycosidic links between $N$. acetylmuramic acid and $N$-acetylglucosamine in the glycan moiety, and (iii) $\mathrm{N}$-acetylmuramyl-LSer linkages at the junction between peptide and glycan. As result of these investigations, the structure shown in Fig. 9 could be assigned to the $B$. rettgeri peptidoglycan; D-Lys and DOrn bridges occur in the ratio of $2: 1$.

\section{Molecular Size of the Peptide Moieties}

The tightness of the peptidoglycan network depends upon the frequency with which the polysaccharide chains are substituted by peptide subunits, and also upon the frequency with which these peptide subunits are, in turn, interlinked. The extent of the peptide cross-linking can be estimated by measuring the terminal amino and carboxyl groups occurring in the native peptidoglycan. For example, measurement of these groups in $S$. aureus, one of the tightest peptidoglycans, shows that the average size of the peptide polymer does not exceed 10 peptide subunits. It is likely that the peptide moieties in all peptidoglycans are polydisperse systems. Examples of such systems have been given in the cases of $M$. lysodeikticus and of $E$. coli. The distribution of the peptide oligomers of various sizes, as they occur in a bacterial peptidoglycan, may sometimes be studied by gel filtration of walls which have been degraded by appropriate enzymatic treatments. Walls of $L$. acidophilus (J. M. Ghuysen et al., Biochemistry, in press), after thorough degradation by an endogenous endo- $N$-acetylmuramidase autolysin, have been shown to possess a system in which $9 \%$ of the peptide subunits occur as monomers, $38 \%$ as dimers, and $30 \%$ as trimers. Walls of $L$. casei (D. Hungerer, Federation Proc., p. 294, 1968) and of B. rettgeri (M. Guinand, Biochemistry, in press) contain, respectively, peptide monomers (13 and $18 \%$ ), dimers (23 and $24 \%$ ), trimers (31 and 17\%), and higher oligomers (33 and $41 \%)$.

In the foregoing description of the bacterial peptidoglycans, the peptide subunits have been 
presented as tetrapeptides having a $\mathrm{D}$-Ala residue at their $\mathrm{C}$ termini. It should be understood that these sequences are typical of those subunits which are in the endo position in the peptide moiety. The peptide subunits located at the $\mathrm{C}$ terminus of a peptide polymer may be pentapeptides L-Ala-D-Glu-(L-Lys or meso-DAP)-DAla-D-Ala i.e., presenting the same sequences found in the peptidoglycan precursors), or tetrapeptides L-Ala-D-Glu-(L-Lys- or meso-DAP)D-Ala, like those in endo-position, or tripeptides L-Ala-D-Glu-(L-Lys or meso-DAP). These two latter peptides may result from the elimination of one or two D-Ala residues from the peptide precursors at the time of assembly through the action of specific carboxypeptidases. It follows that a peptide monomer preparation obtained after endopeptidase treatment may be a mixture of several compounds containing peptide subunits which, in the native peptidoglycan, are located both in endo-position and at the $\mathrm{C}$ termini. Attention should also be called to the peptide subunits which are located at the $N$ termini of the peptide polymer. These are often substituted by uncross-linked peptide bridges. In many cases, these open chains can be degraded by aminopeptidase, which provides a convenient way of determining the average molecular size of these units.

\section{Peptidoglycan as a Taxonomic Character}

\section{Gram-Negative Bacteria}

In spite of the fact that the walls of gram-negative bacteria contain a wide array of amino acids, so far as is known, the peptidoglycan contains only those present in the peptide subunit with meso-DAP as diamino acid. There is a general belief that the type of peptidoglycan presented in Fig. 4 and 13 may be ubiquitous in this group of eubacteria. Indirect evidence for cross-linking between DAP and D-Ala has only been provided in a few cases, viz., Brucella abortus (83), Aerobacter cloacae $(62,146)$, and Spirillum serpens (71). The extent of cross-linking seems to vary according to the species, and different techniques have revealed the existence primarily of peptide monomers and dimers, with some trimers and tetramers also being present.

\section{Actinomycetes}

In 1957, Hoare and Work (52) made an initial study of the distribution of the DAP stereoisomers among the actinomycetes. MesoDAP was found in several species of Mycobacterium and of Nocardia. Species of Actinomyces and Streptomyces, on the other hand, were shown to contain LL-DAP, meso-DAP being completely absent or present only in trace amounts. Micromonospora sp. contain both meso- and LL-DAP. In these studies, the characterization of LL- and meso-DAP rested upon chromatographic separation by the technique of Rhuland et al. (127), the specific decarboxylation of the meso-isomer using a meso-DAP decarboxylase (180), and the specific enzymatic epimerization of LL-DAP into meso-DAP. With three species of Micromonospora, the meso-DAP spot obtained after paper chromatography in the solvent system of Rhuland et al. was found to be only partially sensitive to meso-DAP decarboxylase. Since DDDAP has the same mobility as meso-DAP in the above chromatographic system, it was suggested that part of the DAP was in the DD form in the walls of these three microorganisms. In more recent studies $(120,160,185)$, a tentative classification of various genera of actinomycetes was proposed on the basis of the cell wall composition as well as of morphology. (For a general review on this topic, see 85.) Several different types of cell wall composition were observed, although these did not always correlate with the conventional taxonomic groups. The genus Actinomyces contains L-Lys alone, or both L-Lys and L-Orn. Streptomyces contain LL-DAP associated with Gly (103). Nocardia contain meso- or DD-DAP or both. Streptosporangium contain meso- or DD-DAP associated with a smaller amount of LL-DAP, or both. One group of Actinoplanaceae have meso- or DD-DAP associated with Gly and traces of LL-DAP, or both. Another group of Actinoplanaceae contain 2,6 diamino-3-hydroxy-pimelic acid associated with glycine and traces of meso- or DD-DAP, or both. The location of the glycine residues in the actinomycetal peptidoglycans is not yet known.

\section{Gram-Positive Eubacteria}

L-lysine-containing peptidoglycans are typical of the families of Micrococcaceae and Lactobacteriaceae and DAP-containing peptidoglycans are typical of the Bacillaceae, Propionobacteriaceae, and Corynebacteriaceae families. The two latter families are included in the order Eubacteriales according to the classification in Bergey's manual (7). The nature of the diamino acid, however, is not an absolute familial characteristic. For example, $M$. varians (137), $L$. inulinus, and $L$. plantarum (178) contain mesoDAP. Both L-Lys and meso-DAP occur in Plectridium tetani Mikhailov (Clostridium tetani; 163) and L-Lys alone occurs in A. crystallopoietes (74, $75,171)$. Among the DAP-containing peptidoglycans of gram-positive eubacteria, meso-DAP is the isomer most frequently encountered. 
However, LL-DAP has been found in a local strain of Propionobacterium $(2,52)$ and in the following strains (163): $P$. arabinosum NICB 5958, Welchia perfringens BP 6K (C. welchii), C. botulinum Gunnison and Corynebacterium anaerobium (Prevot 3103 and 3471). DD-DAP has been identified in walls of $B$. megaterium KM (9).

The structure of the DAP-containing peptidoglycans among the gram-positive bacteria is largely unknown. One may postulate that D-AlaDAP linkages are also involved in peptide crosslinking $(9,35,54)$, but exceptions will certainly be found. It has already been postulated (119) that in the LL-DAP-containing peptidoglycan of $C$. welchii, some of the peptide subunits are linked through D-Ala-L-Ala linkages in a "head to tail" sequence similar to that demonstrated in $M$. lysodeikticus peptidoglycan. This hypothesis was not entirely confirmed, however, by very recent experiments (M. Leyh-Bouille and J. M. Ghuysen, unpublished data, and $\mathrm{O}$. Kandler, personal communication) the results of which indicate that Gly also serves as a bridge, extending from LL-DAP to D-Ala. Walls of $M$. varians contain 3 to 4 glutamic acid residues per meso-DAP residue. Solubilization of these walls by a still unclassified endopeptidase from Streptomyces (M. Leyh-Bouille and J. M. Ghuysen, unpublished data) results in the appearance of $\mathrm{N}$ terminal glutamic acid but not of $\mathrm{N}$-terminal DAP, thus strongly suggesting that one or several glutamic acid residues serve as bridges between peptide subunits. These investigations carried out on $C$. welchii and $M$. varians very strongly suggest that, in some DAP-containing peptidoglycans, peptide bridges are mediated through additional intervening amino acids, i.e. a structure analogous to that of the L-Lys-containing peptidoglycans type II (Fig. 5, 6).

The peptidoglycans of many members of the Micrococcaceae and Lactobacteriaceae families have been studied. In some investigations, the walls were sequentially degraded with highly specific enzymes according to procedures previously described. A second type of investigation involved, on the one hand, the characterization of the peptidoglycan nucleotide precursors accumulated in the presence of D-cycloserine, vancomycin, or penicillins and, on the other hand, partial acid hydrolyses of the walls or of chemically stripped peptidoglycans, followed by isolation and characterization of significant oligopeptides. The enzymatic procedure which, originally, was the only procedure available for a comprehensive study of the peptidoglycan structure, is a time consuming process requiring enzymes which are frequently not readily available.
The chemical procedure is much faster and has yielded valuable information. Using this latter method, about 50 species of Lactobacillus, Streptococcus, and Leuconostoc have been examined by Kandler and his colleagues $(63,124$, 140, 141). Tables 2 and 3 represent a tentative classification of Micrococcaceae and Lactobacillaceae based on the chemistry of the peptidoglycan. It is possible to distinguish four distinct subgroups among the peptidoglycans type II. In subgroup A, the bridges are composed of L-amino acid residues. In subgroup $B$, the bridges are composed of Gly residues. In subgroup C, the bridges are composed of Gly and L-amino acid residues. In subgroup $D$, the bridges are composed of a single D-isoasparaginyl residue. In all cases, the peptide bridges extend from the $\epsilon$-amino group of L-Lys (or from one amino group of L-Orn, as in the case of $M$. radiodurans) to the carboxyl group of D-Ala.

\section{Unified View of the Bacterial Peptidoglycans}

The mechanisms involved in the biosynthesis of the peptidoglycan have been elegantly studied in the cases of $E$. coli, $S$. aureus, and other Micrococci. Since this subject has already been reviewed several times $(38,157)$, only the essential points will be recalled here.

Uridine diphospho- $N$-acetylglucosamine and UDP $\quad N^{\alpha_{-}}(\boldsymbol{N}$-acetylmuramyl-L-alanyl- $\boldsymbol{\gamma}$-D-glutamyl)-(L-lysyl or meso-diaminopimelyl)-D-alanyl-D-Ala are the nucleotide precursors. The reactions involved in their synthesis are all catalyzed by soluble enzymes. Particularly, it is known that the amino acids are added stepwise to UDP- $N$-acetylmuramic acid, each step being under the control of enzymes specific for both the uridine nucleotide and the amino acid substrates. Each of the reactions is thus catalyzed by a distinct enzyme requiring adenosine triphosphate (ATP) and either $\mathbf{M g}^{++}$or $\mathbf{M n}^{++}$. The last sequence, D-alanyl-D-Ala, however, is added in one step to the UDP- $N$-acetylmuramyl-tripeptide. D-Cycloserine is known to specifically inhibit the synthesis of the dipeptide D-alanyl-DAla $(107,133)$. The synthesis of the nucleotide precursors is followed by a complex reaction sequence, which results in the formation of uncross-linked peptidoglycan strands. This sequence is catalyzed by particulate enzymes which have been identified as membrane fragments by electron microscopy (L. Matz and J. L. Strominger, Bacteriol. Proc., p. 64, 1968). Three successive transfers are involved in this reaction cycle. (i) From UDP- $N$-acetylmuramylpentapeptide, phospho- $N$-acetylmuramyl-pentapeptide is transferred to a membrane-bound polyisoprenoid phosphate (51) resulting in forma- 
TABLE 2. Peptidoglycans in micrococcaceae ${ }^{a}$

\begin{tabular}{|c|c|c|}
\hline Genus and species & Peptide bridges & Chemical group \\
\hline $\begin{array}{l}\text { Sarcina lutea } \\
\text { Micrococcus lysodeikticus }(31) \\
\text { M. } \text { flavus }^{b} \\
\text { M. } \text { citreus }^{b}\end{array}$ & $\begin{array}{l}\text { Polymerized peptide subunits } \\
\text { Polymerized peptide subunits } \\
\text { Polymerized peptide subunits } \\
\text { Polymerized peptide subunits }\end{array}$ & III; Fig. 7 \\
\hline $\begin{array}{l}\text { M. roseus } \mathrm{R}^{27}(117) \\
M . \text { roseus } \mathrm{Thr}^{-}(117)\end{array}$ & $\begin{array}{l}N^{\epsilon}-(\text { L-Ala-L-Ala-L-Ala-L-Thr)-L-Lys } \\
N^{\epsilon}-(\text { L-Ala-L-Ala-L-Ala)-L-Lys }\end{array}$ & II (A); Fig. 5 \\
\hline $\begin{array}{l}\text { M. radiodurans } \\
\text { Staphylococcus aureus Copenhagen (117) }\end{array}$ & $\begin{array}{l}N \text {-(Gly-Gly)-L-Orn } \\
N^{\bullet}-(\text { Gly-Gly-Gly-Gly-Gly)-L-Lys }\end{array}$ & II (B); Fig. 5 \\
\hline $\begin{array}{l}\text { S. epidermidis } \\
\text { Gaffkya tetragena }\end{array}$ & $\begin{array}{l}N_{-}^{\epsilon_{-}}\left(\mathrm{Gly}_{\mathrm{n}} ; \operatorname{Ser}_{\mathrm{n}}\right)-\mathrm{L}-\mathrm{Lys}^{d} \\
N_{-}\left(\mathrm{Gly}_{4} ; \mathrm{L}-\mathrm{Ala}\right)-\mathrm{L}-\mathrm{Lys}^{e} \\
N^{\epsilon}\left(\mathrm{Gly}_{\mathrm{n}} ; \operatorname{Ser}_{\mathrm{n}}\right)-\mathrm{L}-\mathrm{Lys}^{f}\end{array}$ & II (C); Fig. 5 \\
\hline
\end{tabular}

a Peptide subunit. Group II (A, B, C) : $N^{\alpha}-(\mathrm{L}-\mathrm{Ala}-\mathrm{D}-\mathrm{isoGIN})-\mathrm{L}-\mathrm{Lys}-\mathrm{D}-\mathrm{Ala}$. (In $M$. radiodurans, L-Lys is replaced by L-Orn.) Group III: $N^{\alpha}-[\mathrm{L}-\mathrm{Ala}-\gamma(\alpha-\mathrm{D}-\mathrm{Glu}-\mathrm{Gly})]-\mathrm{L}-\mathrm{Ly}$-D-D-Ala .

$b$ J. Campbell et al., Biochemistry, in press.

c J. M. Ghuysen, unpublished data.

${ }^{d}$ D. J. Tipper, Federation Proc., p. 294, 1968.

- K. H. Schleifer et al., Arch. Mikrobiol., in press.

${ }^{f}$ M. Lache and J. M. Ghuysen, unpublished data.

TABLe 3. Peptidoglycans in lactobacillaceae ${ }^{a}$

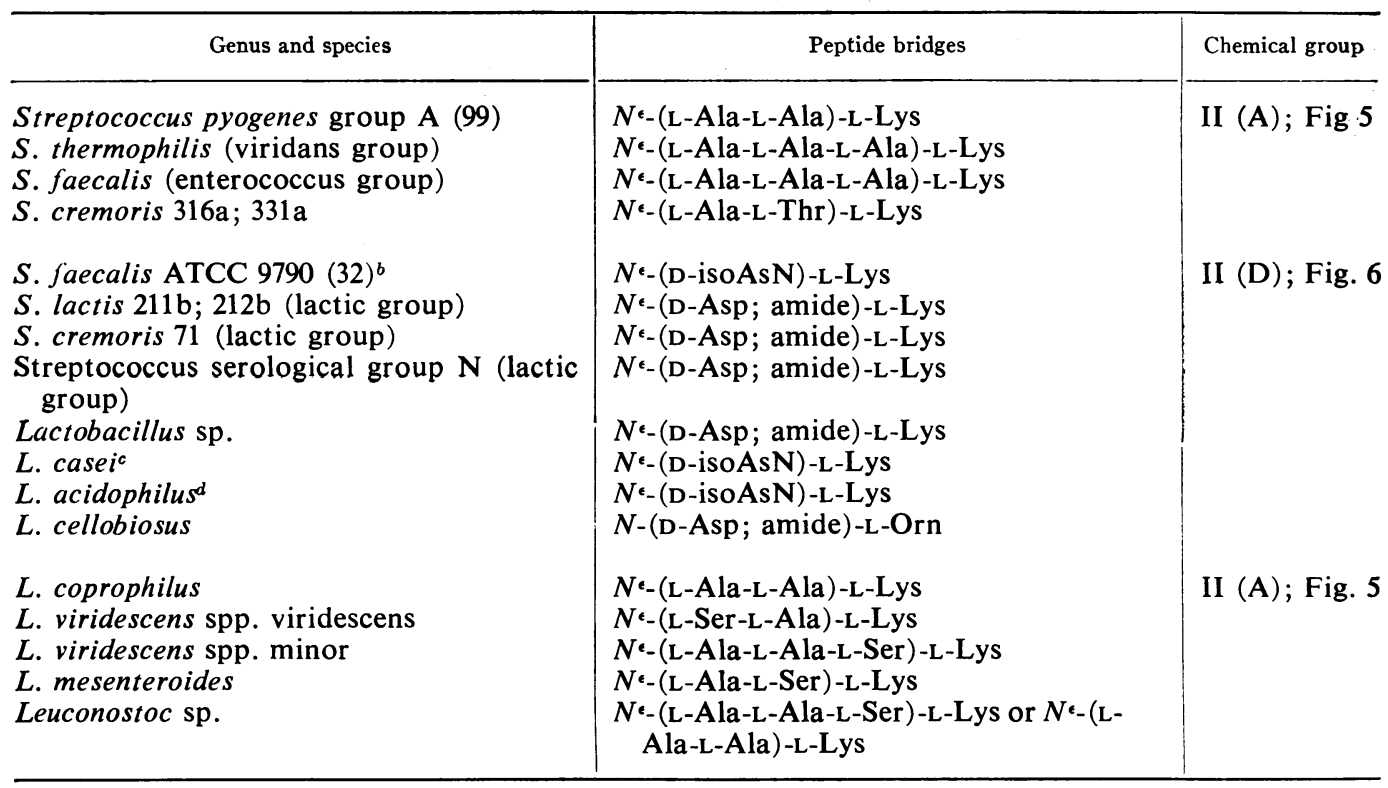

a Peptide subunit $=N^{\alpha}($ L-Ala-D-isoGIN)-L-Lys-D-Ala. References: 63, 124, 140, 141 (unless otherwise specified).

${ }^{b}$ Recently identified as a $S$. faecium var. durans (O. Kandler, personal communication).

c D. Hungerer, Federation Proc., p. 294, 1968.

d J. M. Ghuysen, Biochemistry, in press.

tion of uracil monophosphate (UMP) and the attachment of $N$-acetylmuramyl-pentapeptide to the lipid by means of a pyrophosphate bridge [Lipid-P-P-MurNAc(pentapeptide)]. (ii) Next,
$N$-acetylglucosamine is transferred by transglycosylation from UDP- $N$-acetylglucosamine to the lipid-P-P-MurNAc(pentapeptide), with the liberation of UDP and the formation of $\beta-1,4$ 
GlcNAc - MurNAc(pentapeptide) - P - P - lipid. (iii) This disaccharide pentapeptide is, in turn, transferred from the lipid intermediate to an endogenous acceptor, probably an incomplete peptidoglycan. The carrier is released as the pyrophosphate (P-P-lipid) which is subsequently dephosphorylated, yielding the original polyisoprenoid phosphate compound which can now begin another cycle. Vancomycin, ristocetin, and bacitracin interfere with the above reaction cycle. Bacitracin specifically inhibits the dephosphorylation of the pyrophosphate lipid, which appears as end product of the cycle, and thus prevents the lipid carrier from reentering the cycle (152). The precise mechanism by which vancomycin and ristocetin inhibit the above mechanism is not yet fully understood. During the former reaction, and while the disaccharide peptide subunit is bound to the lipid carrier, other modifications in the pentapeptide moiety occur. (i) In $S$. aureus, the $\alpha$-carboxyl group of glutamic acid is amidated (153) in the presence of ATP and ammonium ions. (ii) In M. lysodeikticus, the same group is substituted by a Gly residue in the presence of ATP (68). (iii) Bridging peptides, such as the pentaglycine in $S$. aureus, are added to the $\epsilon$-amino group of the L-Lys residue in the peptide subunit. The glycine donor for the formation of the pentaglycine bridges is glycyltRNA $(12,108)$. Similarly, L-Thr (129) and LAla (128) have been shown to be activated as L-threonyl-tRNA or as L-alanyl-tRNA for incorporation in the bridges of $M$. roseus $\mathrm{R} 27$ and $A$. crystallopoietes, respectively. Similar mechanisms are involved in the incorporation of L-Ser and Gly into interpeptide bridges in $S$. epidermidis (118). The above complex reaction cycle may be visualized as a means of transporting the "disaccharide-pentapeptide-peptide bridge" subunit in the form of a lipid intermediate from the intracellular site of synthesis to the extracellular site of utilization (i.e., as a mechanism of passing through the plasma membrane). The lipid moiety of the intermediate has been recently characterized (51) as a $C_{55}$ isoprenoid alcohol. The existence, in $S$. aureus, of an ATP-dependent phosphokinase which catalyzes the phosphorylation of free $\mathrm{C}_{55}$-isoprenoid alcohol has also been described (Y. Higashi et al., Federation Proc., p. 294, 1968). $C_{55}$ isoprenoid alcohol seems to have a wide functional importance since it is also involved in the biosynthesis of mannan in $M$. lysodeikticus (M. Sher and W. J. Lennarz, Federation Proc., p. 293, 1968) and of the $O$ antigens of Salmonella (M. A. Cynkin and M. S. Osborn, Federation Proc., p. 293, 1968; 184). In this latter case, trisaccharide units (of mannose, rhamnose, and galactose) linked through pyrophosphate to the lipid (Man-Rh-Gal-P-Plipid) are first polymerized forming $O$-antigen chains (Man-Rh-Gal) ${ }_{n}$-P-P-lipid, which subsequently are transferred to the "core" to form the completed lipopolysaccharide (184). Much remains to be done with regard to the exact mechanism through which the tRNA participates in the cell wall synthesis by activating the amino acids for their incorporation into the bridges. It seems clear, however, that ribosomes are not involved in this mechanism, which means this process differs from "normal" protein synthesis. It should be noted that the incorporation of amino acids into the peptide bridges can also be mediated by mechanisms other than those which have just been described. In $L$. viridescens, of which the bridges are $N^{\epsilon}$-(L-Ser-L-Ala)-L-Lys, the initial amino acceptor for the tRNA-dependent incorporation of L-amino acids is apparently not the lipid intermediate (R. Plapp, Federation Proc. p. 294, 1968), since a soluble enzyme system was shown to be able to catalyze a direct ATP, $\mathrm{Mg}^{++}$and tRNA-dependent incorporation of either L-Ala or L-Ser into UDP- $N$-acetylmuramyl-pentapeptide precursor. In $S$. faecalis and $L$. casei, of which the bridges are $N^{\epsilon}$-(DisoAsN)-L-Lys, the lipid intermediate is the initial acceptor for D-aspartic acid incorporation; aminoacyl-tRNA, however, is not required and the incorporation is not sensitive to ribonuclease (W. Standenbauer, Federation Proc., p. 294, 1968).

The bridge-closing reaction, the last step in the synthesis of the peptidoglycan net, results from a transpeptidation in which the bond energy of the terminal dipeptide (D-Ala-D-Ala) in the peptide subunit is utilized to effect the closure of the peptide cross-link with the concomitant release of the terminal D-Ala residue, i.e., the formation, for example, of a D-Ala-Gly linkage, in the case of $S$. aureus, or a D-Ala-(D)meso-DAP, in the case of $E$. coli. In this transpeptidation reaction, no exogenous energy source is necessary, and it can occur outside the cell membrane at a site where ATP is not available. Penicillins and cephalosporins are specific inhibitors of this transpeptidation. It has been hypothesized that their actions depend upon a structural analogy with the D-alanyl-D-Ala peptide at the end of the peptide subunit (157, 169). A direct demonstration of the transpeptidation reaction in $E$. coli has been given (58). The hypothesis that this reaction is generally involved in the biosynthesis of the peptidoglycans rests upon indirect evidence, such as experiments showing that in the presence of penicillins, for example, uncross-linked cell walls are formed.

From the foregoing, it is becoming evident that 
the biosynthetic mechanisms involved in the formation of the wall peptidoglycans are consistent throughout the microbial world. A fourstage mechanism can be proposed. First, all bacterial peptidoglycans are synthesized from two nucleotide precursors, the UDP- $N$-acetylglucosamine and an UDP- $N$-acetylmuramyl pentapeptide. The amino acid, located at the $\mathrm{N}$-terminus of the pentapeptide, and the third residue in the sequence may vary. Depending upon the bacterial species, the three first amino acids in the sequence are L-Ala-D-Glu-L-Lys, L-Ala-D-Glu-L-Orn, and L-Ala-D-Glu-meso, or LL- or DD-DAP, L-Ala-D-Glu-diaminobutyric acid, Gly-D-Glu-homoSer, L-Ser-D-Glu-L-Orn, etc. In all bacteria, however, the pentapeptide would terminate in a D-alanyl-D-Ala dipeptide at the $\mathbf{C}$ terminus. In all of these examples, the D-Glu is linked to the next amino acid through its $\gamma$-carboxyl group. As pointed out above, each of these different sequences would be determined by individual soluble enzymes performing the stepwise addition of each amino acid to the UDP muramyl precursors.

Second, the assembly of the nucleotide precursors into disaccharide peptide units and their transport through the plasma membrane would be brought about, in all bacteria, with the help of the polyisoprenoid phosphate carrier via the cyclic reaction described above.

Third, the pentapeptide subunits, while either in the form of nucleotide precursors or in the form of lipid intermediates, undergo various modifications. The most important modifications are, of course, the incorporation of the amino acids which will serve as cross-peptide bridges. Amidation of carboxyl groups and incorporation of other substituents, such as a Gly residue in the pentapeptide of $M$. lysodeikticus, have also been described. Other modifications of the pentapeptides would be, for examples, (i) the substitution of the $\alpha$-carboxyl group of glutamic acid by the $\epsilon$-amino group of a D-Lys residue (in $B$. rettgeri) or by the $\delta$-amino group of a D-Orn residue (in $C$. poinsettiae and $B$. rettgeri), (ii) the hydroxylation of L-Lys (in $S$. faecalis, under special growth conditions), and the hydroxylation of glutamic acid in Microbacterium lacticum (143).

Fourth, the final closure of the bridges between peptide subunits might be, in all bacteria, the result of a transpeptidation involving the $D$ alanyl-D-Ala dipeptide of one pentapeptide subunit and a second peptide subunit as acceptor with the concomitant loss of the terminal D-Ala. This acceptor is the $\mathbf{N H}_{2}-(\mathrm{D})$-meso-DAP of another peptide subunit $(E$. coli) or the amino terminus of the peptide bridge grouping, such as Gly ( $S$. aureus), L-Ala ( $S$. pyogenes), D-isoasparagine ( $S$. faecalis), $\alpha-\mathrm{NH}_{2}$-D-Lys ( $B$. rettgeri), or $\alpha-\mathrm{NH}_{2}-\mathrm{D}-\mathrm{Orn}$ ( $C$. poinsettiae and $B$. rettgeri). Again, it should be understood that these bridge groupings may substitute either the L-Lys residue of the peptide subunit, as it is in most cases, or the $\alpha$-glutamic acid, as in $B$. rettgeri and $C$. poinsettiae.

Finally, attention should be called to the biosynthesis of those peptides bridges, found in M. lysodeikticus and other related Micrococcaceae, in which several peptide subunits are linearly linked in "head to tail" sequences through D-alanyl-L-Ala linkages (Fig. 7, 16). The formation of such bridges might occur through successive alternating transpeptidation and amidase activities $(31,142)$, following the sequence shown in Fig. 18. In reaction No. 1, a transpeptidation, the penultimate $\mathrm{D}$-Ala residue of of peptide $B$ is transferred to the lysine residue of peptide $A$ with the concomitant loss of the terminal D-Ala residue. Reaction No. 2 is an amidase action in which the amide linkage at the N-L-Ala terminus of peptide $B$ is hydrolyzed. Reaction No. 3, a second transpeptidation, results in the penultimate $\mathrm{D}$-Ala residue of peptide $\mathrm{C}$ being bound to the $\mathrm{N}$-terminal $\mathrm{L}$-Ala residue of peptide $B$ with the expulsion of one D-Ala residue. Reactions 4 to 9 would follow in the indicated order, resulting ultimately in the formation of the peptide hexamer. In addition to the amidase, two different transpeptidases would be involved, the specificities of which depend upon the structure of the amino acceptor (i.e., the $\epsilon$-amino group of L-Lys in reaction No. 1 and the amino

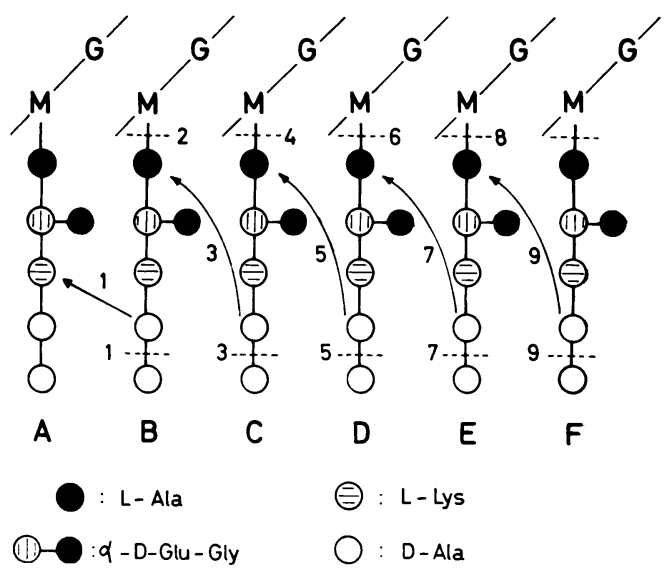

Fig. 18. Proposed biosynthetic sequences of the peptide hexamer unit of $M$. lysodeikticus peptidoglycan (Fig. 7). Reactions 2, 4, 6, and 8 are amidasic hydrolyses. Reactions 1, 3, 5, 7, and 9 are transpeptidations (31; figure reprinted by permission). 
group of L-Ala in reactions 3, 5, 7, and 9). The above mechanism has the result, of course, that on the average the glycan strands have a low extent of peptide substitution. Exposure of additional receptor sites in the glycan through the action of endo- $N$-acetylmuramidase autolysins could result in the loss of some unsubstituted glycan segments. This provides an explanation for the observation (J. Campbell et al., Biochemistry, in press) that in some micrococcal peptidoglycans type III (Fig. 7), the number of disaccharide units is significantly lower than the number of peptide subunits.

The biosynthetic reactions hereby postulated may provide a way to unify our concept of the bacterial peptidoglycan. In spite of the extreme variations in chemical composition and in structural details present in bacterial peptidoglycans, they all possess the same type of network and appear to be synthesized by means of analogous mechanisms.

\section{Lytic Enzymes as a Means for the Study of the Link Between the Peptidoglycan AND OTHER COMPONENTS IN WALls of Gram-Positive Bacteria}

Early electron microscopic examinations of isolated cell walls of gram-positive bacteria showed bag-shaped structures of rather uniform and homogeneous appearances. Immunological studies, however, strongly suggested that the rigid peptidoglycan network and the other polymers of the walls, most frequently proteins, polysaccharides, or teichoic acids (or both), were interlinked in a specific and organized manner. Besides the peptidoglycan, the $S$. pyogenes group A walls, for example, contain at least two other polymers $(73,87)$, the groupspecific C-polysaccharide and the type-specific $\mathbf{M}, \mathbf{R}$, and $\mathbf{T}$ proteins. The group C-polysaccharide contains $\alpha$-1,3-linked L-rhamnose (25, 48 ) and terminal $N$-acetylglucosamine linked to rhamnose by a $\beta-1,3$ bond (50). A portion of the rhamnose units, however, is also substituted in the 2-position, and some of the glucosamine residues may not be terminal (48). The structures of the type-specific $M$ protein, which is probably related to virulence, and of the $R$ and $T$ proteins are still largely unknown. Suitable proteases can remove these proteins from the walls without affecting the viability of the microorganism or the physical appearance of the walls. Further treatment of the walls with hot formamide eliminates, in turn, the group $\mathbf{C}$ polysaccharide, leaving, at the end of the process, an insoluble peptidoglycan which has the bag-shaped appearance of the original walls. It seems obvious that such a sequential exposure of immunological determinants must result from a distinct layering of the chemical components. Using improved sectioning, fixation, and staining techniques, direct demonstration of a layered structure among walls of gram-positive bacteria has been recently achieved. The macromolecular arrangement of the surface of the walls of $B$. polymyxa (106) consists of a rectangular array of 7-nm globules with a repeating interval of $10 \mathrm{~nm}$. This outermost layer, mainly composed of protein, is approximately $8 \mathrm{~nm}$ thick, and it is removable by hydrogen bond-breaking reagents or by trypsin. An underlying structure of 4-nm thickness is a polysaccharide complex which appears to be covalently bound to the deepest layer of $12 \mathrm{~nm}$ of thickness (probably the peptidoglycan), from which it can be removed by hot formamide. Similarly, the walls of $B$. megaterium, (105) have been shown to be composed of a rigid peptidoglycan layer of about $10 \mathrm{~nm}$ in thickness, surrounded by an elastic layer $(12 \mathrm{~nm})$ formed by bristles of teichoic acid. This type of architecture is perfectly consistent with the biological roles that the teichoic acids play in the bacterial cells. The immunological activity of the teichoic acid in $S$. aureus has been proved by a variety of techniques. It has been shown by haptene inhibition studies, for example, that the $\alpha$ - and $\beta-N$-acetylglucosamine residues, which substitute the polyribitol phosphate skeleton of the teichoic acid, are the specific antigenic determinants responsible for cell wall agglutination (104). Moreover, evidence has also been given that some of the $N$-acetylglucosamine residues on the teichoic acid are involved in phage fixation in $S$. aureus (18). Similar conclusions were reached by Young, who found that phage fixation by $B$. subtilis requires that the teichoic acid be glucosylated $(188,189)$, and by Glaser et al. (42), who presented evidence that phage $\mu$ may recognize teichoic acid as part of the receptor site of $B$. subtilis. Another illustration of a complex layering is that of the pigmented walls of $M$. radiodurans (183). They were shown to be composed of (i) an outermost network removable by trypsin; (ii) a fragile soft layer, pink in color, containing carotenoids, lipid, protein, and polysaccharide and presenting hexagonally packed subunits; (iii) a perforated rigid L-Orn-containing peptidoglycan layer. Other beautiful demonstrations of detailed organization of the various components in bacterial walls have been provided by Murray (101).

From the foregoing, it is obvious that the elucidation of the way in which the various constituent polymers are held together within the bacterial walls is a major, although still largely 
unsolved, problem. Phosphodiester bonds are one means used by bacteria to link together the rigid peptidoglycan and the other polymeric structures. The nonglycan polysaccharide in the walls of $L$. casei, for example, is believed to be joined through the reducing group of its terminal $N$-acetylglucosamine residue to a phosphate group on the peptidoglycan $(45,70)$. Most likely, this is a phosphorylmuramic acid (1). The "atypical" teichoic acid present in the walls of $S$. lactis is linked to the peptidoglycan via phosphodiester bonds between the glycerol and $\mathrm{C}_{4}$ or $\mathrm{C}_{6}$ of muramic acid (13). In the case of $S$. aureus strain Copenhagen, phosphodiester bonds also cross-link the teichoic acid and the peptidoglycan (40). Indirect evidence, based on the estimation of formaldehydogenic end groups by periodate oxidation, suggested that a phosphorylated $N$-acetylglucosamine residue was the peptidoglycan part of this link. This conclusion, however, cannot be regarded as definite, because the linking group was not actually isolated and characterized. According to a recent survey made by Liu and Gotschlich (82), muramic acid 6phosphate represents from 3 to $39 \%$ of all the muramic acid residues present in the walls of M. lysodeikticus, Diplococcus pneumoniae, Mycobacterium butyricum, $S$. aureus NYH 6, and of various species of Streptococcus belonging to groups A, C, and E. Muramic acid phosphate was also detected in mycobacterial walls (64). The importance of muramic acid 6-phosphate in the walls of gram-positive bacteria and actinomycetes is becoming evident. Further information concerning the location of these linking groups in two different walls has been sought by the technique of specific enzymatic degradation.

\section{Micrococcus lysodeikticus}

The polysaccharide component of the $M$. lysodeikticus walls is composed solely of equimolar amounts of D-glucose and 2-acetamido 2deoxymannuronic acid (111). In spite of the reports of Perkins (111) and of Prasad and Litwach (125) to the contrary, the presence of organic phosphate, first detected by Salton (135), in amounts ranging from 0.09 to $0.13 \%$ of the weight of the walls, is now generally accepted $(82,95)$. Walls of $M$. lysodeikticus, as prepared in my laboratory contain (per milligram dry weight) 26 nmoles of organically bound phosphate, 260 nmoles of D-glucose, 480 nmoles of disaccharide and peptide subunits, i.e., a ratio of 1:10:19. After complete degradation of the wall peptidoglycan through sequential action of $\mathrm{ML}$ endopeptidase, $\mathrm{F}_{1}$ endo- $N$ acetylmuramidase and $N$-acetylmuramyl-L-Ala amidase, the polysaccharide polymer was isolated in the form of a complex presenting a ratio for phosphate, glucose, disaccharide units, and peptide units of $1: 10: 2.5: 1$. Analytical data were consistent with a structure in which one peptide subunit substitutes a tetra- or hexasaccharide residue, itself linked to the glucose-containingpolysaccharide polymer through a phosphodiester bond originating from the C-6 of one of the $N$ acetylmuramic acid residue. Another "polysaccharide-glycopeptide fragments" complex of the same established composition and tentative structure was isolated from walls which had been degraded only with an endo- $N$-acetylmuramidase. Since the wall peptide moiety was not attacked in this latter type of degradation, one can postulate that, in the intact walls, those glycan segments which bear phosphate groups are not substituted by cross-linked peptide subunits. There is one phosphate group for every $18 \mathrm{di}$ saccharide units in intact walls. By analogy with chain length determinations carried out in the case of $S$. aureus, this figure of 18 disaccharide units may well represent the average chain length of the glycan strands in $M$. lysodeikticus. Since phosphate bridging and peptide cross-linking do not occur on the same segments of the glycan moiety, not many phosphate bridges can occur in a single glycan strand; therefore it was hypothetized that, on the average, each glycan strand of 18 disaccharide units is joined through one phosphodiester bond to a segment, 10 glucose and 10 aminomannuronic acid residues long, of the polysaccharide polymer.

\section{Streptococcus pyogenes}

Elucidation of the macromolecular structure of the $S$. pyogenes cell wall has been attempted (98). Careful fractionations of the walls treated with trypsine and subsequently solubilized by $\mathrm{F}_{1}$ endo- $N$-acetylmuramidase yielded fractions in which it was possible to distinguish between two types of phosphate groups (Fig. 19). (i) About $20 \%$ of the organic phosphate present in the walls (i.e., $50-\mathrm{nm}$ equivalents $/ \mathrm{mg}$ ) occurs as $N$-acetylmuramic acid 6-phosphate residues. These groups join about $10 \%$ of the peptidoglycan subunits ( $50-\mathrm{nm}$ equivalents/mg) to a polysaccharide polymer which is not the C-polysaccharide. This polymer (complex S3, Fig. 19) was isolated as a disaccharide peptide monomer subunit linked through the phosphodiester bridge to a complex containing, per peptide monomer, five to six D-glucose residues, one glucosamine residue, and four to five unidentified hexosamine residues, possibly aminohexuronic acids. It was proposed that this polymer, referred 


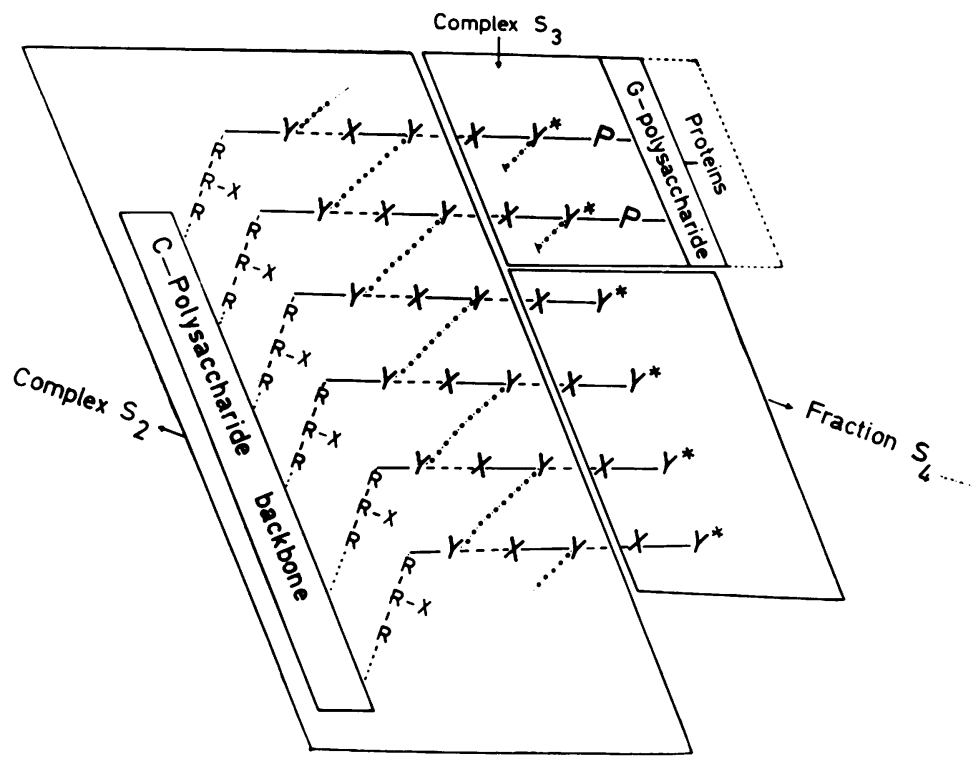

Fig. 19. Proposed molecular arrangement of the four polymeric constituents of the walls of Streptococcus pyogenes type 14. Hydrolysis of the glycosidic linkages between $N$-acetylmuramic acid $(Y)$ and $N$-acetylglucosamine $(X)$ yields three main fractions. Complex $S_{2}$ contains the group-specific $C$-polysaccharide linked to the peptidoglycan via tri-rhamnose $(R)$ groupings. Complex $S_{3}$ contains the glucose-containing $G$-polysaccharide linked to the peptidoglycan via phosphodiester bridges $(P)$. The $G$-polysaccharide would be the anchor points for the type-specific $M, R$, and $T$ proteins. Glycan chains are bound by decapeptides resulting from the cross-linking of two peptide subunits $B$ (Fig. 3) through L-alanyl-L-Ala dipeptides (Fig. S). Fraction $S_{4}$ consists of unsubstituted disaccharide units (about $20 \%$ of the total $N$-acetylhexosamine residues). (For more details, see 98 ; figure reprinted by permission.)

to as the G-polysaccharide, serves as an anchor point for the M-, R-, and T-type proteins. This hypothesis has been strengthened by very recent investigations carried out by Barkulis et al. (Bacteriol. Proc., p. 110, 1968). It is noteworthy that, as with $M$. lysodeikticus, the phosphate group joining the glycan and the G-polysaccharide is located on an $N$-acetylmuramic acid residue bearing an unbridged peptide substituent. (ii) About $70 \%$ of the organic phosphate of the walls (150 $\mathrm{nm}$ equivalents $/ \mathrm{mg}$ ) occurs as glycerol phosphate and glyceryl rhamnoside phosphate (49) in the interior of the C-polysaccharide. The linkage between the $\mathrm{C}$-polysaccharide chains and the peptidoglycan was visualized as consisting of bridges of trirhamnose groupings, each bearing one $\beta$-linked $N$-acetylglucosamine residue (Fig. 19). In this case, each of these trirhamnose units would be bound at the reducing end, either directly or through an as yet undetermined intermediate molecule, to the C-4 of an $N$-acetylmuramic acid residue. After endo- $N$-acetylmuramidase degradation of the walls, a complex has been isolated (complex $S_{2}$, Fig. 19), in which the C-polysaccharide is bound to $N$-acetylmuramic acid residue. This $N$-acetylmuramic acid residue was found to be substituted by one tetrapeptide subunit which, in turn, was linked via a di-L-alanyl bridge to another disaccharide peptide subunit.

As a result of these findings (98), it was proposed that a major part of the walls presented a structure of the type shown in Fig. 19. The $N$ acetylmuramic acid at the nonreducing end of short glycan strands are glycosidically linked to the reducing ends of tri- $\alpha-1,3-\mathrm{L}-$ rhamnosyl fragments extending from the C-polysaccharide bulk. In about $10 \%$ of the glycan strands, some $N$-acetylmuramic acids are substituted on C-6 by phosphate groups extending to the G-polysaccharide polymer. The remaining $N$-acetylmuramic acid residues are substituted by tetrapeptide subunits cross-linked by L-alanyl-L-Ala dipeptides, so that neighboring glycan strands are crosslinked by decapeptide chains.

It should be understood, of course, that the proposed structure represents only one of the possibilities. The phosphorylated $N$-acetylmuramic acid residues need not be terminally located, and the chain length of five hexosamine residues given for the glycan moiety may well be an average resulting from the actual presence of a mixture of longer and shorter chains. Although as yet imprecise, the proposed structure offers an 
explanation at a molecular level for the complex architecture of the walls and, particularly, for the specific interconnection between constitutive polymers.

\section{Autolytic Enzymes as Bacterial Wall CONSTITUENTS}

Whereas the reactions involved in the biosynthesis of the peptidoglycan portion of the bacterial wall are understood at the molecular level, our concept of the mode of growth and replication of the wall at the cellular level is still largely hypothetical. Three different aspects of this problem will be discussed briefly.

\section{Cosynthesis of the Wall Polymers}

The biosynthesis of the bacterial walls (i.e., the peptidoglycan and the other polymers) is an exceedingly complex reaction mechanism in which at least 30 and perhaps as many as 60 enzymes are involved. If, for example, one considers the structure of the walls of $S$. pyogenes (Fig. 19), it would appear logical that biosynthesis and integration of each polymeric component occur simultaneously, if one is to arrive at such a structure in which all the polymers are cross-linked in a specific ordered manner. Some results have been obtained which support this hypothesis. One approach has involved the marking of the walls of a living cell of $S$. pyogenes at a given time, by fluorescein-labeled antibodies specific for the wall type $M$ protein or for the wall group C polysaccharide (17). By following the partition of the markers among daughter cells after division, the events involved in the wall replication appeared identical irrespective of the antibody used for the labeling; thus, it has been possible to conclude that the synthesis of these two antigens is synchronized and occurs at identical sites. It would be most important, however, that identical experiments be repeated with fluorescent antibody specific to the wall peptidoglycan matrix. Similarly, it has also been observed that application of any inhibitor of peptidoglycan synthesis leads to concomitant nhibition of teichoic acid synthesis (131), suggesting interrelationship between the formation of the two polymers.

\section{Site of Synthesis of Cell Wall Material}

All bacteria do not replicate their cell wall material in the same manner. Essentially two mechanisms have been shown to exist (17). In one type of replication, new wall material appears localized in a specific area of the parent wall. Examples of this are $S$. pyogenes (17) and $S$. faecalis (149), wherein, as shown by the fluorescent antibody technique, peripheral wall and cross-wall (septum) formation are initiated at the same time along an equatorial ring, with the result that the daughter cocci grow "back-toback." Initiation of new bands of synthesis occur before the old ones are complete, suggesting a necessity for initiation of new cleavage points. Similarly, it has also been reported by Fitz-James and Hancock (26) that, in the presence of penicillin, a fibrous material is formed at a specific growing point of the cell wall of $B$. megaterium. As suggested by Strominger et al. (Federation Proc., p. 9-22, 1967), this disorganized fibrous material would represent the peptidoglycan strands which continue to be formed in the presence of penicillin, but remain uncross-linked. The second type of replication, found in species of Salmonella (17) or of E. coli (177), is a diffuse process. As also shown by the fluorescent antibody technique or by following, microautoradiographically, the incorporation and distribution of ${ }^{3} \mathrm{H}$-labeled DAP, new wall material appears to be continuously inserted into existing material at multiple sites along the surface of the wall. D-Methionine was shown by Lark et al. (77) to induce the formation in Alcaligenes faecalis of a fibrous material which, in contrast with the situation observed in $B$. megaterium treated with pencillin, was not localized, but occurred over the entire bacterial surface. Since D-methionine, or some other D-amino acids, is capable, like penicillin, of reversing the transpeptidation in the last step of the peptidoglycan biosynthesis, it was also suggested that this fibrous material was some uncross-linked peptidoglycan (J. L. Strominger et al., Federation Proc., p. 922, 1967).

Peripheral and cross-wall formation occur at the same time. However, the two processes must be distinct and separately controlled in many organisms, since it is possible to selectively inhibit cross-wall formation, by alteration of the environment, for example, with the resultant formation of greatly elongated septumless filaments. The demonstrated occurrence of mesosomes in close proximity to the developing septa, plus the fact that they are absent in cells growing under conditions where septum formation is interrupted, has led several workers (138) to postulate that these organelles are involved in wall biosynthesis, possibly as a carrier for peptidoglycan precursors. Much, however, remains to be done before the exact function of mesosomes in this regard is established.

\section{Biological Roles of Autolysins}

Many endogenous autolytic systems are fixed in the walls themselves and must be regarded 
as an integral part of these layers. Autolysins, first thought solely a means of self-destruction, have excited considerable interest of late as possible factors involved in wall biosynthesis, regulation, and in the permeation of large molecules. Several reasonable roles might be attributed to these enzymes.

Wall autolysins can be visualized as a means of providing the peptidoglycan net with additional receptor sites to which newly synthesized disaccharide-peptide units could be transferred. Receptor sites, both in the glycan and in the peptide moieties, are needed. $N$-acetylglucosamine residues at the nonreducing termini of glycan segments (i.e., the expected sites for the transfer of disaccharides from the lipid intermediate) could result from the hydrolysis of $\beta-1,4-N$-acetylmuramyl- $N$-acetylglucosamine linkages. Amino termini of peptide bridges or amino groups of the diamino acids of the peptide subunits if the peptide bridging is mediated through direct bonds between peptide subunits, (i.e., the acceptors for the transpeptidation reaction involving the D-alanyl-Dalanine dipeptides of newly synthesized pentapeptides) could be provided by cleavage of linkages at the $\mathrm{C}$ termini of some peptide subunits. According to this thesis, endo- $N$-acetylmuramidases and many of the endopeptidases which have been described are just such tools. Furthermore, and by analogy with the mechanism proposed for the hydrolytic action of lysozyme (16), the endo- $N$-acetylmuramidases might be transglycosilation agents playing an active role in the growth of the glycans. In order to ensure an economic and safe enlargement of the net, a strict coordination of the machinery is required. This coordination would be a character of a wellbalanced growth. One model for such a mechanism in $E$. coli has been proposed by Weidel and Pelzer (177).

Recent developments have provided evidence for a preferential location of the autolysin enzymes in some bacterial walls. The involvement of the autolysin of $S$. faecalis in wall growth has been based upon several observations (149). This activity is only found in the wall fraction, and it is maximal during the period of exponential growth. Furthermore, it was demonstrated by ingenious radioactive labeling that newly synthesized wall material was the first to be dissolved by this autolysin, suggesting that active enzyme was localized at the region of new wall synthesis (i.e., at the coccal equators). It has also been shown that $S$. faecalis walls contain large amounts of latent autolysin, which, in vitro, is activated by trypsin. A process whereby the latent autolysin is proteolytically activated at the future sites of new wall growth can readily be imagined. Further evidence of the localization of the autolytic system at the site of septum formation comes from the earlier observation of Mitchell and Moyle (94) that osmotic shocking of $S$. aureus cells, allowed to autolyse in $1.2 \mathrm{M} \mathrm{NaCl}$, gave rise to hemispherical halves of cell walls. More recently, Cripps and Work (19), working with a strain of $S$. aureus, gave electron microscopic evidence that at the time of lysis there was a localized rupture of the developing septum and extrusion of intracellular high molecular weight material (RNA, DNA, proteins) from this point. It has been proposed that this localized rupture could be the result of an activation of the autolytic system.

The specificity of the wall autolysin in $S$. faecalis and in $S$. aureus has been studied. In $S$. faecalis, the system has been characterized as being an endo- $N$-acetylmuramidase (149) and, hence, a reasonable role for this enzyme would be to break the existing peptidoglycan net and to provide acceptor sites. In $S$. aureus, at least part of the wall autolytic system has been characterized by D. J. Tipper (Bacteriol Proc., p. 48, 1968), who demonstrated the presence in the isolated walls of endo- $N$-acetylmuramyl-L-Ala amidase, endo- $N$-acetylglucosaminidase, and endopeptidase activities. Neither of the two first enzymes would produce acceptors for enlarging the peptidoglycan. They might however serve to separate the two daughter cocci after septum formation is complete. Furthermore, as noted by Tipper, if the glycan were in fact the only acceptor for the synthesis of additional peptidoglycan material, the endo- $N$-acetylglucosaminidase action which produces oligosaccharides with $\quad N$-acetylglucosamine-reducing termini would serve to fragment an otherwise endless polymer.

Another possible role for wall autolysin is based on recent investigations made by $\mathrm{A}$. $\mathrm{H}$. Dadd and R. J. L. Paulton (Proc. Soc. Gen. Microbiol., p. iii, 1968). Working with synchronized $B$. subtilis, they showed that incorporation of cell wall material occurs solely at the time of cell division. Between cell divisions, an increase of $N$-terminal DAP was observed, which must be the result of the activity of a wall endopeptidase system. This suggests a loosening of the net, thus permitting the fixed amount of wall to stretch to accommodate the enlarging cytoplasm. The presence of another "relaxation system" in the walls of competent $B$. subtilis has also been proposed $(186,187,190)$. It has been shown that those strains of $B$. subtilis which are highly susceptible to genetic transformation contain a higher autolytic activity than do the poorly transformable strains. Here again, the 
autolytic system which consists, in part at least, of an $\mathrm{N}$-acetylmuramyl-L-Ala amidase, is associated with the walls and is probably covalently linked to the teichoic acid (W. C. Brown et al., Bacteriol. Proc., p. 48, 1968). It has been suggested that this activity results in a relaxation of the peptidoglycan net, perhaps in a localized area, permitting the passage of DNA. Nothing is known, however, regarding the mechanism involved in the repair of such gaps or how these repair mechanisms are inhibited under the conditions of unbalanced growth required for maximum competence, nor does it explain the binding of DNA to competent cells or its passage through the cytoplasmic membrane. It has also been suggested (F. E. Young, personal communication) that this autolytic amidase may be involved in separation of cells during the final stages of cleavage.

Bacterial wall or envelope enzymes are also likely to be involved in other regulation mechanisms. In $E$. coli, for example, two enzymes, or perhaps two different manifestations of the activity of one enzyme (86), terminate the synthesis of the peptidoglycan (J. L. Strominger et al., Federation Proc., p. 9-22, 1967): the transpeptidase which, as described above, brings about the closure of the bridges between two peptide subunits, and a D-Ala carboxypeptidase which removes the D-Ala residues from the end of one of these two peptide subunits so that oligomers larger than dimers cannot be formed. D-Ala carboxypeptidase is one of the enzyme activities of the complex autolytic system of the $E$. coli envelope. It is possible that this enzyme is, in fact, responsible for the limitation of the size of the polymer moiety. Similarly, the regulation of the size of those peptidoglycans that contain peptide bridges might be mediated by aminopeptidases, which would modify the acceptor sites needed for the closure of the bridges. Finally, autolytic $N$-acetylmuramyl-L-Ala amidases have been reported to be present in walls of an increasing number of bacterial species $(162,164)$. The possible involvement of this enzyme in the formation of "head to tail" peptide sequences, such as those demonstrated in $M$. lysodeikticus (31; Fig. 18) and other related Micrococcaceae (J. Campbell et al., Biochemistry, in press) may be hypothesized.

\section{Conclusion}

In the period of the last 20 years, a new class of heteropolymers, the peptidoglycans in the bacterial walls, were discovered. Studies of their structure and biosynthesis have been developed at a comprehensive molecular level, opening a new area of investigations. The coming years will see, we hope, the widening of our understanding of the tertiary structure and of the intimate functioning of this bacterial organelle as an integral part of coordinated cellular systems.

\section{ACKNOWLEDGMENTS}

This investigation was supported by grant UR-E $E_{4}-$ 10-2 from the U.S. Department of Agriculture under Public Law 480.

I am grateful to the following persons for reading, criticizing, and discussing the manuscript: E. Bricas, Institut de Biochimie, Orsay, France; J. N. Campbell, Department of Microbiology, University of Alberta, Edmonton, Canada; J. Coyette, Service de Bactériologie, Université de Liège, Belgium; M. Guinand, Service de Chimie Biologique, Université de Lyon, France; H. Heymann, Bacteriology Department, Ciba Pharmaceutical Co., Summit, N. J.; O. Kandler, Institut für Angewandte Botanik, Technische Hochschule, Munich, Germany; M. Leyh-Bouille, Service de Bactériologie, Université de Liège, Belgium; E. Muñoz, Instituto de Biologia Cellular, Madrid, Spain; H. Perkins, Medical Research Council, Mill Hill, London, England; J. F. Petit, Institut de Biochimie, Orsay, France; K. Schleifer, Institut für Angewandte Botanik, Technische Hochschule, Munich, Germany; N. Sharon, The Weizmann Institute, Rehovoth, Israel; G. Shockman, Department of Microbiology, Temple University, Philadelphia, Pa.; R. Tinelli, Institut Pasteur, Paris, France; D. Tipper, Pharmacology Department, University of Wisconsin, Madison, Wis.; J. van Heijenoort, Institut de Biochimie, Orsay, France; and F. E. Young, Scripps Clinic and Research Foundation, La Jolla, California.

\section{Literature Cited}

1. Ågren, G., and C. H. De Verdier. 1958. The isolation of protein-bound phosphorylmuramic acid from Lactobacillus casei. Acta Chem. Scand. 12:1927-1936.

2. Allsop, J., and E. Work. 1963. Cell walls of Propionobacterium species: fractionation and composition. Biochem. J. 87:512-519.

3. Barkulis, S. S., C. Smith, J. J. Boltralik, and H. Heymann. 1964. Structure of streptococcal cell walls. IV. Purification and properties of streptococcal phage muralysin. J. Biol. Chem. 239:4027-4033.

4. Battersby, A. R., and J. C. Robinson. 1955. Studies on specific chemical fission of peptide links. Part I. The rearrangement of aspartyl and glutamyl peptides. J. Chem. Soc., p. 259269.

5. Blake, C. C. F., L. N. Johnson, G. A. Mair, A. C. T. North, D. C. Philips, and V. R. Sarma. 1967. Crystallographic studies of the activity of hen egg-white lysozyme. Proc. Roy. Soc. (London) Ser. B 167:378-388.

6. Blake, C. C. F., G. A. Mair, A. C. T. North, D. C. Philips, and V. R. Sarma. 1967. On the conformation of the hen egg-white lysozyme 
molecule. Proc. Roy. Soc. (London) Ser. B 167:365-378.

7. Breed, R. S., E. G. D. Murray, and N. R. Smith. 1957. Bergey's manual of determinative bacteriology. 7th ed. Williams \& Wilkins Co., Baltimore.

8. Brenner, J. F., A. Dark, P. Gerhardt, M. H. Jeynes, O. Kandler, E. Kellenberger, E. Klieneberger-Nobel, K. McQuillen, M. RubioHuertos, M. J. R. Salton, R. E. Strange, J. Tomsick, and C. Weibull. 1958. Bacterial protoplasts. Nature 181:1713.

9. Bricas, E., J. M. Ghuysen, and Ph. Dezélée. 1967. The cell wall peptidoglycan of Bacillus megaterium KM. I. Studies on the stereochemistry of $\alpha, \alpha^{\prime}$-diaminopimelic acid. Biochemistry 6:2598-2607.

10. Bricas, E., P. Lefrancier, J. M. Ghuysen, E. Muñoz, L. Leyh-Bouille, J. F. Petit, and $\mathbf{H}$. Heymann. 1967. Structure et synthèse de la subunité peptidique de la paroi de trois bactéries gram-positif, p. 286-292. In H. C. Beyerman, A. Van de Linde, and W. Maassen van Den Brink (ed.), Peptides. North Holland Co., Amsterdam.

11. Browder, H. P., W. A. Zygmunt, J. R. Young, and P. A. Tavormina. 1965. Lysostaphin: Mechanism of action. Biochem. Biophys. Res. Commun. 19:383-385.

12. Bumsted, R. M., J. L. Dahl, D. Söll, and J. L. Strominger. 1968. Biosynthesis of the peptidoglycan of bacterial cell walls. X. Further study of the glycyl transfer ribonucleic acids active in peptidoglycan synthesis in Staphylococcus aureus. J. Biol. Chem. 243:779-783.

13. Button, D., A. R. Archibald, and J. Baddiley. 1966. The linkage between teichoic acid and glycosaminopeptide in the walls of a strain of Staphylococcus lactis. Biochem. J. 99:11c$14 c$.

14. Chatterjee, A. N., J. B. Ward, and H. R. Perkins. 1967. Synthesis of mucopeptide by L-form membranes. Nature 214:1311-1314.

15. Chipman, D. M., V. Grisaro, and N. Sharon. 1967. The binding of oligosaccharides containing $N$-acetylglucosamine and $N$-acetylmuramic acid to lysozyme: the specificity of binding subunits. J. Biol. Chem. 242:43884397.

16. Chipman, D. M., J. J. Pollock, and N. Sharon. 1968. Lysozyme-catalyzed hydrolysis and transglycosylation reactions of bacterial cell wall oligosaccharides. J. Biol. Chem. 243:487496.

17. Cole, R. M. 1965. Symposium on the fine structure and replication of bacteria and their parts. III. Bacterial cell-wall replication followed by immunofluorescence. Bacteriol. Rev. 29:326-344.

18. Coyette, J., and J. M. Ghuysen. 1968. Structure of the cell wall of Staphylococcus aureus, strain Copenhagen. IX. Teichoic acid and phage adsorption. Biochemistry 7:2385-2389.

19. Cripps, R. E., and E. Work. 1967. The accumu- lation of extracellular macromolecules by Staphylococcus aureus grown in the presence of sodium chloride and glucose. J. Gen. Microbiol. 49:127-137.

20. Cummins, C. S., and H. Harris. 1956. The chemical composition of the cell wall in some grampositive bacteria and its possible value as a taxonomic character. J. Gen. Microbiol. 14:583-600.

21. Dierickx, L., and J. M. Ghuysen. 1962. Purification de la $\beta$-(1-4)- $N$-acetylhexosaminidase secrétée par Streptomyces albus G et active sur les parois de Micrococcus lysodeikticus. Biochim. Biophys. Acta 58:7-18.

21a. Diringer, H. 1968. Über die Bindung der D-Glutaminsaüre im Murein von E. coli. Z. Naturforsch. 23b: 883-884.

22. Diringer, H., and D. Jusic. 1966. Über die Bindung der meso-Diamino-pimelinsaüre im Murein von $E$. coli. Z. Naturforsch. 21 b:603604.

23. Dorer, F. E., E. E. Haley, and D. L. Buchanan. 1966. Quantitative studies of urinary $\beta$-aspartyl oligopeptides. Biochemistry 5:3236-3240.

24. Ensign, J. C., and R. S. Wolfe. 1966. Characterization of a small proteolytic enzyme which lyses bacterial cell walls. J. Bacteriol. 91:524534.

25. Estrada-Parra, S., M. Heidelberger, and P. A. Rebers. 1963. Immunochemical properties of the periodate-oxidized polysaccharide of group A hemolytic Streptococcus. J. Biol. Chem. 238:510-512.

26. Fitz-James, P., and R. Hancock. 1965. The initial structural lesion of penicillin action in Bacillus megaterium. J. Cell. Biol. 26:657-667.

27. Fleming, A. 1922. On a remarkable bacteriolytic element found in tissues and secretions. Proc. Roy. Soc. (London) Ser. B 93:306-317.

28. Fleming, A. 1929. On the antibacterial action of cultures of a penicillium, with special reference to their use in the isolation of $B$. influenzae. Brit. J. Exptl. Pathol. 10:226-236.

29. Fleming, A., and V. D. Allison. 1922. Observations on a bacteriolytic substance ("Lysozyme") found in secretions and tissues. Brit. J. Exptl. Pathol. 3:252-260.

30. Ghuysen, J. M. 1961. Précisions sur la structure des complexes disaccharide-peptide libérés des parois de Micrococcus lysodeikticus sous l'action des $\beta(1-4) \quad N$-acetylhexosaminidases. Biochim. Biophys. Acta. 47:561-568.

31. Ghuysen, J. M., E. Bricas, M. Lache, and M. Leyh-Bouille. 1968. Structure of the cell walls of Micrococcus lysodeikticus. III. Isolation of a new peptide dimer, $N^{\alpha}$-[L-alanyl- $\gamma-(\alpha-D-$ glutamyl - glycine)] - L - lysyl - D - alanyl - $N^{\alpha}$ [L - alanyl - $\gamma-(\alpha-D$ - glutamyl - glycine $)]$ L - lysyl-D-alanine. Biochemistry 7:1450-1460.

32. Ghuysen, J. M., E. Bricas, M. Leyh-Bouille, M. Lache, and G. D. Shockman. 1967. The peptide $N^{\alpha}$ - (L - alanyl - D - isoglutaminyl) $N^{e}$ - (D - isoasparaginyl) - L - lysyl - D - alanine and the disaccharide $N$-acetylglucosaminyl- 
$\beta-1,4-N$-acetylmuramic acid in cell wall peptidoglycan of Streptococcus faecalis strain ATCC 9790. Biochemistry 6:2607-2619.

33. Ghuysen, J. M., L. Dierickx, M. Leyh-Bouille, J. L. Strominger, E. Bricas, and C. Nicot. 1965. Structure of the cell wall of Staphylococcus aureus strain Copenhagen. V. Isolation of peptidases active on the peptide moiety of the cell walls of some gram-positive bacteria. Biochemistry 4:2237-2244.

34. Ghuysen, J. M., M. Leyh-Bouille, and L. Dierickx. 1962. Structure des parois de Bacillus megaterium KM. I. Isolement de l'amidase et d'un enzyme nouveau sécrétés par Streptomyces albus $\mathbf{G}$ et actifs sur les parois de Bacillus megaterium KM et de Micrococcus lysodeikticus. Biochim. Biophys. Acta 63:286-296.

35. Ghuysen, J. M., J. F. Petit, E. Muñoz, M. LeyhBouille, and L. Dierickx. 1966. Action des enzymes bactériolytiques, autres que le lysozyme, sur le peptidoglycane des parois cellulaires bactériennes. Exposes Ann. Biochem. Med. 27:101-110.

36. Ghuysen, J. M., and J. L. Strominger. 1963. Structure of the cell wall of Staphylococcus aureus, strain Copenhagen. I. Preparation of fragments by enzymatic hydrolysis. Biochemistry 2:1110-1119.

37. Ghuysen, J. M., and J. L. Strominger. 1963. structure of the cell wall of Staphylococcus aureus, strain Copenhagen. II. Separation and structure of disaccharides. Biochemistry 2: 1119-1125.

38. Ghuysen, J. M., J. L. Strominger, and D. J. Tipper. 1968. Bacterial cell walls, p. 53-104. In M. Florkin and E. H. Stotz (ed.), Comprehensive biochemistry, vol. 26A. American Elsevier Publishing Co., New York.

39. Ghuysen, J. M., D. J. Tipper, C. H. Birge, and J. L. Strominger. 1965. Structure of the cell wall of Staphylococcus aureus, strain Copenhagen. VI. The soluble glycopeptide and its sequential degradation by peptidases. Biochemistry 4:2244-2254.

40. Ghuysen, J. M., D. J. Tipper, and J. L. Strominger. 1965. Structure of cell wall of Staphylococcus aureus, strain Copenhagen. IV. The teichoic acid-glycopeptide complex. Biochemistry 4:474-485.

41. Ghuysen, J. M., D. J. Tipper, and J. L. Strominger. 1966. Enzymes that degrade bacterial cell walls, p. 685-699. In S. P. Colowick and N. O. Kaplan (ed.), Methods in enzymology. Academic Press, Inc., New York.

42. Glazer, L., H. Ionescu, and P. Schaeffer. 1966. Teichoic acids as components of a specific phage receptor in Bacillus subtilis. Biochim. Biophys. Acta 124:415-417.

43. Guze, L. B. editor, 1968. Microbial protoplasts, spheroplasts and L-forms. Williams \& Wilkins Co., Baltimore.

44. Haley, E. E., B. J. Corcoran, F. E. Dorer, and D. L. Buchanan. 1966. $\beta$-aspartyl peptides in enzymatic hydrolysates of protein. Biochemistry 5:3229-3235.

45. Hall, E. A., and K. W. Knox. 1965. Properties of the polysaccharide and mucopeptide components of the cell wall of Lactobacillus casei. Biochem. J. 96:310-318.

46. Hash, J. H. 1963. Purification and properties of staphylolytic enzymes from Chalaropsis sp.. Arch. Biochem. Biophys. 102:379-388.

47. Hash, J. H., and M. V. Rothlauf. 1967. The $N, O$-diacetylmuramidase of Chalaropsis species. I. Purification and crystallization. J. Biol. Chem. 242:5586-5590.

48. Heymann, H., J. M. Manniello, and S. S. Barkulis. 1963. Structure of streptococcal cell walls. I. Methylation study of C-polysaccharide. J. Biol. Chem. 238:502-509.

49. Heymann, H., J. M. Manniello, and S. S. Barkulis. 1967. Structure of streptococcal cell walls. V. Phosphate esters in the walls of group A Streptococcus pyogenes. Biochem. Biophys. Res. Commun. 26:486-491.

50. Heymann, H., J. M. Manniello, L. D. Zeleznick, and S. S. Barkulis. 1964. Structure of streptococcal cell walls. II. Group A biose and group A triose from C-polysaccharide. J. Biol. Chem. 230:1656-1663.

51. Higashi, Y., J. L. Strominger, and Ch. C. Sweeley. 1967. Structure of a lipid intermediate in cell wall peptidoglycan synthesis: a derivative of a $C_{65}$ isoprenoid alcohol. Proc. Natl. Acad. Sci. U.S. 57:1878-1884.

52. Hoare, D. S., and E. Work. 1957. The stereoisomers of $\alpha-$-diamino-pimelic acid. 2. Their distribution in the bacterial order Actinomycetales and in certain Eubacteriales. Biochem. J. 65:441-447.

53. Hofschneider, P. H., and H. H. Martin. 1968. Diversity of surface layers in L-forms of Proteus mirabilis. J. Gen. Microbiol. 51:23-33.

54. Hughes, R. C. 1968. The cell wall of Bacillus licheniformis NCTC 6346. Isolation of low molecular-weight fragments from the soluble mucopeptide. Biochem. J. 106:49-59.

55. Ikawa, M. 1964. The configuration of aspartic acid in cell walls of lactic acid bacteria and factors affecting the racemization of aspartic acid. Biochemistry 3:594-597.

56. Ikawa, M., and E. E. Snell. 1960. Cell wall composition of lactic acid bacteria. J. Biol. Chem. 235:1376-1382.

57. Ito, E., and J. L. Strominger. 1964. Enzymatic synthesis of the peptide in bacterial uridine nucleotides. III. Purification and properties of L-lysine adding enzyme. J. Biol. Chem. 239:210-214.

58. Izaki, K., M. Matsuhashi, and J. L. Strominger. 1966. Glycopeptide transpeptidase and Dalanine carboxypeptidase: penicillin sensitive enzymatic reactions. Proc. Natl. Acad. Sci. U.S. 55:656-663.

59. Jarvis, D., and J. L. Strominger. 1967. Structure of the cell wall of Staphylococcus aureus. VIII. Structure and chemical synthesis of the basic 
peptides released by the Myxobacterium enzyme. Biochemistry 6:2591-2598.

60. Jeanloz, R. W., N. Sharon, and H. M. Flowers. 1963. The chemical structure of a disaccharide isolated from Micrococcus lysodeikticus cell wall. Biochem. Biophys. Res. Commun. 13: 20-25.

61. Juŝić, D., C. Roy, A. J. Schocker, and R. W. Watson. 1963. Preparation and properties of isomeric 2,4-dinitrophenyl derivatives of $\alpha$-є-diaminopimelic acid. Can. J. Chem. 41: 2715.

62. Juŝić, D., C. Roy, and R. W. Watson. 1964. Sequence studies on bacterial cell wall peptides. Can. J. Biochem. 42:1553.

63. Kandler, O., R. Plapp, und W. Holzapfel. 1967. Die Aminosequenz des Serinhaltigen Mureins von L. viridescens und Leuconostoc. Biochim. Biophys. Acta 147:252-261.

64. Kanetsuna, F. 1968. Chemical analyses of mycobacterial cell walls. Biochim. Biophys. Acta 158:130-143.

65. Kato, K., T. Hirata, Y. Murayama, H. Suginaka, and S. Kotani. 1968. Studies on the mode of action of Flavobacterium L-11 enzyme on the cell walls of Staphylococcus aureus strain Copenhagen. Identification of isolated cell wall peptides. Biken's J. 11:1-12.

66. Kato, K., and J. L. Strominger. 1968. Structure of the cell wall of Staphylococcus aureus. IX. Mechanism of hydrolysis by the L-11 enzyme. Biochemistry 7:2754-2762.

67. Kato, K., J. L. Strominger, and S. Kotani. 1968. Structure of the cell wall of Corynebacterium diphteriae. I. Mechanism of hydrolysis by the L-3 enzyme and the structure of the peptide. Biochemistry 7:2762-2773.

68. Katz, W., M. Matsuhashi, C. P. Dietrich, and J. L. Strominger. 1967. Biosynthesis of the peptidoglycans of bacterial cell walls. IV. Incorporation of glycine in Micrococcus lysodeikticus. J. Biol. Chem. 242:3207-3217.

69. Katz, W., and J. L. Strominger. 1967. Structure of the cell wall of Micrococcus lysodeikticus. II. Study of the structure of the peptides produced after lysis with the Myxobacterium enzyme. Biochemistry 6:930-937.

70. Knox, K. W., and E. A. Hall. 1965. The linkage between the polysaccharide and mucopeptide components of the cell wall of Lactobacillus casei. Biochem. J. 96:302-309.

71. Kolenbrander, P. E., and J. C. Ensign. 1968. Isolation and chemical structure of the peptidoglycan of Spirillum serpens cell walls. J. Bacteriol. 95:201-210.

72. Kotani, S., K. Kato, T. Matsubara, Y. Mori, M. Chimori, and H. Kishida. 1964. Changes in susceptibility of Staphylococcus aureus and Corynebacterium diphteriae cell walls to egg white lysozyme, the $\mathbf{L}_{s}$ and $\mathbf{L}_{11}$-enzymes, caused by trichloroacetic acid treatment. $\mathrm{Bi}$ ken's J. 6:317-320.

73. Krause, R. M. 1963. Symposium on relationship of structure of microorganisms to their immunological properties. IV. Antigenic and biochemical composition of hemolytic streptococcal cell walls. Bacteriol. Rev. 27:369-380.

74. Krulwich, T. A., J. C. Ensign, D. J. Tipper, and J. L. Strominger. 1967. Sphere-rod morphogenesis in Arthrobacter crystallopoietes. I. Cell wall composition and polysaccharides of the peptidoglycan. J. Bacteriol. 94:734-740.

75. Krulwich, T. A., J. C. Ensign, D. J. Tipper, and J. L. Strominger. 1967. Sphere-rod morphogenesis in Arthrobacter crystallopoietes. II. Peptides of the cell wall peptidoglycan. J. Bacteriol. 94:741-750.

76. Kusaka, I. 1967. Growth and division of protoplasts of Bacillus megaterium and inhibition of division by penicillin. J. Bacteriol. 94: 884-888.

77. Lark, C., D. Bradley, and K. G. Lark. 1963. Further studies on the incorporation of Dmethionine into the bacterial cell wall. Its incorporation into the R-layer and the structural consequences. Biochim. Biophys. Acta 78:278-288.

78. Lechevalier, H. A., and M. P. Lechevalier. 1967. Biology of Actinomycetes. Ann. Rev. Microbiol. 21:71-100.

79. Lederberg, J. 1957. Mechanism of action of penicillin. J. Bacteriol. 73:144.

80. Lefrancier, P., and E. Bricas. 1967. Synthèse de la subunité peptidique du peptidoglycane de la paroi de trois bactéries gram-positif et de peptides de structure analogue. Bull. Soc. Chim. Biol. 49:1257-1271.

81. Leyh-Bouille, M., J. M. Ghuysen, D. J. Tipper, and J. L. Strominger. 1966. Structure of the cell wall of Micrococcus lysodeikticus. I. Study of the structure of the glycan. Biochemistry 5:3079-3090.

82. Liu, T. Y., and E. C. Gotschlich. 1967. Muramic acid phosphate as a component of the mucopeptide of gram-positive bacteria. J. Biol. Chem. 242:471-476.

83. Mardarowicz, C. 1966. Isolierung und Charakterisierung des Murein-Sacculus von Brucella. Z. Naturforsch. 21 b:1006-1007.

84. Martin, H. H. 1964. Composition of the mucopolymer in cell walls of the unstable and stable L-forms of Proteus mirabilis. J. Gen. Microbiol. 36:441.

85. Martin, H. H. 1966. Biochemistry of bacterial cell walls. Ann. Rev. Biochem. 35 (part 2): 457-483.

86. Martin, H. H. 1967. Murein structure in cell walls of normal bacteria and L-forms of Proteus mirabilis and the site of action of penicillin. Folia Microbiol. (Prague) 12: 234-239.

87. McCarty, M., and S. L. Morse. 1964. Cell wall antigens of gram-positive bacteria. Advan. Immunol. 6:249-285.

88. McQuillen, K. 1955. Bacterial protoplasts: growth and division of protoplasts of Bacillus megaterium. Biochim. Biophys. Acta 18:458461. 
89. Miller, I., R. Plapp, and O. Kandler. 1966. The amino acid sequence of the serine containing murein of Butyribacterium rettgeri. Biochem. Biophys. Res. Commun. 25:415-420.

90. Miller, I., R. Plapp, and O. Kandler. 1968. Isolierung und Identifizierung eines Serinhaltigen UDP-Muramyl-Tripeptides aus Butyribacterium rettgeri. Z. Naturforsch. 23b:217220.

91. Mirelman, D., and N. Sharon. 1966. Isolation and characterization of two disaccharidepeptides from lysozyme digests of Micrococcus lysodeikticus cell walls. Biochem. Biophys. Res. Commun. 24:237-243.

92. Mirelman, D., and N. Sharon. 1967. Isolation and study of the chemical structure of low molecular weight glycopeptides from Micrococcus lysodeikticus cell walls. J. Biol. Chem. 242:3414-3427.

93. Mirelman, D., and N. Sharon. 1968. Isolation and characterization of the disaccharide $N$-acetylglucosaminyl- $\beta(1-4) \quad N$-acetylmuramic acid and two tripeptide derivatives of this disaccharide from lysozyme digests of Bacillus licheniformis ATCC 9945 cell walls. J. Biol. Chem. 243:2279-2288.

94. Mitchell, P., and J. Moyle. 1957. Autolytic release and osmotic properties of "protoplasts" from Staphylococcus aureus. J. Gen. Microbiol. 16:184-194.

95. Montague, M. D., and J. D. Moulds. 1967. The phosphorus content of cell walls of Micrococcus lysodeikticus. Biochim. Biophys. Acta 135:565-567.

96. Mori, Y., K. Kato, T. Matsuhara, and S. Kotani. 1960. Lysis of the cell walls of Corynebacterium diphteriae by extracellular enzymes of Streptomyces sp. I. Production and concentration of the lytic factor. Biken's J. 3:139149.

97. Mori, Y., and S. Kotani. 1962. Lysis of the cell walls of Corynebacterium diphteriae by extracellular enzymes of Streptomyces sp. II. Production of "protoplasts" by treatment with a purified cell wall lytic enzyme. Biken's J. 5:55-56.

98. Muñoz, E., J. M. Ghuysen, and H. Heymann. 1967. Cell walls of Streptococcus pyogenes Type 14. C polysaccharide-peptidoglycan and G polysaccharide-peptidoglycan complexes. Biochemistry 6:3659-3670.

99. Muñoz, E., J. M. Ghuysen, M. Leyh-Bouille, J. F. Petit, H. Heymann, E. Bricas, and P. Lefrancier. 1966. The peptide subunit $N^{\alpha}$ - (Lalanyl-D-isoglutaminyl)-L-lysyl-D-alanine in cell wall peptidoglycans of Staphylococcus aureus strain Copenhagen, Micrococcus aureus R 27 and Streptococcus pyogenes group A, type 14. Biochemistry 5:3748-3764.

100. Muñoz, E., J. M. Ghuysen, M. Leyh-Bouille, J. F. Petit, and R. Tinelli. 1966. Structural variations in bacterial cell wall peptidoglycans studied with Streptomyces $\mathrm{F}_{1}$ endo-N-acetylmuramidase. Biochemistry 5:3091-3098.
101. Murray, R. G. E. 1968. Bacterial cell wall anatomy in relation to the formation of spheroplasts and protoplasts, p. 1-19. In L. B. Guze (ed.), Microbial protoplasts, spheroplasts and L-forms. Williams \& Wilkins Co. Baltimore.

102. Murray, R. G. E., P. Steed, and H. E. Elson. 1965. The location of the mucopeptide in sections of the cell wall of Escherichia coli and other gram-negative bacteria. Can. J. Microbiol. 11:547-560.

103. Nakamura, T., G. Tamura, and K. Arima. 1967. Structure of the cell walls of Streptomyces. J. Ferment. Technol. 45:869-878.

104. Nathenson, S. G., N. Ishimoto, J. S. Anderson, and J. L. Strominger. 1966. Enzymatic synthesis and immunochemistry of $\alpha$ - and $\beta-N$ acetylglucosaminyl-ribitol linkages in teichoic acids from several strains of Staphylococcus aureus. J. Biol. Chem. 241:651-658.

105. Nermut, M. V. 1967. The ultrastructure of the cell wall of Bacillus megaterium. J. Gen. Microbiol. 49:503-512.

106. Nermut, M. V., and R. G. E. Murray. 1967. Ultrastructure of the cell wall of Bacillus polymyxa. J. Bacteriol. 93:1949-1965.

107. Neuhaus, F. C., and J. L. Lynch. 1964. The enzymatic synthesis of D-alanyl-D-alanine. III. On the inhibition of D-alanyl-D-alanine synthetase by the antibiotic D-cycloserine. Biochemistry 3:471-480.

108. Nitomporn Bunrugang, J. L. Dahl, and J. L Strominger. 1968. Biosynthesis of the peptidoglycan of bacterial cell walls. IX. Purification and properties of the glycyl transfer ribonucleic acids synthetase from Staphylococcus aureus. J. Biol. Chem. 243:773-779.

109. Pelzer, H. 1963. Mucopeptidhydrolasen in Escherichia coli B. I. Nachweis und Wirkungsspezifität. Z. Naturforsch. 18b:950-956.

110. Perkins, H. R. 1960 . The structure of a disaccharide liberated by lysozyme from the cell walls of Micrococcus lysodeikticus. Biochem. J. 74:182-186.

111. Perkins, H. R. 1963. A polymer containing glucose and aminohexuronic acid isolated from the cell walls of Micrococcus lysodeikticus. Biochem. J. 86:475-483.

112. Perkins, H. R. 1965. 2,6-Diamino-3-hydroxypimelic acid in microbial cell wall mucopeptide. Nature 208:872-873.

113. Perkins, H. R. 1965 . Homoserine in the cell walls of plant pathogenic Corynebacteria. Biochem. J. 97:3c-5c.

114. Perkins, H. R. 1965. The action of hot formamide on bacterial cell walls. Biochem. J. 95:876-882.

115. Perkins, H. R. 1967. The use of photolysis of dinitrophenyl-peptides in structural studies on the cell-wall mucopeptide of Corynebacterium poinsettiae. Biochem. J. 102:29c-32c.

116. Perkins, H. R., and C. S. Cummins. 1964. Ornithine and 2,4-diaminobutyric acid as 
components of the cell walls of plant pathogenic Corynebacteria. Nature 201:1105-1109.

117. Petit, J. F., E. Muñoz, and J. M. Ghuysen. 1966. Peptide cross-links in bacterial cell wall peptidoglycans studied with specific endopeptidases from Streptomyces albus G. Biochemistry 5:2764-2776.

118. Petit, J. F., J. L. Strominger, and D. Söll. 1968. Biosynthesis of the peptidoglycan of bacterial cell walls. VII. Incorporation of serine and glycine into interpeptide bridges in Staphylococcus epidermidis. J. Biol. Chem. 243:757768.

119. Pickering, B. T. 1966. Components of the cell wall of Clostridium welchii (Type A). Biochem. J. 100:430-440.

120. Pine, L., and C. J. Boone. 1967. Comparative cell wall analyses of morphological forms within the genus Actinomyces. J. Bacteriol. 94:875-883.

121. Plapp, R., and O. Kandler. 1967. Isolation of an ornithine-containing cell wall precursor of Lactobacillus cellobiosus. Biochem. Biophys. Res. Commun. 28:141-145.

122. Plapp, R., and O. Kandler. 1967. Identification of $\mathbf{L}$-ornithine and $\delta$-aminosuccinyl ornithine in cell wall hydrolysates of Lactobacillus cellobiosus. Nature 213:803-804.

123. Plapp, R., and O. Kandler. 1967. Die Aminosaüresequenz des Asparaginsaüre enthaltenden Mureins von Lactobacillus coryneformis und Lactobacillus cellobiosus. Z. Naturforsch. 22 b:1062-1067.

124. Plapp, R., K. H. Schleifer, and O. Kandler. 1967. The amino acid sequence of the mureins of lactic acid bacteria. Folia Microbiol. (Prague) 12:206-213.

125. Prasad, A., and G. Litwack. 1965. Growth and biochemical characteristics of Micrococcus lysodeikticus sensitive or resistant to lysozyme. Biochemistry 4:496-501.

126. Ressler, C., and D. V. Kashelikar. 1966. Identification of asparaginyl and glutaminyl residues in endo position in peptides by dehydration-reduction. J. Am. Chem. Soc. 88: 2025-2035.

127. Rhuland, L. E., E. Work, R. F. Denman, and D. S. Hoare. 1955. The behaviour of the isomers of $\alpha, \epsilon$-diaminopimelic acid on paper chromatograms. J. Am. Chem. Soc. 77:48444846.

128. Roberts, W. S. L., J. F. Petit, and J. L. Strominger. 1968. Biosynthesis of the peptidoglycan of bacterial cell walls. VIII. Specificity in the utilization of $\mathrm{L}$-alanyl transfer ribonucleic acid for interpeptide bridge synthesis in $A r$ throbacter crystallopoietes. J. Biol. Chem. 243:768-773.

129. Roberts, W. S. L., J. S. Strominger, and D. Söll. 1968. Biosynthesis of the peptidoglycan of bacterial cell walls. VI. Incorporation of L-threonine into interpeptide bridges in Micrococcus roseus. J. Biol. Chem. 243:749757.
130. Rogers, H. J. 1965. The outer layers of bacteria: the biosynthesis of structure. Symp. Soc. Gen. Microbiol. 15:186-219.

131. Rogers, H. J., and A. J. Garrett. 1965. The interrelationship between mucopeptide and ribitol teichoic acid formation as shown by the effect of inhibitors. Biochem. J. 96:231243.

132. Rogers, H. J., and H. R. Perkins. 1968. Cell walls and membranes. Spon's Biochemical Monographs. E. and F. N. Spon Ltd., London.

133. Roze, U., and J. L. Strominger. 1966. Alanine racemase from Staphylococcus aureus; conformation of its substrates and its inhibitor, D-cycloserine. Mol. Pharmacol. 2:92-94.

134. Russell, D. W. 1963. Studies on the photochemical behaviour of 2,4-dinitrophenyl derivatives of some amino acids and peptides. Biochem. J. 87:1-4.

135. Salton, M. R. J. 1953. Studies on the bacterial cell wall. IV. The composition of the cell walls of some gram-positive and gramnegative bacteria. Biochim. Biophys. Acta 10: 512-523.

136. Salton, M. R. J. 1961. The structure of substrates for lysozyme and related enzymes. Proc. 2nd Symposium on Fleming's lysozyme. Milan. Vol. II, p. 1, xii.

137. Salton, M. R. J. 1964. The bacterial cell wall. American Elsevier Publishing Co., New York.

138. Salton, M. R. J. 1967. Structure and function of bacterial cell membranes. Ann. Rev. Microbiol. 21:417-442.

139. Salton, M. R. J., and J. M. Ghuysen. 1960. Acetylhexosamine compounds enzymatically released from Micrococcus lysodeikticus cell walls. III. The structure of di- and tetrasaccharides released from cell walls by lysozyme and Streptomyces $F_{1}$ enzyme. Biochim. Biophys. Acta 45:353-363.

140. Schleifer, K. H., and O. Kandler. 1967. Zur chemischen Zusammensetzung der Zellwand der Streptokokken. I. Die Aminosaüresequenz des Mureins von Str. thermophilus und Str. faecalis. Arch. Mikrobiol. 57:335-365.

141. Schleifer, K. H., and O. Kandler. 1967. Zur chemischen Zusammensetzung der Zellwand der Streptokokken. II. Die Aminosaüresequenz des Mureins von Streptococcus lactis und cremoris. Arch. Mikrobiol. 57:365-381.

142. Schleifer, K. H., and O. Kandler. 1967. Micrococcus lysodeikticus: a new type of crosslinkage of the murein. Biochem. Biophys. Res. Commun. 28:965-971.

143. Schleifer, K. H., R. Plapp, and O. Kandler. 1967. The amino acid sequence of a glycinecontaining cell wall precursor of Microbacterium lacticum. Biochem. Biophys. Res. Commun. 26:492-496.

144. Schleifer, K. H., R. Plapp, and O. Kandler. 1967. Identification of threo-3-hydroxyglutamic acid in the cell wall of Microbacterium 
lacticum. Biochem. Biophys. Res. Commun. 28:566-570.

145. Schleifer, K. H., R. Plapp, and O. Kandler. 1968. Die Aminosaüresequenz des Mureins von Microbacterium lacticum. Biochim. Biophys. Acta 154:573-582.

146. Schocher, A. J., S. T. Bayley, and R. W. Watson. 1962. Composition of purified mucopeptide from the wall of Aerobacter cloacae. Can. J. Microbiol. 8:89-98.

147. Sharon, N., T. Osawa, H. M. Flowers, and R. W. Jeanloz. 1966. Isolation and study of the chemical structure of a disaccharide from Micrococcus lysodeikticus cell walls. J. Biol. Chem. 241:223-230.

148. Shockman, G. D. 1965. Symposium on the fine structure and replication of bacteria and their parts. IV. Unbalanced cell-wall synthesis: autolysis and cell-wall thickening. Bacteriol. Rev. 29:345-358.

149. Shockman, G. D., H. M. Pooley, and J. S. Thompson. 1967. Autolytic enzyme system of Streptococcus faecalis. III. Localization of the autolysin at the sites of cell wall synthesis. J. Bacteriol. 94:1525-1530.

150. Shockman, G. D., J. S. Thompson, and M. J. Conover. 1965. Replacement of lysine by hydroxylysine and its effects on cell lysis in Streptococcus faecalis. J. Bacteriol. 90:575588.

151. Shockman, G. D., J. S. Thompson, and M. J. Conover. 1967. The autolytic enzyme system of Streptococcus faecalis. II. Partial characterization of the autolysin and its substrate. Biochemistry 6:1054-1065.

152. Siewert, G., and J. L. Strominger. 1967. Bacitracin: an inhibitor of the dephosphorylation of lipid pyrophosphate, an intermediate in biosynthesis of the peptidoglycan of bacterial cell walls. Proc. Natl. Acad. Sci. U.S. 57:767773.

153. Siewert, G., and J. L. Strominger. 1968. Biosynthesis of the peptidoglycan of bacterial cell walls. XI. Formation of the isoglutamine amide group in the cell walls of Staphylococcus aureus. J. Biol. Chem. 243:783-791.

154. Sondheimer, E., and R. W. Holley. 1957. Imides from asparagine and glutamine. II. $\alpha$-aminoglutarimide. J. Am. Chem. Soc. 79:37673770.

155. Stolp, H., and H. P. Starr. 1965. Bacteriolysis. Ann. Rev. Microbiol. 19:79-104.

156. Strominger, J. L., and J. M. Ghuysen. 1967. Mechanisms of enzymatic bacteriolysis. Science 156:213-221.

157. Strominger, J. L., and D. J. Tipper. 1965. Bacterial cell wall synthesis and structure in relation to the mechanism of action of penicillins and other antibacterial agents. Am. J. Med. 39:708-721.

158. Suginaka, H., S. Kotani, K. Kato, S. Kashiba, and T. Amano. 1968. Action of a staphylolytic enzyme (ALE) of a strain of Staphylococcus epidermidis. Biken's J. 11:13-24.
159. Swallow, D. L., and E. P. Abraham. 1958. Formation of $\epsilon$-(amino-succinyl)-lysine from $\epsilon$-aspartyl-lysine from bacitracin A, and from the cell walls of Lactobacilli. Biochem. J. 70:364-373.

160. Szaniszlo, P. J., and H. Gooder. 1967. Cell wall composition in relation to the taxonomy of some Actinoplanaceae. J. Bacteriol. 94: 2037-2047.

161. Takebe, I. 1965. Extent of cross linkage in the murein sacculus of Escherichia coli B cell wall. Biochim. Biophys. Acta 101:124-126.

162. Tinelli, R. 1965. Etude de l'autolyse des parois de Listeria monocytogenes. Compt. Rend. 261:4265.

163. Tinelli, R. 1966. Etude de la composition du glycopeptide des parois de bactéries grampositives par une microtechnique de chromatographie sur couche mince. Bull. Soc. Chim. Biol. 48:182-185.

164. Tinelli, R. 1968. Mise en évidence d'enzymes autolytiques dans les parois de différentes Sporulales. Compt. Rend. 266:1792.

165. Tinelli, R., and J. Pillot. 1966. Etude de la composition du glycopeptide de Treponema reiteri. Compt. Rend. 263:739.

166. Tipper, D. J. 1968. Alkali-catalyzed elimination of D-lactic acid from muramic acid and its derivatives and the determination of muramic acid. Biochemistry 7:1441-1449.

167. Tipper, D. J., J. M. Ghuysen, and J. L. Strominger. 1965. Structure of the cell wall of Staphylococcus aureus, strain Copenhagen. III. Further studies of the disaccharides. Biochemistry 4:468-473.

168. Tipper, D. J., W. Katz, J. L. Strominger, and J. M. Ghuysen. 1967. Substituents on the $\alpha$-carboxyl group of D-glutamic acid in the peptidoglycan of several bacterial cell walls. Biochemistry 6:921-929.

169. Tipper, D. J., and J. L. Strominger. 1965. Mechanism of action of penicillins: a proposal based on their structural similarity to acylD-alanyl-D-alanine. Proc. Natl. Acad. Sci. U.S. 54:1133-1141.

170. Tipper, D. J., and J. L. Strominger. 1966. Isolation of $4-O-\beta-N$-acetylmuramyl- $N$-acetylglucosamine and 4-O- $\beta-N$, 6-O-diacetylmuramyl-N-acetylglucosamine and the structure of the cell wall polysaccharide of Staphylococcus aureus. Biochem. Biophys. Res. Commun. 22:48-56.

171. Tipper, D. J., J. L. Strominger, and J. C. Ensign. 1967. Structure of the cell wall of Staphy. lococcus aureus, strain Copenhagen. VII. Mode of action of the bacteriolytic peptidase from Myxobacter and the isolation of intact cell wall polysaccharides. Biochemistry 6:906920.

172. Tipper, D. J., J. L. Strominger, and J. M. Ghuysen. 1964. Staphylolytic enzyme from Chalaropsis: mechanism of action. Science 146:781-782.

173. Toennies, G., B. Bakay, and G. D. Shockman. 
1959. Bacterial composition and growth phase. J. Biol. Chem. 234:3269-3275.

174. Tsai, C. S., D. R. Whitaker, L. Jurášek, and D. C. Gillespie. 1965. Lytic enzymes of Sorangium sp. Action of the $\alpha$ - and $\beta$-lytic proteases on two bacterial mucopeptides. Can. J. Biochem. 43:1971-1983.

175. Veerkamp, J. H., R. Lambert, and Y. Saito. 1965. The composition of the cell wall of Lactobacillus bifidus var. pennsylvanicus. Arch. Biochem. Biophys. 112:120-125.

176. Weibull, C. 1953. The isolation of protoplasts from Bacillus megaterium by controlled treatment with lysozyme. J. Bacteriol. 66: 688-695.

177. Weidel, W., and H. Pelzer. 1964. Bagshaped macromolecules: a new outlook on bacterial cell walls. Advan. Enzymol. 26:193-232.

178. Weiss, N., R. Plapp, and O. Kandler. 1967 Die Aminosaüresequenz des DAP-haltigen Mureins von Lactobacillus plantarum und Lactobacillus inulinus. Arch. Mikrobiol. 58:313-323.

179. Welsch, M. 1966. Bacteriolyse et parois cellulaires bactériennes. Pathol. Microbiol. 29: 571-601.

180. White, P. J., B. Kelly, A Suffling, and E. Work. 1964. Variation of activity of bacterial diaminopimelate decarboxylase under different conditions of growth. Biochem. J. 91:600-610.

181. Whitney, J. G., and E. A. Grula. 1968. A major attachment site for D-serine in the cell wall mucopeptide of Micrococcus lysodeikticus. Biochim. Biophys. Acta 158:124-129.

182. Work, E. 1964. Amino acids of walls of Micrococcus radiodurans. Nature 201:110-115.

183. Work, E., and H. Griffiths. 1968. Morphology and chemistry of cell walls of Micrococcus radiodurans. J. Bacteriol. 95:641-657.

184. Wright, A., M. Dankert, P. Fennessey, and P. W. Robbins. 1967. Characterization of a polyisoprenoid compound functional in $\mathrm{O}$ antigen biosynthesis. Proc. Natl. Acad. Sci. U.S. 57:1798-1803.

185. Yamaguchi, T. 1965. Comparison of the cellwall composition of morphologically distinct actinomycetes. J. Bacteriol. 89:444-453.

186. Young, F. E. 1966. Fractionation and partial characterization of the products of autolysis of cell walls of Bacillus subtilis. J. Bacteriol. 92:839-846.

187. Young, F. E. 1967. Competence in Bacillus subtilis transformation system. Nature 213: 773-775.

188. Young, F. E. 1967. Requirement of glycosylated teichoic acid for adsorption of phage in Bacillus subtilis 168. Proc. Natl. Acad. Sci. U.S. 58:2377-2384.

189. Young, F. E., and L. Arias. 1967. Biosynthesis of the $N$-acyl-galactosamine in cell walls of Bacillus subtilis. J. Bacteriol. 94:1783-1784.

190. Young, F. E., D. J. Tipper, and J. L. Strominger. 1964. Autolysis of cell walls of Bacillus subtilis. Mechanism and possible relationship to competence. J. Biol. Chem. 239:3600-3602. 